\title{
Light Technology for Efficient and Effective Photodynamic Therapy: A Critical Review
}

\author{
José Francisco Algorri ${ }^{1,2, *(1)}$, Mario Ochoa ${ }^{1,2}$, Pablo Roldán-Varona ${ }^{1,2,3}$, , Luís Rodríguez-Cobo ${ }^{3}(\mathbb{D}$ \\ and José Miguel López-Higuera 1,2,3 \\ 1 Photonics Engineering Group, University of Cantabria, 39005 Santander, Spain; \\ mario.ochoa@unican.es (M.O.); pablo.roldan@unican.es (P.R.-V.); lopezhjm@unican.es (J.M.L.-H.) \\ 2 Instituto de Investigación Sanitaria Valdecilla (IDIVAL), 39011 Santander, Spain \\ 3 CIBER-bbn, Institute of Health Carlos III, 28029 Madrid, Spain; luis.rodriguez@unican.es \\ * Correspondence: algorrijf@unican.es
}

check for

updates

Citation: Algorri, J.F.; Ochoa, M.; Roldán-Varona, P.; Rodríguez-Cobo, L.; López-Higuera, J.M. Light Technology for Efficient and Effective Photodynamic Therapy: A Critical Review. Cancers 2021, 13, 3484. https://doi.org/10.3390/ cancers13143484

Academic Editors: Olivier Cuvillier and Michael Höpfner

Received: 1 June 2021

Accepted: 7 July 2021

Published: 13 July 2021

Publisher's Note: MDPI stays neutral with regard to jurisdictional claims in published maps and institutional affiliations.

Copyright: (c) 2021 by the authors. Licensee MDPI, Basel, Switzerland. This article is an open access article distributed under the terms and conditions of the Creative Commons Attribution (CC BY) license (https:// creativecommons.org/licenses/by/ $4.0 /)$.
Simple Summary: Photodynamic therapy (PDT) is a promising treatment for cancerous tumours in which light technologies play a crucial role. An attempt to answer a long-standing question about which light source and light parameters are superior is carried out by reviewing the works reporting their effects on PDT outcome. We have identified the light characteristics that primarily affect the PDT process, based on the current evidence found in the literature. This review also examines cutting-edge technologies aiming to surpass the main challenge of PDT: low light penetration through the tissue. Whereas these technologies overcome several initial technical issues, they generate new challenges and pose limitations. We hope this review may be of interest to a broad audience, from bioengineers to clinical oncologists. The overall contribution we hope to make is to identify key roadblocks and provide a broad overview of light-based technologies, to foster improved developments and new perspectives towards enhanced PDT.

Abstract: Photodynamic therapy (PDT) is a cancer treatment with strong potential over wellestablished standard therapies in certain cases. Non-ionising radiation, localisation, possible repeated treatments, and stimulation of immunological response are some of the main beneficial features of PDT. Despite the great potential, its application remains challenging. Limited light penetration depth, non-ideal photosensitisers, complex dosimetry, and complicated implementations in the clinic are some limiting factors hindering the extended use of PDT. To surpass actual technological paradigms, radically new sources, light-based devices, advanced photosensitisers, measurement devices, and innovative application strategies are under extensive investigation. The main aim of this review is to highlight the advantages/pitfalls, technical challenges and opportunities of PDT, with a focus on technologies for light activation of photosensitisers, such as light sources, delivery devices, and systems. In this vein, a broad overview of the current status of superficial, interstitial, and deep PDT modalities - and a critical review of light sources and their effects on the PDT process-are presented. Insight into the technical advancements and remaining challenges of optical sources and light devices is provided from a physical and bioengineering perspective.

Keywords: photodynamic therapy; cancer; lasers; optical devices

\section{Introduction}

Cancer is currently one of the deadliest diseases causing millions of deaths every year. According to the world health organisation, cancer is the second leading cause of death globally, accounting for an estimated 9.6 million deaths, or one in six deaths, in 2018 [1] Despite the established standard strategies (surgery, radiotherapy, and chemotherapy) have reasonable success for certain cancers, resistant cancer cells, recurrence, and metastases remain common. Cancer is adaptive and has some intriguing survival strategies. In some 
cases, it is capable of pumping out some drugs out of the cells or find alternative pathways to inhibit cell death. In early cancers, surgery can remove primary tumours, but undetected, residual cancer cells develop into a life-threatening recurrence. This versatility is one of the main obstacles to improving mortality rates. To do this, it is essential to provide further technologies for assisting and treating all cancer stages and, especially, to treat metastases. These new technologies would grant more chances of survival, including ineligible patients for standard management. However, these new technologies must be able to offer additional benefits or fewer side effects compared to the currently established ones. For this reason, finding alternative options is key for future cancer treatments.

A non-conventional therapeutic modality for solid tumours, which offer advantages over standard treatments, is photodynamic therapy (PDT). In the current paradigm, the standard PDT relies on three main elements, a photosensitiser (PS), light, and molecular oxygen to elicit cell death through oxidative damage. First, a non-toxic PS is placed topically or injected systemically. After some time, the PS reaches a maximum concentration within the vasculature and subsequently in the tumour. When the PS reaches the maximum concentration at the tumour as compared to healthy tissue, appropriate light wavelengths excite the PS, which can transfer its excited-state energy, among other de-excitation processes, to either tissue substrate or surrounding oxygen. These reactions produce reactive oxygen species (ROS), specifically superoxide anion radicals and reactive singlet oxygen molecules, which kill tumour cells by both direct and indirect cell death mechanisms. Thus, the clinical effect can be produced by direct cell death (necrosis, apoptosis, among others), vascular damage (leading to tissue ischemia), immune modulation, or a combination of these. The efficacy of these mechanisms depends on many factors, such as the type of PS, cell, overall light dose or/and tumour oxygenation status, among others. PDT cytotoxicity mechanisms are different from the ones of chemotherapy, radiation therapy and immunotherapy (and their consequences too):

- $\quad$ PDT biological effects may be at least partially localised to the tumour, resulting in a higher concentration of the PS within the tumour in comparison to healthy cells.

- $\quad$ PDT uses non-ionizing radiation (in most cases) and its cytotoxic mechanisms produce limited damage to DNA and connective tissue structures (i.e., collagen), which after the treatment act as a scaffold enabling, potentially, the healing of the treated volume [2].

- Considering the previous point, this treatment could be used as many times as required by clinicians, something that is not possible with the current established treatments (surgery, chemotherapy, and radiotherapy). PDT has no "memory effect" as radiotherapy.

- There is also a rapidly increasing body of evidence that the damage and unique mechanism of PDT treatment on tumours and their microenvironments could inhibit drug resistance pathways and re-sensitize resistant cells to standard therapies [3].

- Emerging evidence now suggests that PDT can stimulate strong immunological responses, which depend on multiple factors that are being investigated [4]. This is a key effect to destroy tumours that extend to distant sites after local treatment and is actively investigated [5].

All of these different characteristics compared with those of the standard treatments, confer PDT an attractive option to be used alone or complementary (before or after) to current standard therapies. Despite the great potential of this technology, its application to deep-seated cancer and metastases remains challenging. Some issues must be solved to surpass actual technological paradigms. For example, limited light penetration depth, non-ideal photosensitisers, complex dosimetry, and complicated implementations in the clinic. Radically new light sources, advanced PS, measurement devices, and innovative application strategies are investigated to exploit the full potential of PDT.

The general aims of this review are to highlight the advantages/pitfalls, technical challenges, and opportunities of PDT from a physical and engineering perspective with a focus on technologies for light activation of PSs such as light sources, delivery devices, and systems. Important stages for PDT such as detection, imaging, and dosimetry (monitoring 
and dose adaptation) to enable enhanced treatments, or clinical trials and cell death mechanisms, are beyond the scope of this review. For imaging, the reader is referred to $[6,7]$ and for dosimetry to [8,9] (and references therein). If the reader is interested in cell death mechanisms, detailed reviews can be found elsewhere [10-16]. Finally, for a compilation of actual clinical trials, the interested reader is referred to [17]. We hope this review will be of interest to a broad audience, from bioengineers to clinical oncologists.

The manuscript is organised as follows. Section 2 is divided into three main subsections. First, a background subsection provides a brief description of the light absorption in tissues, PDT mechanisms and basic terminology of dose and beam parameters relevant for PDT. Then, we critically review the light sources and delivery devices for different PDT modalities. In this review, we include several PDT modalities into three main categories:

- Superficial PDT: involves skin treatments with low light penetration depth (typically $<2 \mathrm{~mm}$ ). It is also usually referred to as external PDT.

- Interstitial PDT (I-PDT): can treat tumours beyond $1 \mathrm{~cm}$ assisted by the use of needles, catheters, and optical fibres, but using conventional light sources-with its light penetration limits—similarly as superficial PDT.

- Deep PDT: includes a wide variety of technologies aiming at deeper penetration beyond what is achieved by conventional light sources. This section includes NIR radiation of upconversion materials, advanced PSs excited with novel nonlinear optical techniques, ionising radiation, self-illuminated compounds, and emerging implants.

In Section 2.2, conventional light sources and delivery devices for superficial and I-PDT are critically reviewed. Superficial and I-PDT are combined in one section because they share several common points such as the light sources type and some delivery devices (e.g., optical fibre technologies, among others). We provide another perspective on the role of the light sources (e.g., lasers, LEDs and broadband lamps) as the one typically found in previous reviews. For instance, in the first few years of the 2000s, a couple of reviews have described the capabilities and generalities of the current and emerging light sources for PDT at that time $[18,19]$. Recently, some others described the operating principles and basic physics of light sources highlighting advantages and disadvantages and reviewing the main studies using different light sources [8,20]. In previous reviews, less attention has been paid to the role of fundamental light characteristics (e.g., coherence and beam size) and light waveforms on the PDT efficacy and the light penetration into the tissue [21]. It is still debated if coherent or pulsed light is beneficial for PDT or light penetration. Thus, we provide a detailed and updated review focused on the impact of light coherence, beam size, and different light waveforms (e.g., pulsed and continuous wave) on PDT. Based on the existing literature, the main objective of this section is to highlight the evidence regarding the light source properties and/or parameters more suitable for PDT or deeper light penetration.

Recent developments on deep PDT are addressed in Section 2.3. Alternative light sources for deep PDT include electromagnetic radiation such as NIR light using nonlinear optic techniques (Section 2.3.1), ionising radiation such as X-rays or Cherenkov (Section 2.3.2), self-illuminated systems based on chemiluminescent and bioluminescent mechanisms (Section 2.3.3). Recently, another deep PDT modality that has gained attention due to advancements in nanotechnology and materials science is based on implants. The status and potential of emerging implants are critically reviewed in Section 2.3.4.

Then, we discuss the critical aspects of light sources for an efficient and effective PDT, and highlight the technical advancements and challenges of each PDT modality covered in this review.

\section{Light Technology for PDT}

2.1. Background

\subsubsection{Light Absorption in Biological Tissues}

Being a light-based therapy, PDT strongly relies on the light-tissue interaction and its influence on the activation of the PS. Light-tissue interaction depends primarily on the light 
characteristics, absorption, and scattering properties of the biological tissue $[18,19]$. Tissues are composed of cells and elements with different sizes ranging from tenths of nanometers to tenths of micrometres and can be optically inhomogeneous depending on the tissue type [22]. Therefore, the optical properties, size, shape and density of these structures influence absorption and scattering in tissues. In general, the absorption properties of tissues can be separated into their tissue constituents. Figure 1 shows the absorption coefficient of primary tissue constituents such as haemoglobin, water, fat, elastin, collagen and melanin. Melanin and haemoglobin have the highest absorption coefficient $\left(\mu_{a}\right)$ for wavelengths $(\lambda)<1000 \mathrm{~nm}$ and dominate the absorption in this region. In spite $\mu_{a}$ of melanin being high, it is typically highly localized in low concentrations at specific regions (e.g., skin), thus its absorption is not relevant in most tissues. For $\lambda>1000 \mathrm{~nm}$, water dominates the absorption with significant individual contributions from fat, collagen, elastin, etc., depending on the tissue type. Considering the $\mu_{a}$ of main tissue constituents, an optical window exhibiting the lowest light absorption lies between 600 to $1300 \mathrm{~nm}$. More details on the absorption and scattering properties of specific tissues is given in Section 2.2.2.

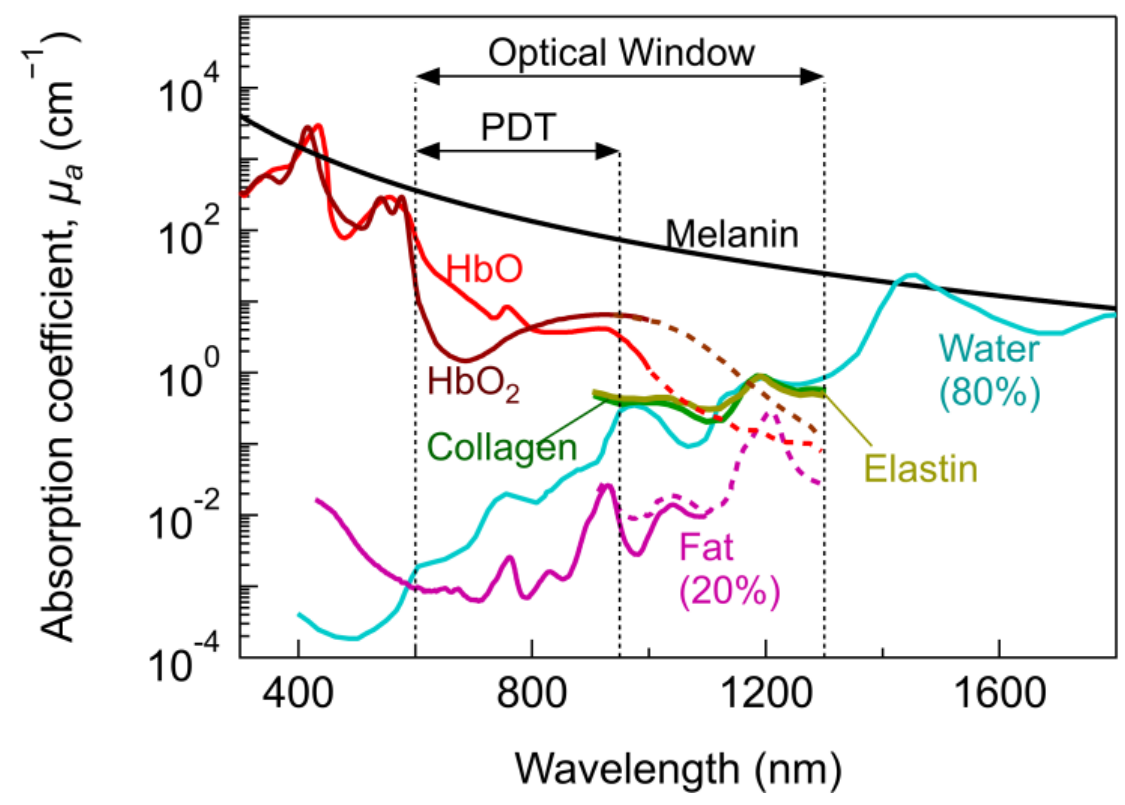

Figure 1. Absorption coefficient as a function of wavelength for several tissue constituents. Data for $\mathrm{HbO}(150 \mathrm{~g} / \mathrm{L}), \mathrm{HbO}_{2}(150 \mathrm{~g} / \mathrm{L})$ and melanin are taken from [23]. Purified pig and human (dashed lines) fat from [24] and [25], respectively. Water from [26]. Collagen and elastin from [25]. $\mathrm{HbO}_{2}$ and $\mathrm{HbO}$ shown as dashed lines are taken from [27] (adjusted to match the data at $1000 \mathrm{~nm}$ ).

Within the optical window, the so-called PDT therapeutic window is defined according to the optical properties and concentration of tissue constituents, the PS and the suitability for monitoring or imaging. Hence, defining unique therapeutic windows is difficult and several therapeutic windows with different ranges can be found in the literature [28-30]. On the one hand, PDT effects have been accomplished from UV to NIR, ranging from superficial to deeper tumour treatments. On the other hand, the most common PDT therapeutic window is usually restricted between $\sim 600-950 \mathrm{~nm}$ (sometimes referred to as NIR-I) [29]. Superficial PDT lies within 400-600 nm (UV-vis) [28]. For $\lambda>950 \mathrm{~nm}$, water absorption increases significantly and may result in excessive tissue heating [29].

\subsubsection{PDT Mechanism of Action upon Absorption}

PDT mechanism of action is based on the interaction of light, PS, and oxygen. The PS reacts with surrounding oxygen upon light excitation generating either free radicals (type I process) or singlet oxygen (type II process) capable to produce cell death mechanisms. 
The generation of singlet oxygen $\left({ }^{1} \mathrm{O}_{2}\right)$ is the most common process in PDT, and will be described below. Not all the competing photochemical and photophysical processes will be described, only those enabling a general-and simplified—description of the singlet oxygen generation in PDT. More details of such competing processes and energy transitions that may influence the PDT mechanism of action can be found in [31,32] and specifically about cell death pathways in [10-16].

Briefly, upon light excitation of the PS by absorption of suitable light wavelength, an orbital electron from the ground state $\left(\mathrm{S}_{0}\right)$ is promoted to higher vibrational energy levels (Figure 2a). Such energy levels $\left(S_{x}\right)$ are unstable, therefore, after some time, (ps-regime) vibrational relaxation occurs (non-radiatively) and the electron may reach the lowest excited energy state $\left(\mathrm{S}_{1}\right)$. In this state, it can undergo several possible de-excitation pathways. These pathways include the transition back to $S_{0}$ non-radiatively, or radiatively emitting fluorescence (ns regime), or transition to a triplet state $\left(\mathrm{T}_{1}\right)$ configuration (involving a flip of the spin of the electron) through a process known as intersystem crossing (ISC). Once in $T_{1}$, the transition between $T_{1}$ to $S_{0}$ is spin-forbidden, thus $T_{1}$ is a relatively longlived intermediate state [7]. Since the ground state electronic configuration of diatomic oxygen is a triplet $\left({ }^{3} \mathrm{O}_{2}\right)$, it enhances the probability of energy transfer from the PS in $\mathrm{T}_{1}$ to surrounding oxygen [7]. Such energy transfer excites oxygen to its singlet state $\left({ }^{1} \mathrm{O}_{2}\right)$ and provides a mechanism for dissipation of the PS to return to the ground state [7]. The singlet reacts almost immediately with nearby cells and because the PS is not consumed in the process (unless photobleaching or photo-destruction of the PS occurs), the same PS could generate many singlet oxygen molecules. The direct energy transfer required for the transition from ${ }^{3} \mathrm{O}_{2}$ to ${ }^{1} \mathrm{O}_{2}$ is $0.974 \mathrm{eV}$ (or $22.4 \mathrm{kcal} / \mathrm{mol}$ ). However, $\mathrm{T}_{1}$ requires additional energy than $0.974 \mathrm{eV}$ for the irreversible formation of ${ }^{1} \mathrm{O}_{2}$, setting minimum energy of $1.13 \mathrm{eV}$, which is met by most PSs [7].

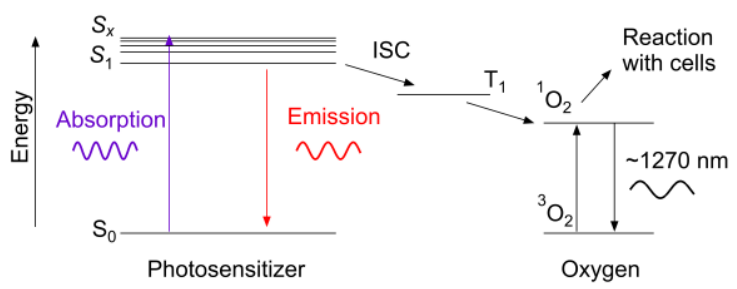

(a)

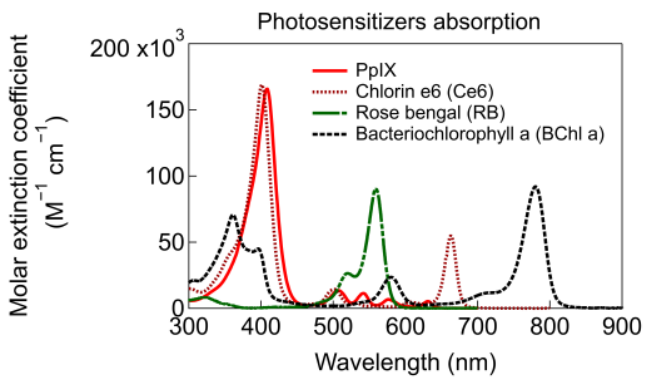

(b)

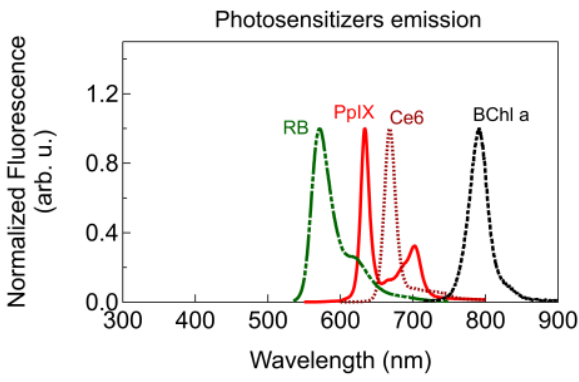

(c)

Figure 2. (a) Simplified Perrin-Jablonski diagram including PDT mechanism of action (ISC: Intersystem crossing). Each arrow indicates an energy conversion process (for simplicity not all possible conversions are depicted). Emission corresponds to the fluorescence of the PS and the $1270 \mathrm{~nm}$ emission from the singlet oxygen phosphorescence. (b) Molar extinction coefficient for absorption. (c) Fluorescence emission of typical PSs (data taken from [33,34]). Solvents used for measurements: chloroform for PpIX, toluene for Bacteriochlorophyll a, ethanol for rose bengal and chlorin e6. Additional parameters for common PSs, and PS targeting two-photon absorption can be found in pp. 32-36 in [7], [35], and [21], respectively.

Most common PSs can be classified into three generations: (first) Photofrin based, (second) other single agents used alone or in combination [36], and (third) single agents coupled 
to molecules or nanoparticles that aid in localization, targeting, formulation, etc. [37]. In general, first-generation PSs exhibited long skin photosensitizing effects and suboptimal tissue penetration. Second generation PSs improved absorption within the optimal therapeutic window. Third generation PSs are mainly second-generation PSs bound to antibodies and liposomes for selective accumulation within the tumour tissue [36]. Figure $2 b$ depicts the absorption coefficient of common PSs with absorption peaks lying within the energy range to fulfil the requirement for singlet oxygen generation. For imaging applications, blue light is typically used for monitoring PS fluorescence, which is employed as a contrast agent p. 15 in [7]. Photosensitiser fluorescence (Figure 2c) can be used to track tumours and is easier to filter or separate blue light from the emission light of the PS ( 650 nm). Photosensitisers activated beyond $800 \mathrm{~nm}$ are usually not efficient in promoting an oxygen molecule from the triplet to the singlet state [8]; however, they are under continuous research and more details will be given in Section 2.3.1.

\subsubsection{Dose and Beam Parameters}

The photodynamic dose is defined as the number of photons absorbed by the PS per gram of tissue [38]. In general, the properties of the PS (e.g., absorption coefficient, quantum yield, photobleaching rate), the local oxygen concentration in the treatment site, and the applied light determine the PDT dose. The PDT dose is very challenging to determine precisely [9]. Concerning light, the most important physical quantities are the fluence rate and time used for illumination because they are directly linked to the PDT dose. The radiant energy fluence rate is defined as the total power incident on an infinitesimal sphere and divided by the cross-section area of the sphere [38]. It has units of $\mathrm{W} / \mathrm{cm}^{2}$. One could also define another parameter such as the fluence as the integral of the fluence rate over time with units in $\mathrm{J} / \mathrm{cm}^{2}$. It is of paramount importance to report the fluence rate and the time used for illumination (or exposure time), and not only the fluence. The same energy fluence may be achieved by a light fluence rate of $1 \mathrm{~W} / \mathrm{cm}^{2}$ for $1 \mathrm{~s}$ and $0.001 \mathrm{~W} / \mathrm{cm}^{2}$ for $1000 \mathrm{~s}$; however, each treatment may result in a very different PDT outcome. The reader is referred to [38] (and references therein) for more details regarding PDT terminology including dosimetry.

To define the fluence one should know the corresponding beam parameters. For continuous wave illumination (a light source emitting light continuously), the most important parameters are the power, centre wavelength, spectral bandwidth, beam spot size or cross-section and beam profile (e.g., Gaussian, top-flat). If a pulsed light is applied (a series of light pulses with on and off periods), additional parameters include the peak radiant power, average radiant power, frequency, and pulse width (or pulse duration on and off).

The influence on PDT efficacy of light source characteristics such as coherence, irradiated area or type of delivery (e.g., point, surface), etc., will be described in Sections 2.2.1 and 2.2.2. Due to the strong implications of beam parameters and dose on PDT, a complete description of main guidelines and recommendations on how to properly report beam parameters, and other physical quantities has been provided by Jenkins and Carrol [39]. Figure 3 shows different types of light-tissue interaction for different exposure times and light fluence applied [40]. The most common fluences for PDT (covered by the shaded region corresponding to photochemical reactions) ranges from $0.1-200 \mathrm{~J} / \mathrm{cm}^{2}$ and fluence rates below $300 \mathrm{~mW} / \mathrm{cm}^{2}$ (in some cases tissue heating may occur for this upper limit) [8,41], which results in exposure times of seconds to tenths of minutes. 


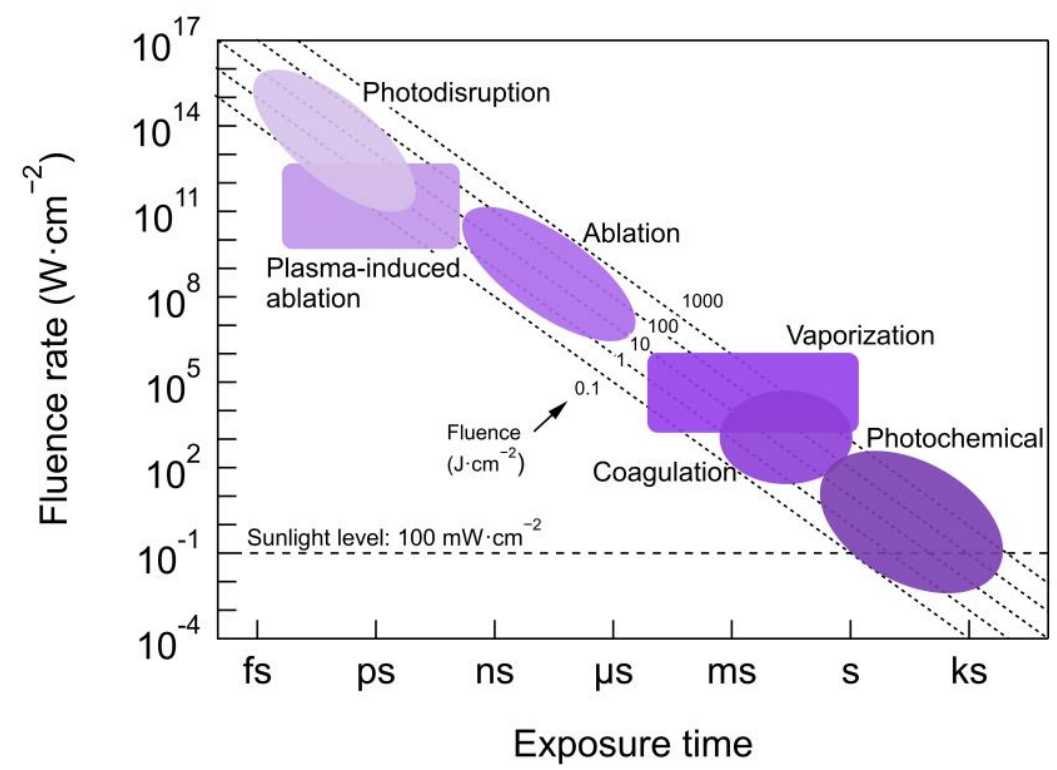

Figure 3. Different types of light-tissue interaction dependent on fluence and exposure times including PDT (within photochemical reactions region). Coagulation and vaporization are thermal effects caused by light exposure at a wavelength of high absorption in the tissue producing selective and localized heating. Ablation, involves the absorption of high energy photons (UV) exciting electrons to high non-bonding orbitals, breaking up the molecules and removing the tissue precisely without tissue damage arising from thermal effects. Plasma-induced ablation occurs when high fluence rates $\left(>10^{11} \mathrm{~W} / \mathrm{cm}^{2}\right)$ of ns-pulses imping on the tissue and generate a plasma that precisely removes the tissue. Photodisruption includes plasma-induced ablation accompanied by mechanical processes such as acoustic and cavitation effects. More details about light-tissue interaction can be found in [40]. This figure is adapted from [40]. Photochemical reactions range use data taken from $[40,42]$.

\subsection{Conventional PDT: Superficial and Interstitial}

The complexity underlying the guiding of light into the human body to activate PSs in deep target internal organs has traditionally made superficial PDT a main application of the technique. Most skin lesions are now treated by topical PS application, using ALA or MAL [43-45]. The topical application of PS allows only 1-2 mm of light penetration into the tissue, which is suitable only for treating superficial lesions [28]. ALA/MAL PDT has similar excellent tumour control rates for actinic keratosis and Bowen's disease compared with surgical or topical chemotherapy $[45,46]$. Additionally, PDT is also approved in Europe for MAL treatment of superficial basal cell tumours of the skin, reporting a 95\% response rate, that is, patients who had a complete response to therapy [28,47].

It is well-known light penetration is one of the main challenges for extended use of PDT [48,49]. For deep-seated or large tumours $(>1 \mathrm{~cm})$, I-PDT has emerged as a suitable type of treatment enabled by guiding light through optical fibres inserted into needles or catheters, and usually including a light delivery/dosimetry device $[8,50,51]$. The main drawback is that cancer has to be completely localized. Hence, I-PDT partially overcomes the deep penetration challenge by delivering light directly to the tumour. In addition, deep penetration achieved by the light source itself (optical fibres and catheters), and not by using complex delivery devices, is still beneficial to enhance treatment procedures and outcomes in many high-volume or thick tumours, since it may allow more homogenous extended illumination. The light source properties and parameters (e.g., coherence, wavelength, beam size, fluence, waveforms), delivery devices, the optical properties of the tissues, and PSs play a crucial role in light penetration into the tissue, as will be discussed below. 


\subsubsection{Light Source Types}

A wide variety of light sources (coherent and incoherent) have shown their capabilities to achieve PDT anti-tumour effects for different superficial [41] and interstitial treatment sites $[8,18,49]$. Thanks to the advent of laser sources, coherent light has been available for countless applications. Coherence is an ideal property of waves of equal frequency (monochromatic), which have a fixed relationship between phases. On the contrary, noncoherent waves have a random or changing phase relationship. Xenon lamps, metal halide lamps, lasers, and LEDs are some examples demonstrating beneficial PDT could be achieved independently of the light source characteristics [52]. The main advantages of coherent light sources against incoherent ones are their monochromaticity (can be targeted to narrow bands for specific PS), their high power, as well as their top-notch efficiency in the coupling of optical fibres (specifically for I-PDT). Besides, uniform irradiance can be easily achieved through iris and beam expanders [8,18]. It is possible to obtain precise control of the fluence that applies to the malignancy. Non-coherent sources stand out fundamentally for their low cost and by their wide illumination field (typically beam angles of around $120^{\circ}$ [53]), because of their large beam divergence. This is highly advantageous for wholebody treatment, or superficial accessible tumours, e.g., skin or oral cavity [8], in which the need for additional optical elements is minimised. The required fluence rates in PDT are typically around $100-300 \mathrm{~mW} / \mathrm{cm}^{2}$ [8] (for the upper limit and beyond tissue heating may occur). These values can be reached by non-coherent sources, therefore, the use of these types of sources does not necessarily involve an increase in the treatment time. Table 1 lists the fundamental characteristics of each type of source.

Table 1. Main benefits and limitations of coherent (laser) and non-coherent (LED, lamp) light sources in superficial PDT. The table is adapted from [8].

\begin{tabular}{|c|c|c|}
\hline Light Source & Main Benefits & Limitations \\
\hline $\begin{array}{c}\text { Laser } \\
\text { (coherent) }\end{array}$ & $\begin{array}{c}<0.1 \mathrm{~nm} \text { spectral bandwidth } \\
\text { High power } \\
\text { Efficient coupling to optical fibres } \\
\text { Uniform irradiance can be easily achieved } \\
\text { Adaptive emission (VCSEL, } \\
\text { Edge-emitting laser) } \\
\text { Faster modulation than LEDs } \\
\text { Possibility for ultra-short pulses (fs-regime) }\end{array}$ & $\begin{array}{c}\text { Expensive } \\
\text { High maintenance } \\
\text { Bulkier than an LED } \\
\text { Less choice of wavelengths }\end{array}$ \\
\hline $\begin{array}{c}\text { LED } \\
\text { (non-coherent) }\end{array}$ & $\begin{array}{c}\text { Low cost } \\
\text { Small } \\
\text { Adaptive emission (SLED, ELED) } \\
\text { Used for whole-body or point treatment } \\
\text { LEDs can fit down biopsy channels } \\
\text { permitting deep-seated PDT }\end{array}$ & $\begin{array}{c}\text { 5-10 nm spectral bandwidth } \\
\text { (FWHM) } \\
\text { Large beam divergence } \\
\text { Thermal effects for I-PDT (low } \\
\text { electro-optical } \\
\text { conversion efficiency) }\end{array}$ \\
\hline $\begin{array}{c}\text { Lamp } \\
\text { (non-coherent) }\end{array}$ & $\begin{array}{c}\text { Low cost } \\
\text { Simple design } \\
\text { Wide illumination field } \\
\text { Multi-wavelength irradiance }\end{array}$ & $\begin{array}{c}\text { UV and NIR radiation (optical } \\
\text { filtering is needed) } \\
\text { Large beam divergence } \\
\text { High coupling losses with } \\
\text { light guides }\end{array}$ \\
\hline
\end{tabular}

For I-PDT, solid-state lasers are the most commonly used light source, mainly because of the higher beam quality and better optical fibre alignment than other light sources (i.e., LEDs). I-PDT using lasers has been applied successfully to different treatment sites with localised tumours [49]. For instance, head and neck [54], pancreas [55], prostate [41,56], lung [57], brain [58], and more recently primary breast cancer [59,60]. In most cases, I-PDT has the main advantage to improve treatment outcomes for patients in which the standard of care therapy failed or needs better treatment options [49].

Alternatively, LEDs are promising light sources for cost-effective solutions and easier to transfer to clinical procedures for specific treatment sites and conditions. Nevertheless, 
LEDs have lower power output efficiency than lasers and given the broader spectrum, higher power is required to deliver equivalent fluence. Due to their lower electrical to optical conversion efficiency, thermal issues could be more important. All in all, the use of LEDs for PDT was demonstrated in the mid-1990s by Schmid et al. in brain tumours of canines treated with porifrin [52]. Presently, the rapid growth of LEDs led to the development of LED arrays of various wavelengths and handheld systems achieving the high power required for PDT [61-64]. For instance, array systems delivering a fluence rate of $100 \mathrm{~mW} / \mathrm{cm}^{2}$ demonstrated a $90 \%$ of cell death in ovarian cancer cell line using LED modules reaching a fluence of $50 \mathrm{~J} / \mathrm{cm}^{2}$ [62]. More recently, LEDs have been used for human breast cancer cell lines showing effective PDT without thermal issues [65] and for illumination of nanoparticles loaded with the photosensitizer in a human prostate tumour model [66]. As mentioned previously, thermal control is of paramount importance not only for avoiding possible damage to tissues and organs at risk but also because any temperature variation influences tissue optical properties and biological effects, adding complexity to dosimetry optimisation. Although LEDs could open pathways for an easier transfer to clinical procedures, just a few works have been reported targeting I-PDT applications. The ability of LED systems to achieve the power and thermal control requirements once coupled to fibre optics is still to be demonstrated. In contrast, for many superficial applications, LEDs are a simple and efficient solution widely accepted as a treatment light source.

Choosing one or another light source usually depends on the specific treatment site, cost, adaptability, wavelength - to activate PS - and power requirements for PDT. Several studies of coherent and incoherent light sources have been reported independently, using distinct parameters and conditions whose comparison is not possible [8]. Even though all possible parameters are kept equal, the comparison between LED and laser light involves additional complications [67]. For instance, laser light exhibit Gaussian beam profiles and typical parameters for the beam are usually not reported, e.g., beam cross-section [39]. Different beam cross-section would strongly impact the fluence applied and PDT outcome. Moreover, the impact of coherence on the light distribution within the tissue is still debated (as will be described in next section. Such impact would not take place using LEDs, or incoherent light. Overall, just a few works have reported a direct comparison between light sources, in which similar results $[68,69]$ or slightly superior performance using lasers were found [70]. Therefore, it is not possible to conclude whether coherent or incoherent sources are more suitable for PDT. The main criteria followed on choosing the light source have likely remained practical, and to a lower extent fundamental. Undoubtedly, more efforts are required to demonstrate the type of light and its optimal characteristics for enhanced PDT.

\subsubsection{Penetration Depth and Light Source Characteristics}

In PDT, besides the optical absorption of the tissue constituents (Section 2.1.1), the penetration depth is also limited by scattering mechanisms and light absorption of the PS. In general, the light penetration depth is proportional to an effective attenuation coefficient (including absorption and scattering properties) and depends logarithmically on the PS properties (concentration, absorption coefficient, quantum yield, and other effects such as saturation and photobleaching), and other factors-i.e., fluence rate, exposure time, etc. [71]. In this section, we focus on the role of the light characteristics affecting absorption and scattering events. For instance, light wavelength, phase (degree of spatial and temporal coherence), polarisation, and geometric characteristics such as the diameter of the spot size, spatial light patterns, among others [22]. In the following, only the light characteristics regarding wavelength, coherence, and spot size are covered.

From diffusion theory and for wide uniform beams, the light penetration problem might be simplified to a useful and well-known analytical expression, i.e., $\varphi=k E e^{-\mu_{e f f} z}$ [71]. The fluence rate is given by $\varphi, \mathrm{E}$ is the irradiance, $z$ the depth of the tissue and $k$ is a depth-dependent backscattering term usually ranging between 1 and 5 [22,71]. The effective attenuation coefficient $\left(\mu_{e f f}\right)$ is a function of the absorption $\left(\mu_{a}\right)$ and scattering $\left(\mu_{s}\right)$ components. The latter is further modified by an anisotropy factor $g$ via $\mu_{s}^{\prime}=\mu_{s}(1-g)$ that depends 
on the phase angle propagation of scattered light. The analytical expression might be an oversimplification of a complex problem of light-tissue interaction; however, it allows to highlight the main parameters affecting light propagation within tissues.

In this context, the attenuation of light in scattering media such as tissues (i.e., homogenous) is defined as $\mu_{\text {eff }}=\left(3 \mu_{a}\left(\mu_{a}+\mu_{s}^{\prime}\right)\right)^{1 / 2}$. To determine $\mu_{\text {eff }}$, both quantities, $\mu_{a}$ and the reduced scattering coefficient $\mu_{s}^{\prime}$, are wavelength-dependant measurable parameters [72]. Hence, the penetration depth is defined as $\delta(\lambda)=\mu_{e f f}^{-1}(\lambda)$, and it is the distance in which light intensity decreases by $1 / e$.

Scattering is one of the main attenuators of light into the tissue. Main scatters lie within the range of the wavelength used for excitation of the PS, and even though photons are not lost due to scattering, it enhances the probability of absorption near the origin of the scattering event limiting the penetration depth. Scattering intensity is proportional to $\lambda^{-w}$, where $w$ depends on the characteristics and concentration of scatterers in the tissue. For particles much smaller than the wavelength, Rayleigh scattering dominates and $w=4$. More realistic situations are $w$ in the range of 0.2-1.7 [73]. Hence, longer excitation wavelengths are desirable because scattering intensity strongly diminishes with wavelength. Bashkatov et al. calculated the wavelength dependence of optical depth in different tissues [73]. Figure 4 shows an example of the wavelength dependence of $\delta$ for skin tissue and mucous tissue similar to that find in the bladder, stomach, oesophagus, among others. The maximum optical depth lies within the optical and PDT window, however, there are significant variations in optical depth even within the PDT window ( $>1 \mathrm{~mm}$ for mucous tissue).

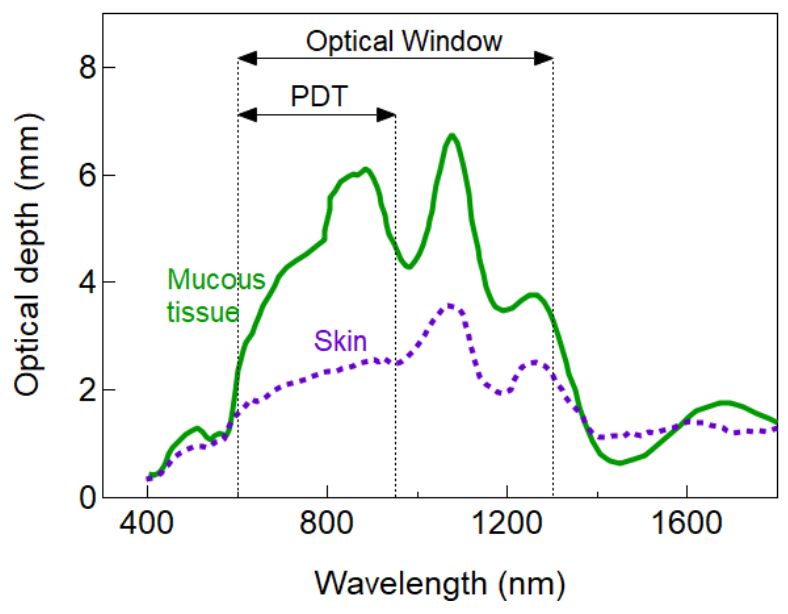

Figure 4. Example of the wavelength dependence of penetration depth for two different tissue types. Data were taken from [73]. The light wavelength has a strong impact on light penetration. For I-PDT, typically red light (around $650 \mathrm{~nm}$ ) is employed and the expected penetration depth for most tissues is below $1 \mathrm{~cm}(<4 \mathrm{~mm}$ for mucous tissue).

The optical penetration depth of Figure 4 is just an illustrative example to highlight the wavelength dependence of light attenuation that can be useful to select a suitable PS for a given tissue. However, such dependence might significantly differ from tissue to tissue. Indeed, higher complexity in the calculation of the penetration depth is also expected because the optical properties of living tissue may significantly vary depending on the content and concentration of tissue constituents and absorption of the PS. For instance, it has also been suggested cancerous sites (as compared to healthy cells) exhibit different optical properties caused by inflamed blood vessels (stronger absorption of haemoglobin) with $\delta$ about 7 times lower than normal tissue [74]. The complexity is even further increased because the optical properties of living tissue are also subject to patient-to-patient, site-tosite, and even temporal variations [75]. 
Besides wavelength, other light properties such as coherence may influence the penetration depth. Most tissues exhibit anisotropy factors $g>0.7$ [75]. A positive $g$ value implies that scattering is dominated by forward contributions; therefore, it is expected that coherent sources promoting forward scattering (i.e., laser) exhibit deeper light penetration. Within this context, the laser light interaction with tissue is often argued to modify the incident light, in which coherence and collimation are lost, due to scattering experienced after light propagation of a few micrometres [76]. Hence, it is reasonable to expect that any type of light (coherent or incoherent) would in principle act similarly inside the tissue, and the only desirable fact is that PS absorbs the incident light. However, this might not necessarily be the case. Fixler et al. found coherence is not lost for static tissue, but it is partially lost when there is a flow of fluid through the tissue, as suggested by the direct correlation of the volumetric flow with the loss of spatial coherence [77]. Hode et al. reported that laser light is still coherent enough to form laser speckles after passing through $2 \mathrm{~cm}$ thickness of highly scattering media (meat) [76]. The speckle pattern is not static due to fluid movement (in agreement with Fixler), but coherence is not lost within living tissue [76]. This means the speckle pattern fluctuates over time at a rate dependent on the fluid movement within the tissue but does not necessarily mean coherence is lost. If spatial coherence is not lost within the tissue, it may have additional implications. It was shown by Monte Carlo simulations that the speckle intensity distribution can exhibit individual regions with higher or lower fluence (up to 5 times) than the mean fluence [78]. An increased fluence at specific sites-within the proper limits to avoid tissue heating or damage-could achieve deeper regions with a sufficient threshold to activate the PS. A decreased fluence at specific sites could fall below the intensity thresholds required for PS activation. Hence, previous studies not only suggest an effective deeper penetration for coherent light sources could be achieved locally but also highlight that inhomogeneous light distribution could influence PDT mechanisms. Indeed, Rubinov has shown that laser light leading to speckle formation causes the appearance of inter- and intracellular gradient forces that affect biological processes [79]. To what extent these gradients and intensity variations impact PDT mechanisms (involving a PS) or light penetration is not well-known. Empirically, it has been difficult to compare and establish a deeper light penetration for either coherent or incoherent sources in experiments involving PDT effects. The few comparisons have been reported mainly on PDT efficacy terms (with similar results or without the possibility to benchmark between studies, see Section 2.1.1), which depend on other key parameters such as the structure of PS and localisation, drug-light time interval, treatment (oxygen) conditions, the fluence rate and time, etc. [80,81].

Alternatively, different effects can be found whether the light source causes a point treatment or a surface treatment, depending on whether the light locally strikes or totally covers the injured tissue, respectively. For PDT, the light at the activation wavelength of the PS is required, as well as the light fluence necessary to activate enough PS for lesion destruction. If this is accomplished for small (point treatment) or large (surface treatment) illumination areas, they can be used interchangeably. In this context, a wide illumination field is typically chosen to reduce the treatment time and achieve a greater penetration depth (as long as the irradiance remains constant) [82]. This has been shown using Monte Carlo simulations, in which light penetration increases with the beam size [82]. The penetration depth is approximately 10 times larger for the same fluence rate by increasing the beam diameter from 0.5 to $3 \mathrm{~mm}$. Minimum increased penetration depth is estimated for beams larger than 5 to $10 \mathrm{~mm}$, and no further increase above $10 \mathrm{~mm}$ (in agreement with [83]). Such simulations assume a flat beam, fixed anisotropy factor, absorption, and scattering coefficients for the two layers epidermis and dermis. According to [82], deeper penetrations in tissue due to wider beams are enabled by sufficient backscattering and a small value of $\mu_{\mathrm{a}}$ compared to $\mu_{\mathrm{s}}$. This combination of parameters is usually accomplished in most tissues [75]. Since the edge losses from the beam may extend three times the penetration depth, it is reasonable to reduce such losses by using beam cross-sections much greater than three times the penetration depth [75]. Hence, homogeneous light within 
the tumour is an important parameter not only to achieve a deeper penetration but also for nominally homogeneous PS activation. It should be reminded the previous reasoning applies for cases in which $\varphi=k E e^{-\mu z}$ effectively describes the tissue optics, and given the broad range of tissues and their heterogeneity found in some cases, this may no longer be valid and more accurate modelling is required [84].

Typically, large beam cross-sections $\left(1-3 \mathrm{~cm}^{2}\right)$ are required to treat large lesions such as those occurring in the skin [28]. In lasers, this is easily achieved using beam expanders. By adding spatial filters before the expander, it is possible to achieve a quasi-uniform illumination of the tissue [8,18]. For I-PDT, maximisation of tumour coverage is attempted by the use of different delivery devices along with advanced modelling (see Section 2.2.4).

The deeper light penetration is also pursued to a greater or lower extent following diverse approaches-namely, two-photon excitation [85], repeated PDT procedures [86,87], enhanced PS [88], a combination of PSs [89], X-rays, and internal bioluminescence [90]. The use of optical clearing agents is promising not only for deep-light delivery but also for characterisation and deep-monitoring [91,92]. More details on approaches related to Deep PDT will be given in Section 2.2.

\subsubsection{Pulsed, Continuous, and Other Light Waveforms for PDT}

Continuous-wave (CW) and pulsed light are the most common waveforms used for superficial or I-PDT. Whereas CW sources are the workhorse for most PDT applications, just a few studies can be found regarding the effects of pulsed light on PDT. The main argument for beneficial PDT outcome using pulsed light is that light-off periods may allow tissue re-oxygenation and re-accumulation of specific PS at the lesion [21]. Such light-off periods could also allow the tissue to recover from a possible temperature rise. Regarding the light penetration, pulsed lasers achieving the same average fluence but using high fluence peaks could achieve a therapeutic threshold for PS activation in deeper regions of the tissue. This could be beneficial as long as a higher fluence peak rate does not increase the temperature to a point detrimental for the tissue.

Even though several studies reported the beneficial effects on PDT using either pulsed or CW waveforms, it is still debated if pulsed or CW exhibit deeper penetration depths or better PDT efficacy. In the following, a brief review of such studies is given.

Theoretically, Sterenborg et al. studied the effect of pulsed lasers on PS excitation and singlet oxygen yield [93]. The influence of the pulse duration and repetition frequency, and CW illumination on the PDT effect was also evaluated. They showed pulsed and CW have identical effects for rates below $40 \mathrm{~kW} / \mathrm{cm}^{2}$. This value is far beyond the required fluence rate for PDT. At higher fluence rates, the effectiveness of PDT drops significantly. Then, Pogue et al. showed empirical slightly deeper penetration depths in tissue-simulating dosimeters by use of pulsed light (10-ns pulses of $10 \mathrm{~Hz}$ and maximum time-averaged irradiance of $300 \mathrm{~mW} / \mathrm{cm}^{2}$ ) [94]. They suggested that consumption and photobleaching of the PS allow for less attenuation by the PS, and subsequent light can propagate deeper into the tissue. Kawauchi et al. reported on the effects of ns-pulsed light $\left(1 \mathrm{MW} / \mathrm{cm}^{2}\right.$ at $30 \mathrm{~Hz}$ and $\mathrm{CW}$ with a total light dose of $40 \mathrm{~J} / \mathrm{cm}^{2}$ ) in photobleaching and oxygen consumption. They found, pulsed light promotes lower decomposition of PS and suppressed oxygen consumption, which resulted in a lower cytotoxicity effect compared to CW [95].

Recently, Grecco et al. used femtosecond laser pulses (temperature increase measured $<4{ }^{\circ} \mathrm{C}$ ) to compare two PSs. They found induced depth of necrosis with Photogen was greater with pulsed laser $(2.0 \pm 0.2 \mathrm{~mm})$ compared with $\mathrm{CW}$ laser $(1.0 \pm 0.2 \mathrm{~mm})$, whereas using Photodithazine induced greater necrosis with CW laser $(2.9 \pm 0.2 \mathrm{~mm})$ compared with pulsed laser $(2.0 \pm 0.2 \mathrm{~mm})[96,97]$. They attributed higher absorption and saturation effects for the PS of second generation when pulsed light was used. This resulted in a lower generation of singlets able to promote cell death and highlighted the sensitivity of the PS to different light waveforms and PDT efficacy. Grecco et al. also reviewed in 2016 studies regarding pulsed and CW light sources (see [97] and references therein). The results are controversial and difficult to compare due to the different parameters and conditions 
used. The challenge for a proper comparison is to achieve the same fluence for a pulsed and $\mathrm{CW}$ source including the wide variety of pulsed time-regimes (from ns to fs) and keeping the other experimental parameters and conditions comparable. More recently, Klimenko et al. reported a theoretical analysis using pulsed light $(200 \mathrm{~ms}$ pulse width and $700 \mathrm{~ms}$ repetition period). Singlet oxygen generation and tissue re-oxygenation benefited from a pulsed light source compared to CW [98]. They confirmed experimentally that the pulsed mode promoted apoptotic cell death of $k 562$ cells in a pulsed mode, whereas CW induced necrotic cell death. Table 2 summarises the works using pulsed and CW found in the literature.

PDT effects using pulsed or CW have shown dependence with PS (as expected due to different absorption properties influencing light penetration depth and singlet oxygen generation), the light waveforms, and fluence applied. Photosentitiser saturation effects and photobleaching may also occur depending on the fluence rate, or peak fluence rate. Whereas saturation effects assist in achieving deeper penetrations (limiting PDT effect locally where PS is saturated), it could lead to photobleaching [94]. One common point among several studies is that PDT mechanisms using pulsed light are more favourable to induce apoptosis, whereas CW is prompt to induce necrosis [98-100]. Regarding light penetration, controversial results can be found either for interstitial or superficial applications [94-96,101].

Table 2. Characteristics and conclusions derived from empirical studies using pulsed light sources in superficial and I-PDT. $T_{O N}$ stands for the pulse duration of the laser, PRR for the pulse repetition rate or frequency, $\varphi$ for the average fluence rate and $\Phi$ for the average fluence. Adapted and updated from [97].

\begin{tabular}{|c|c|c|c|c|}
\hline & Pulsed Light Source & Parameters & CW Light Source & Conclusions \\
\hline$[102,103]$ & Long-pulsed dye laser & $\begin{array}{ll}- & \lambda=585 \mathrm{~nm} \\
\text { - } & T_{O N}=1.5-40 \mathrm{~ms} \\
\text { - } & \text { PRR }=1 \mathrm{~Hz} \\
\text { - } & \Phi=4-7.5 \mathrm{~J} / \mathrm{cm}^{2}\end{array}$ & NA & $\begin{array}{l}\text { - Treatment of AKs using pulsed } \\
\text { lasers following topical 5-ALA } \\
\text { application is safe and } \\
\text { effective. }\end{array}$ \\
\hline [101] & $\begin{array}{l}\text { Pulsed Dye Laser } \\
\text { Broadband flashlamp } \\
\text { filtered pulsed light }\end{array}$ & $\begin{array}{ll}\text { - } & \lambda=595 \mathrm{~nm} \\
\text { - } & T_{O N}=10 \mathrm{~ms} \\
\text { - } & \Phi=7.5 \mathrm{~J} / \mathrm{cm}^{2} \\
\text { - } & \lambda=500-650 \mathrm{~nm} \\
\text { - } & T_{O N}=20 \mathrm{~ms} \\
\text { - } & \Phi=24 \mathrm{~J} / \mathrm{cm}^{2}\end{array}$ & $\begin{array}{l}\text { - } \quad \text { CW blue light } \\
\text { - } \varphi=10 \mathrm{~mW} / \mathrm{cm}^{2}\end{array}$ & $\begin{array}{l}\text { Pulsed light sources are } \\
\text { capable of activation of PDT } \\
\text { but produce dramatically less } \\
\text { PDT reaction than the standard } \\
\text { CW blue-light source. }\end{array}$ \\
\hline [94] & $\begin{array}{l}\text { Nd:YAG laser pumped } \\
\text { optical parametric } \\
\text { oscillator (OPO) }\end{array}$ & $\begin{array}{ll}\text { - } & \lambda=690 \mathrm{~nm} \\
\text { - } & T_{O N}=10 \mathrm{~ns} \\
\text { - } & \text { PRR }=10 \mathrm{~Hz} \\
\text { - } & \varphi=300 \mathrm{~mW} / \mathrm{cm}^{2}\end{array}$ & $\begin{array}{ll}- & \text { Argon-laser }+ \text { Dye; } \\
-\quad & \lambda=690 \mathrm{~nm} \\
-\quad & \varphi \text { as pulsed }\end{array}$ & $\begin{array}{l}\text { Pulsed irradiation allowed } \\
\text { modest deeper light } \\
\text { penetration in tissue. }\end{array}$ \\
\hline$[100]$ & $\begin{array}{l}\text { Nd:YAG laser-pumped } \\
\text { OPO }\end{array}$ & $\begin{array}{ll}\text { - } & \lambda=514.5 \mathrm{~nm} \\
\text { - } & T_{O N}=7-9 \mathrm{~ns} \\
\text { - } & \text { PRR }=10 \mathrm{~Hz} \\
\text { - } & \varphi=100 \mathrm{~mW} / \mathrm{cm}^{2} \\
\text { - } & \Phi=1 \text { to } 10 \mathrm{~J} / \mathrm{cm}^{2}\end{array}$ & $\begin{array}{ll}- & \text { Argon-laser } \\
- & \lambda=514.5 \mathrm{~nm} \\
- & \varphi, \Phi \text { as pulsed }\end{array}$ & $\begin{array}{l}\text { Dead cells irradiated by the } \\
\text { pulsed laser light were induced } \\
\text { through apoptosis. } \\
\text { - CW laser light irradiation led } \\
\text { to necrosis. }\end{array}$ \\
\hline [95] & $\begin{array}{l}\text { Nd:YAG + OPO } \\
\text { system }\end{array}$ & $\begin{array}{ll}\text { - } & \lambda=670 \mathrm{~nm} \\
\text { - } & T_{O N}=5 \mathrm{~ns} \\
\text { - } & \mathrm{PRR}=30 \mathrm{~Hz} \\
\text { - } & \varphi=180 \text { or } 270 \mathrm{~mW} / \mathrm{cm}^{2} \\
\text { - } & \Phi=40 \mathrm{~J} / \mathrm{cm}^{2}\end{array}$ & $\begin{array}{ll}\text { - } & \text { Diode laser } \\
\text { - } & \lambda=670 \mathrm{~nm} \\
\text { - } & \varphi, \Phi \text { as pulsed }\end{array}$ & $\begin{array}{l}\text { Pulsed light caused suppressed } \\
\text { oxygen consumption and } \\
\text { lower cytotoxicity } \\
\text { - } \quad \text { Pulsed light induced a lower } \\
\text { decomposition rate of the PS }\end{array}$ \\
\hline
\end{tabular}


Table 2. Cont

\begin{tabular}{|c|c|c|c|c|}
\hline & Pulsed Light Source & Parameters & CW Light Source & Conclusions \\
\hline [96] & $\begin{array}{l}\text { Ti:sapphire + optical } \\
\text { parametric amplifier }\end{array}$ & $\begin{array}{ll}\text { - } & \lambda=630 \mathrm{~nm} \\
\text { - } & T_{O N}=70 \mathrm{fs} \\
\text { - } & \text { PRR }=1 \mathrm{kHz} \\
\text { - } & \varphi=74 \mathrm{~mW} / \mathrm{cm}^{2} \\
& \Phi=150 \mathrm{~J} / \mathrm{cm}^{2}\end{array}$ & $\begin{array}{ll}\text { - } & \text { Diode laser } \\
\text { - } & \lambda=630 \mathrm{~nm} \\
\text { - } & \varphi, \Phi \text { as pulsed }\end{array}$ & $\begin{array}{l}\text { - Twice as deep necrosis for } \\
\text { ultra-fast pulsed laser } \\
\text { using hematoporphyrin } \\
\text { from Photogem }{ }^{\circledR} \text {. } \\
\text { - } \\
\text { Temperature increase }<4{ }^{\circ} \mathrm{C} \\
\text { using a pulsed laser. }\end{array}$ \\
\hline [99] & $\begin{array}{l}\text { Diode pumped solid } \\
\text { state yellow laser }\end{array}$ & $\begin{array}{ll}\text { - } & \lambda=584 \mathrm{~nm} \\
\text { - } & T_{O N}=15 \mathrm{~ns} \\
\text { - } & \mathrm{PRR}=10 \mathrm{~Hz} \\
\text { - } & \varphi=160 \mathrm{~mW} / \mathrm{cm}^{2} \\
\text { - } & \Phi=140,170 \text { and } 200 \\
& \mathrm{~J} / \mathrm{cm}^{2}\end{array}$ & $\begin{array}{ll}\text { - } & \text { Diode Laser } \\
\text { - } & \lambda=593 \mathrm{~nm} \\
\text { - } & \varphi, \Phi \text { as pulsed }\end{array}$ & $\begin{array}{l}\text { Pulsed mode mainly led to } \\
\text { apoptotic cell death, while, } \\
\text { in the case of CW mode, } \\
\text { the cancer cells underwent } \\
\text { necrosis. } \\
\text { - Similar photobleaching } \\
\text { observed for both light } \\
\text { sources }\end{array}$ \\
\hline
\end{tabular}

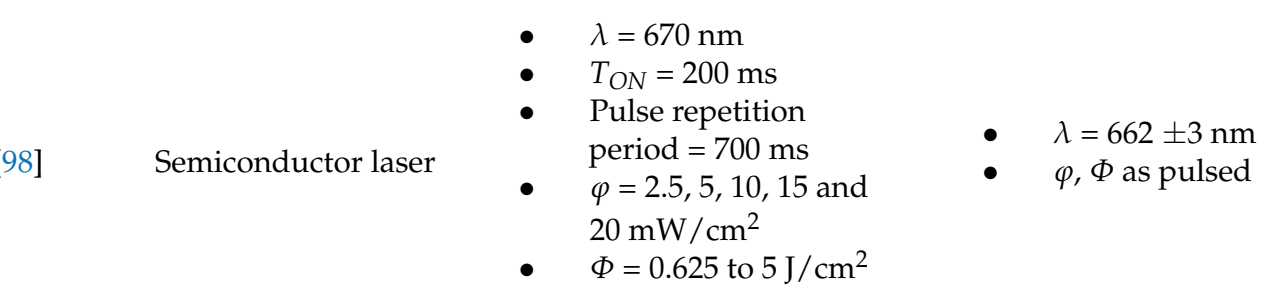

The beneficial effect of pulsed or CW light for PDT is still an open question and many parameters have not been fully explored. Given the reported dependence of PDT efficacy on the fluence [80,81], it appears plausible to study the influence of different light waveforms on PS activation - considering different PS and oxygen concentration dynamics—and PDT of different types of light pulses and parameters, i.e., burst, super-pulse, pulse parameters (e.g., pulse width, shape). Less attention has been paid to advanced techniques such as wavefront shaping to achieve deeper light delivery penetration. Such techniques have demonstrated deeper light focusing, thus penetration depths. Besides, in certain cases (e.g., well-defined cancer margins), highly localized beams favour the selectivity of the treatment region with the potential to avoid organs at risk. Wavefront shaping can be accomplished by tailoring the multiple scattering light through the tissues varying spatial profiles and the phases of the incident wavefront [104-106]. This approach has been suggested mainly for enhancing penetration depth and optical resolution of optical microscopy techniques for imaging. Their higher complexity might not deem appropriate for light delivery in PDT. Hence, the feasibility of such techniques for deeper light delivery has to be envisaged.

\subsubsection{Delivery Devices}

For superficial PDT, there are many novelties regarding delivery devices that have emerged recently. For instance, artificial daylight PDT is a field explored in recent times. Maire et al. conducted a study in 2020 whereby artificial white light sources were used as photoactivation alternatives to daylight for treating actinic keratosis [107]. This device (CE-marked) delivers uniform illumination with $2.9 \mathrm{~mW} / \mathrm{cm}^{2}$ over a $314 \mathrm{~cm}^{2}$ surface. Likewise, different approaches have also been developed to obtain uniform light distributions for artificial daylight PDT, such as multi-wavelength LED [108], or non-coherent UV-protected greenhouses for therapy [109] and textile fabrics [110]. In 2018, O'Mahoney et al. implemented a uniform-illumination light source for artificial daylight photodynamic therapy [111]. The light source is capable of tuning the direction of light emission, thus pro- 
viding uniformity across large anatomical surfaces, such as the head or leg. The light source implements LED chips that can independently emit seven distinct wavebands of light. In 2013, Cochrane et al. developed and tested a textile light diffuser based on commercial polymer optical fibre Figure 5a) [112]. The device is based on a wave pattern [113] and is designed to produce a large diffuser (useful width of $20 \mathrm{~cm}$ ). The light source is a $5 \mathrm{~W}$ laser diode $(635 \mathrm{~nm})$ that generates a quasi-homogeneous intensity of $18.2 \mathrm{~mW} / \mathrm{cm}^{2}$. Despite it is not very homogenous, it has the capability to tune the wavelength of the light source using the same diffuser and can be bent when applied to a non-planar surface. In 2019, Masuda et al. manufactured a flexible LED unit designed for multi-wavelength excitation of 5-ALA (Figure 5b) [114]. Therefore, it is possible to achieve more uniform irradiation of even areas, enhancing the therapeutic effects of PDT. Finally, because it is necessary to illuminate with light in therapy, it is equally important to have a real-time dosimetry system and, if possible, a probe for precise tumour delineation. Xie et al. developed a fibre optic probe for therapy guidance and monitoring [115]. It allows the tumour delineation using fluorescence/reflectance spectroscopy with an error of less than $5 \%$.

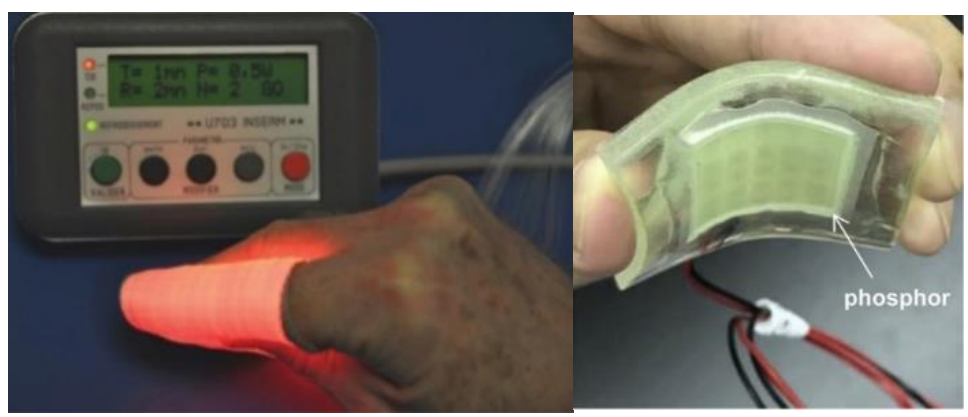

(a)

(b)

Figure 5. (a) Textile light diffuser applied on a finger-curved surface (image adapted from [112]). (b) Flexible LED unit designed for multi-wavelength excitation of 5-ALA (image adapted from [114]).

For I-PDT, delivery devices include diffusers of different geometries such as spherical, balloons, and cylindrical for wider illumination areas [8,116]. Their sizes range from some $\mathrm{mm}$ to tenths of $\mathrm{mm}$ and have been applied to several treatment sites - such as prostate, breast, oesophagus, lung, or biliary duct-among others. Other delivery devices such as fibre-focusing types have been benchmarked for oral surgery [117]. Recently, the use of sapphire capillary needles coupling optical fibres inside the needles with different tips and light patterns has been demonstrated [51,118,119]. Figure 6a depicts an example of such advanced capillary sapphire needles incorporating several types of needle tips with different geometry to control the direction of tissue light exposure and the amount of exposed tissue [119]. In this line, micro-focusing needles, allowing for lower energy required for treatment have also been developed. Such sapphire needles are advantageous because they can avoid degradation of their properties for multiple applications and sterilisation [120].

Complete systems including a set of fibres inserted into catheters or needles and guided through MRI (Figure 6b), X-ray markers (including real-time monitoring, see Figure 6c) or ultrasound images have been used for head and neck [121], brain [122], prostate [50], among others. For instance, the simultaneous light delivery using four fibres inserted into gauge needles and allowing for energy deposition of $20 \mathrm{~J}$ and an illumination area of about $10 \mathrm{~mm}$ in radius has been accomplished [121]. To achieve deeper penetration, the fibres are inserted into the deepest tumour area (guided by MRI) and subsequently withdrawn to illuminate other parts of the tumour (see Figure 6b).

Similarly, one of the most advanced systems for I-PDT includes simultaneous dosimetry and light delivery. It has been applied to localised tumours in the prostate using a set of bare optical fibres - in principle, for more accurate measurement of optical properties-on a brachytherapy-type template $[41,50,123]$. The system can deliver light and monitor pa- 
rameters simultaneously by use of a set of 18 fibres inserted into needles to deliver and monitor the excitation and light emission. Departing from an ultrasound input image, a 3D model of the prostate and tumour is generated and light dosimetry is constantly adjusted considering patient-to-patient variations in tissue optical properties.

(a)

(I)
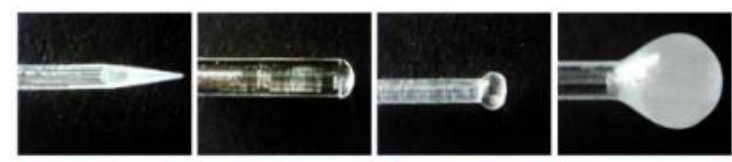

(II)
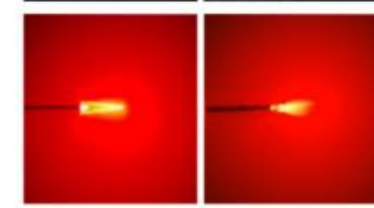

(III)
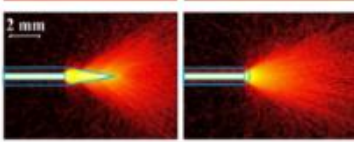

(IV)
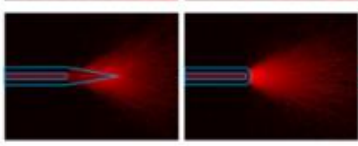

(b)

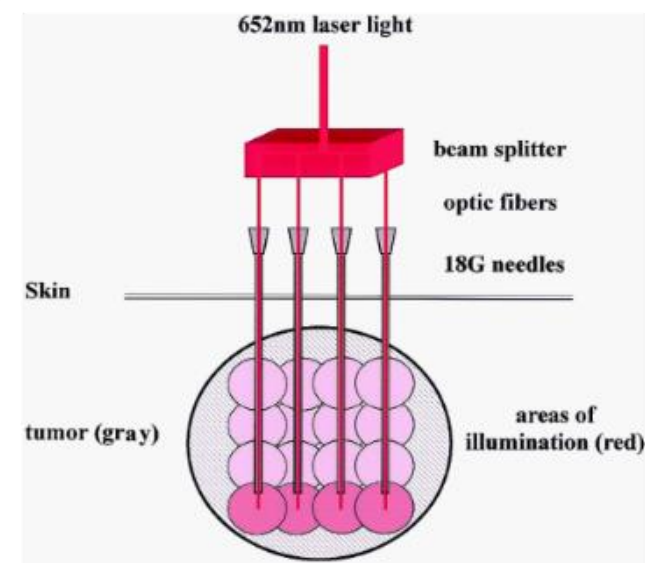

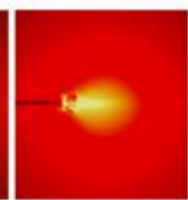
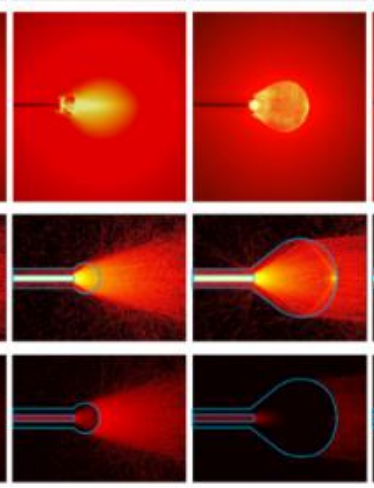

(c)

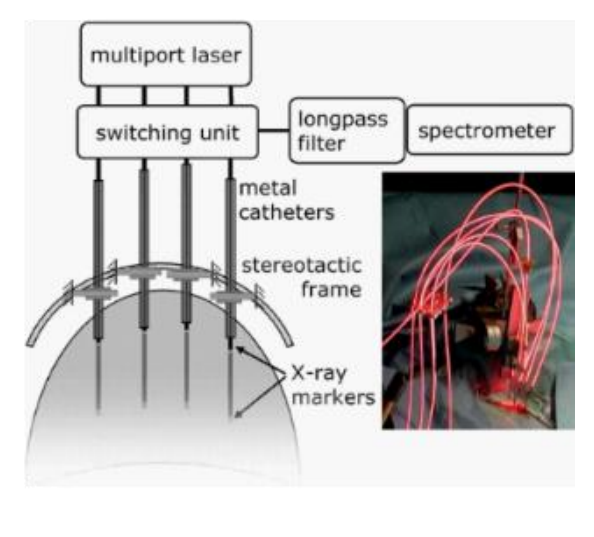

Figure 6. (a) Examples and application of advanced sapphire capillary needles for light delivery. (I) Sapphire tips; (II) laser light $(632.8 \mathrm{~nm})$ distribution produced by the sapphire tips in a diluted intralipid solution; corresponding to the (III) transmitted $\ln \mathrm{I}_{\mathrm{T}}$ and (IV) absorbed $\ln \mathrm{I}_{\mathrm{A}}$ intensities. The image and caption are adapted from their original created by Dolganova et al. [119] under a Creative Commons Attribution 4.0 Unsorted licence. (b) Schematic of I-PDT system including four fibres inserted into gauge-needles for simultaneous delivery light to treat head and neck cancer (image adapted from [121]). (c) Schematic of I-PDT system for brain tumour including real-time spectroscopic monitoring and clinical setting (optical fibres, catheters, and fixation device) during treatment (image adapted from [122]).

Other delivery devices aiming at the maximisation of tumour coverage and increased PDT efficacy have been proposed, namely light blankets [124], optical surface applicators [125], scalpels combining ROS, oxygen, and light delivery [126], and novel light sources acting as optical batteries [127].

In previous studies, it has been widely demonstrated I-PDT efficacy is highly improved upon the implementation of optimised dosimetry and light delivery $[8,9,50,128]$. Dosimetry and light delivery are not challenging in superficial PDT because there are no organs at risk nearby, and it is possible to illuminate the full lesion [41]. In deep-seated 
tumours, besides proximity to organs at risk (OAR), there could be heterogeneity in tissue optical properties, PS distribution, and microenvironment before and during the treatment (tumour oxygenation and vascular network). Hence, real-time systems are crucial for the maximisation of I-PDT efficiency. Concerning the design of delivery devices, it is highly dependent on the treatment site and geometry, thus the delivery systems need to adapt to specific sites and incorporate monitoring stages for enhanced I-PDT. Investigations on the modelling and specific adaptable treatment planning considering various sites and optically heterogeneous tissues have been conducted to assist this purpose $[84,129,130]$. Despite proper dynamic dosimetry demonstrated its validity and success in specific cases, it is very challenging to achieve complete dosimetry, and many realistic implementations in the clinic may focus on determining the key factors governing dosimetry to perform the minimum essential measurements [9].

\subsection{Deep PDT}

This section addresses Deep PDT technologies aiming to overcome the challenge of low light penetration through the tissue from conventional light sources. Deep PDT sources are based on electromagnetic radiation such as NIR (Section 2.3.1), X-rays or Cherenkov radiation section (Section 2.3.2), self-illuminated systems enabled by chemiluminescent and bioluminescent mechanisms (Section 2.3.3), and novel implants positioned in —and in some cases within-the tumour microenvironment (Section 2.3.4).

\subsubsection{NIR Radiation}

Within the PDT therapeutic window, a specific NIR window can be defined aiming for deeper light penetration through the tissues. It lies within 780 to $950 \mathrm{~nm}$ [29]. Despite this narrow window offers the highest transparency in tissues (Figures 1a and 4), it has been limited by the lack of suitable PSs. Most common PSs are better excited in the visible region rather than NIR (see Figure 2b). Some approved NIR absorbing PSs are Talaporfin $(664 \mathrm{~nm})$ and Palladium bacteriopheophorbide $(770 \mathrm{~nm})$, and novel compounds with extended range are being investigated (a complete list can be found in [131]).

In this context, there are several ways to enable the use of NIR radiation for PDT. In the following, we address three main approaches to excite directly or indirectly the PSs: (i) two-photon absorption, (ii) novel nonlinear optical photon conversion techniques, and (iii) the use of the so-called upconversion materials and nanoparticles (UCNPs). Any of these approaches involve the upconversion of two or more photons to higher energy levels to directly (i) or indirectly (ii) excite the PS by subsequent radiative light emission or non-radiative energy transfer (iii).

Two-photon absorption (TPA) is a nonlinear optical process involving simultaneous absorption of two NIR photons that combined promote an electron to a higher energy level than a single photon. TPA excites the PSs directly, or indirectly by exciting dedicated nanomaterials as will be described below. For direct excitation, specifically designed PSs are required [85,132]. To enable direct excitation of the PS through TPA, light sources with ultra-fast pulses $(<10 \mathrm{ps}$ ) of high photon density (focused beams) are typically required due to the low absorption probability of the TPA process in most PSs. Advantageously, TPA is a nonlinear process and the absorption increases quadratically with the laser intensity enabling the excitation of the PSs [132]. One main advantage of TPA is the use of laserfocused beams, localising the illumination area, thus providing high selectivity (preserving organs at risk in well-defined cancer margins) and minimizing off-target toxicity [21]. Another advantage is that PS conjugates for TPA show very little autofluorescence in the biological window, which is beneficial for optical imaging [133]. In the first attempts using TPA for PDT, the technique demonstrated the capabilities to excite some common PSs; however, it was not enough to promote cytotoxic effects [134]. Hence, the low TPA cross-section of common PSs (e.g., PpIX, Photofrin, or Visudyne) was identified as the main bottleneck on the use of TPA [21]. Then, the development of new PSs enabled the demonstration of TPA with deep light penetration (about $2 \mathrm{~cm}$ ) and its effectivity 
in vivo [29], and in a living mammal when applied to blood vessels occlusion [135]. TPA typically requires high fluence rates and not easily accessible systems, and despite the increased efficiency of the two-photon absorption cross-section, the low anti-tumour effects still limit its use.

Recently, a radically new approach was proposed by Kachynski et al. [136]. It consists of the indirect excitation of the PS (also using ultra-fast high-intensity lasers) by exploiting nonlinear optical photon conversion mechanisms occurring in many biological tissue constituents. These mechanisms include second-harmonic generation (SHG), and fourwave mixing (FWM), including coherent anti-Stokes Raman scattering (CARS). As stated by Kachynski et al., SHG is a second-order nonlinear optical process occurring in collagen, which is abundant in tumours and CARS/FWM, a third-order nonlinear optical process produced by proteins, lipids, nucleic acids, and aquatic biological environments [136]. Kachynski et al. demonstrated deeper light penetration and phototoxicity effects with lower radiation thresholds by using a combination of these novel techniques as compared to TPA alone. Fluences employed ranged between $30-90 \mathrm{~J} / \mathrm{cm}^{2}$ (no significant thermally induced cytotoxicity was detected by control experiments of irradiated samples without PS). After 75 scans $\left(4500 \mathrm{~J} / \mathrm{cm}^{2}\right)$, nearly $70 \%$ of cells were necrotic or detached by employing SHG/TPA to excite chlorin e6, which was higher as compared to CARS/FWM/TPA or TPA alone. They suggested that many reported TPA induced PDT studies using lasers in the range of 750-850 nm may have contributions from the SHG signal (at $\sim 400 \mathrm{~nm}$ ) caused in fibrillar collagens of tumours. Finally, they concluded SHG by collagen fibrils contributes efficiently to the excitation of chlorin e6 producing photodamage.

Another indirect excitation of the PSs is based on the upconversion of NIR photons into visible photons using dedicated upconversion materials, such as nano-transducers or upconverting nanoparticles (UCNPs) [137-143]. Nano-transducers potential candidates are gold nanorods (several orders of magnitude higher two-photon cross-sections than other PSs for TPA) [144], semiconductor quantum dots (QDs) [145] or carbon-quantum dots to avoid toxic elements from QDs [146]. Concerning UCNPs, they are made of ceramic lattice host doped with rare-earth ions (lanthanides) [21]. They can be adjustable in size, shape, and light emission through rational design and suitable doping [147]. One of the main advantages is the use of NIR radiation achieving deeper penetration, and the light emission in the visible region in which most PSs are better excited (Table 3). Besides, the power density required to excite the UCNPs is significantly lower than TPA, i.e., $1-10^{3} \mathrm{~W} / \mathrm{cm}^{2}$ and $10^{6}-10^{9} \mathrm{~W} / \mathrm{cm}^{2}$, respectively [21]. Hence, besides TPA, CW NIR-excitation enables the absorption of two photons. To allow UCNPs emission, the energy from a NIR-excited fluorescent molecule (donor) is transferred to a second molecule (acceptor), which in turn emits the desired wavelength. This energy transfer can be accomplished by a nonradiative process known as Förster resonance energy transfer (FRET). To enable FRET, proximity between the chromophores or fluorochromes is required (50-100 $\AA$ because efficiency is inversely proportional to the sixth power of the distance between donor and acceptor) $[148,149]$, and the absorption spectrum of the acceptor chromophore must overlap the fluorescence emission spectrum of the donor [150]. We will not provide further details because excellent recent reviews exist for this topic [90]. However, we can highlight some of the main challenges are the retention difficulty of the UCNPs within the microvasculature system, and the potential toxicity caused to the normal cells by current upconversion materials [151,152]. 
Table 3. Excitation and emission wavelengths of some reported UCNP, and available laser sources. Note UCNPs excited with 975-980 nm match a high absorption peak from water (Figure 1) which may cause excessive heating of the tissue. To overcome this, neodymium ions can be added to the UCNP which absorb 800 nm [153].

\begin{tabular}{|c|c|c|c|}
\hline Excitation (NIR) & Emission (nm) & Ref. & Laser Diodes (max. Power) \\
\hline \multirow{7}{*}{$980 \mathrm{~nm}$} & $345,360,450,475$ & [154-157] & L980P010 (10 mW) \\
\hline & 450,475 & [158] & LP980-SF15 (15 mW) \\
\hline & 540 & {$[159,160]$} & L980P030 (30 mW) \\
\hline & $520,545,660$ & [161] & L980P100A (100 mW) \\
\hline & $409,541,656$ & [162] & L980P200 (200 mW) \\
\hline & 660 & [162-169] & C3-980-0500-S50 (500 mW) \\
\hline & 540,660 & [170-172] & WSLD-980-001-2 (1 W) \\
\hline \multirow{6}{*}{$975 \mathrm{~nm}$} & \multirow{6}{*}{$\begin{array}{l}340,360,445,475 \\
620660\end{array}$} & \multirow{6}{*}{$\begin{array}{l}{[173]} \\
{[174]}\end{array}$} & 0975L-14A-NI-PT-NF (70 mW) \\
\hline & & & RLTMDL-975-100 (100 mW) \\
\hline & & & RLTMDL-975R-300 (300 mW) \\
\hline & & & PL980P330J $(330 \mathrm{~mW})$ \\
\hline & & & RLTMDL-975-500 (500 mW) \\
\hline & & & RLTMDL-975-1W (1 W) \\
\hline \multirow{9}{*}{$808 \mathrm{~nm}$} & \multirow{9}{*}{$\begin{array}{l}345,360,450,475 \\
350,450 \\
540 \\
540,660 \\
543,654 \\
660\end{array}$} & \multirow{9}{*}{$\begin{array}{l}{[175]} \\
{[156]} \\
{[176]} \\
{[175]} \\
{[177]} \\
{[178]}\end{array}$} & L808P010 (10 mW) \\
\hline & & & L808P030 (30 mW) \\
\hline & & & DBR808PN (42 mW) \\
\hline & & & LP808-SA60 (60 mW) \\
\hline & & & M9-808-0150 (150 mW) \\
\hline & & & L808P200 (200 mW) \\
\hline & & & FPL808S $(250 \mathrm{~mW})$ \\
\hline & & & LD808-SE500g $(500 \mathrm{~mW})$ \\
\hline & & & L808P1000MM (1 W) \\
\hline
\end{tabular}

\subsubsection{Ionising Radiation}

The ionising radiation consists of electromagnetic waves or subatomic particles, with enough energy to ionize atoms or molecules by detaching electrons from them. The energy from one ionisation can break chemical bonds in molecules causing damage to the living tissue. In the case of electromagnetic waves, only those with very high frequencies can be considered as ionising-e.g., gamma rays, X-rays, and the higher ultraviolet part of the electromagnetic spectrum. For subatomic particles, there are four kinds of ionising radiation, namely Beta (consisting of electrons),Alpha (two protons and two neutrons), protons and neutrons. The sources can be natural (any radioactive materials) or artificial (nuclear reactors, particle accelerators, and X-ray tubes).

Ionising radiation has been proposed as an alternative source for PDT achieving deep tissue penetration, specifically, $X$-ray and Cherenkov radiation (see Figure 7).

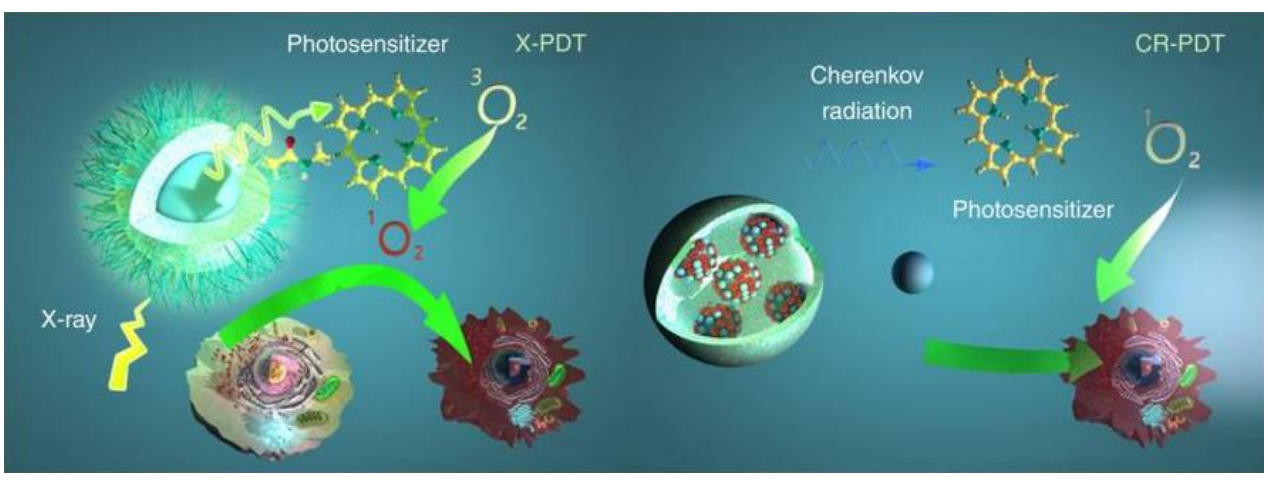

Figure 7. Schematic illustration for X-PDT and CR-PDT. Left: Classic X-PDT. X-rays excite a nanoscintillator to generate $X$-ray luminescence, which in turn activate a PS to produce cytotoxic ROS. Right: Cherenkov radiation PDT. Cherenkov radiation from radioisotopes is harnessed to activate a PS to initiate PDT. Reproduced with permission from B. Cline et al. Wiley Interdisciplinary Reviews. Nanomedicine and Nanobiotechnology published by Wiley, 2019 [179]. 
On the one hand, the required X-ray doses in clinical radiotherapy are in the range of hundreds of $\mathrm{keV}$ to $\mathrm{MeV}$, making it difficult to be used with traditional PS. To overcome this problem, in 2006 the use of X-rays and nanoparticles was proposed [180]. Since then, numerous studies have been reported, which are collected on recent reviews [179,181-184]. In the case of X-ray PDT, the PS can be activated by either persistent luminescence nanoparticles (PLNPs) or scintillating nanoparticles (SCNPs). With PLNPs the X-ray energy is stored at the defects or electron traps, causing a long-lasting afterglow which continuously serves as a light source for PDT activation (can emit light from few minutes to several days) [185]. SCNPs down-convert $\mathrm{X}$-rays energy into visible light through a scintillation process and then transfer the energy to nearby PS. Some reported studies can be found in Table 4 . They can be classified into two major groups, namely doped scintillator and semiconductor [179]. Some important characteristics are a high material density (for a good ionising radiation interaction), high scintillation quantum yield and efficient energy transfer as well as biocompatibility, and adapted in vivo bio-distribution [186]. In the case of a doped scintillator, one of the most studied have been lanthanides with high material density, high atomic number, and strong luminescence intensity [187]. In the case of semiconductor SCNPs the size has to be small to maximize quantum entanglement effects [179]. Despite the promising results, most of the X-ray PDT studies were mainly obtained with cancer cell lines or animal models bearing subcutaneous grafted cancer cells, thus limiting clinical relevance [186].

Table 4. Some reported X-ray SCNPs with the required energy to activate them and the emission wavelengths. Adapted with permission from [179].

\begin{tabular}{|c|c|c|c|}
\hline Excitation (X-ray Dose) & Emission (nm) & X-ray Scintillator (Size) & Ref. \\
\hline $6 \mathrm{MeV}, 30 \mathrm{keV} 1-6 \mathrm{~Gy}$ & 340 & $\mathrm{CeF}_{3}(9 \mathrm{~nm})$ & [188] \\
\hline 50 keV 1-10 Gy & 520 & $\mathrm{SrAl}_{2} \mathrm{O}_{4}: \mathrm{Eu}^{2+}(407 \mathrm{~nm})$ & [189] \\
\hline 90 keV, 3 Gy & 520 & $\mathrm{LaF}_{3}: \mathrm{Ce}^{3+}(2 \mu \mathrm{m})$ & [190] \\
\hline $75 \mathrm{keV}$ & 544 & $\mathrm{LaF}_{3}: \mathrm{Tb}(40 \mathrm{~nm})$ & [191] \\
\hline $75 \mathrm{keV}$ & 540 & $\mathrm{LaF}_{3}: \mathrm{Tb}$ silica coated $(45 \mathrm{~nm})$ & [192] \\
\hline $6 \mathrm{MeV}, 0.4-2 \mathrm{~Gy}$ & 545 & $\mathrm{SiC} / \mathrm{SiOx}$ core/shell nanowires $(40 \mathrm{~nm})$ & [193] \\
\hline $80 \mathrm{keV}$ & 540 & $\mathrm{LaF}_{3}: \mathrm{Tb}(25 \mathrm{~nm})$ & [194] \\
\hline $44 \mathrm{keV}, 11 \mathrm{~Gy}$ & 540 & $\mathrm{~Tb}_{2} \mathrm{O}_{3}$ coated polysiloxane $(10 \mathrm{~nm})$ & [195] \\
\hline $15 \mathrm{keV}$ & 595 & GdEuC12 (4.6 nm) & [196] \\
\hline $225 \mathrm{keV}, 2 \mathrm{~Gy}$ & 500 & HfnMOL (1.2 nm) & [197] \\
\hline 120 keV, 2 Gy & 510 & $\mathrm{ZnS}: \mathrm{Cu}, \mathrm{co}(4 \mathrm{~nm})$ & [198] \\
\hline $220 \mathrm{keV}, 8 \mathrm{~Gy}$ & 305 & $\mathrm{LiYF}_{4}: \mathrm{Ce}(35 \mathrm{~nm})$ & [199] \\
\hline $50 \mathrm{keV}, 5 \mathrm{~Gy}$ & 720 & $\mathrm{LiGa}_{5} \mathrm{O}_{8}: \mathrm{Cr}(100 \mathrm{~nm})$ & [200] \\
\hline $160 \mathrm{keV}, 5 \mathrm{~Gy}$ & 543 & $\mathrm{NaLuF}_{4}: \mathrm{Gd}, \mathrm{Eu}(25 \mathrm{~nm})$ & [201] \\
\hline $1.48 \mathrm{keV}$ & $300-450$ & $\mathrm{Y}_{2.99} \mathrm{Pr}_{0.01} \mathrm{Al}_{5} \mathrm{O}_{12} @ \mathrm{SiO}_{2}(75 \mathrm{~nm})$ & [202] \\
\hline
\end{tabular}

On the other hand, Cherenkov radiation (CR) was proposed in 2011 as an alternative source for in vivo photoactivation [203]. This option can be used along with radiotherapy or even without any external radiation (by using radioactive isotopes) [203]. As it is defined in [186], Cherenkov light is a luminescence signal produced by charged particles that travel faster than the phase velocity of light in a dielectric medium (it can be compared with sound barrier crossing, but for light). Cherenkov photons are produced by successive polarization/depolarization of the medium along the particle path, yielding constructive interferences. When a radioactive isotope decays, charged particles such as Beta are generated. As these particles travel through the dielectric molecules, they polarize the molecules and while returning to their ground state, the molecules emit the energy as photons. If the particles have a speed lower than light in that medium, the polarization field around the moving particle is 
usually symmetric, so the corresponding wavefronts do not interfere. On the contrary, if the particles have a speed higher than light in that medium, the molecules do not have time to go to the ground state before the particle has left, resulting in an asymmetric polarization field, that causes a constructive interference of the wavefronts with a cone-like light emission (at a specific angle). The spectrum of radiation luminescence consists of continuous wavelengths throughout the ultraviolet and visible spectrum, where the number of photons per wavelength is proportional to $1 / \lambda^{2}$ [204].

Some studies have demonstrated that it is possible to use $\mathrm{CR}$ from radionuclides to activate oxygen-independent nanoPSs, such as titanium dioxide $\left(\mathrm{TiO}_{2}\right)[205,206]$ and aminolevulinic acid (ALA) [207]. However, there are some doubts about Cherenkov action in free radical production and cell death. There is also a previous study reporting activation of $\mathrm{TiO}_{2}$ nanoparticles from radioactive ${ }^{32} \mathrm{P}$ without invoking Cherenkov luminescence as the mechanism of action [208]. The main problem is the extremely low fluence rates of Cherenkov radiation, as an example, the average Cherenkov emission from ${ }^{18} \mathrm{~F}$ is approximately three photons per radioactive decay in water (refractive index $n=1.33$ ) over the 250-800 $\mathrm{nm}$ range [208]. Monte Carlo simulations have determined the flux rates for radionuclides to be on the order of $0.01-1 \mathrm{nW} / \mathrm{cm}^{2}$ [209], several orders of magnitude below some reported in vitro and in vivo fluence rates required for PDT, which have found a decrease in cytotoxicity for fluence rates below $5.5 \mathrm{~mW} / \mathrm{cm}^{2}$ [210]. These results indicate that the implied mechanisms are not completely understood. Another issue is the radiation caused by some radioisotopes. For example, one standard radiotracer used in positron emission tomography (PET) has an effective radiation dosage of 5-8 mSv [211]. To compare with X-ray radiation, some common procedures such as chest X-ray or chest computer tomography (CT) have a radiation dosage of around $0.1 \mathrm{mSv}$ [212] and $8 \mathrm{mSv}$ [213], respectively. An approximate comparable time of natural background radiation exposure for a chest X-ray is 10 days and for a chest CT around 2 years [214]. Moreover, CR has proven very inefficient, it needs high doses of charged particles, it gives broad wavelength radiation up to a limit, and it tends to be concentrated in the UV and blue light (as commented before, these wavelengths does not have much penetration depth). Despite this, Cherenkov radiation has potential advantages, for example, the suppression of external irradiation sources or the selective accumulation of many radiopharmaceuticals in tumours after systematic injection (targeting multiple metastases) [215].

\subsubsection{Self-Illuminated Systems}

Self-illuminated systems have emerged as a promising solution to limited penetration depth without ionising sources. There are mainly two mechanisms to produce light without an external source, Chemiluminescence Resonance Energy Transfer (CRET) and Bioluminescence Resonance Energy Transfer (BRET) [216]. As their names indicate, Chemoluminescence is the emission of light as the result of a chemical reaction whereas Bioluminescence is produced by a living organism. In fact, Bioluminescence is a form of chemiluminescence that occurs in some animals and microorganisms. CRET involves a chemiluminescent (CL) donor whose energy is transferred to a suitable biological acceptor (oxidizing agent) and then, the adjacent PS is activated. Since the first proposal of luminol intracellular CL in 2002 [217], this has been the most used excitation source in CRET PDT with an emission peak wavelength of $425 \mathrm{~nm}$ [218-220]. One advantage is that luminol can be mixed with hydrogen peroxide $\left(\mathrm{H}_{2} \mathrm{O}_{2}\right)$, abundant in the tumour microenvironment, to activate the PS. The main drawback is the limitation on PS selection due to the fixed emission peak of these systems. Some works have used also RET intermediate systems to tune the emission peak, as semiconducting polymer dots [221], conjugated polymer nanoparticles (which can luminesce and supply oxygen) [222] or carbon dots [223]. The peak emission can be matched to the peak absorption of the PS. However, one problem of using RET intermediate systems is the reduction of PDT efficiency (as several energy transfer steps are required before ROS generation). Despite this, some works have reported toxicities of $90 \%$ on SMMC-7721 cancer cells (using Ce6 PS) [223]. Despite these reported systems meet the spectral overlap 
requirement for CRET, and have high cytotoxicity and considerable tumour inhibition, there are biocompatibility issues such as low specificity and toxicity for healthy cells.

Alternatively, BRET PDT consists of a light-emitting molecule and a catalysing enzyme (usually called luciferin and luciferase, respectively) that in combination produce bioluminescence (BL). Some commonly reported sources are Firefly and Renilla. In the first case, Firefly luciferase (fLuc) is the most important and studied BL system [224]. This system depends on the surrounding $\mathrm{pH}$ with a peak wavelength of $560 \mathrm{~nm}$ and $620 \mathrm{~nm}$ for basic and acidic $\mathrm{pH}$, respectively $[225,226]$. The first report of the use of this BL for PDT was made in 2003 by Theodossiou et al. [227]. The authors reported ${ }^{1} \mathrm{O}_{2}$ was produced because of the combination of BL with hypericin PS (a 90\% of toxicity rate was measured). A few years later, a similar study demonstrated that firefly BL emission is not sufficient to generate a cytotoxic effect because of insufficient photon generation [228]. These results are intriguing, and highlight the necessity of questioning if the cytotoxic effects reported can be attributed to the BL emission only, or additional factors are implied.

It is known that self-luminescence is relatively weak due to the difficulty to have the substrate and the catalyser close and relatively low quantum yields (that depends on the surrounding medium $\mathrm{pH}$ ). To increase the quantum yield, recent works have proposed the use of RET intermediate systems. In 2019, K. Yang et al. used carbon nanodots (CDs) to upconvert the fLuc emission (to $440 \mathrm{~nm}$ ). The CDs were functionalized to the PS (PpIX, absorption peak around $400 \mathrm{~nm}$ ) that in contact with the fLuc system produced significant ROS in vitro [229]. In the case of Renilla luciferase, when combined with coelenterazine luciferin a blue-green peak wavelength of $480 \mathrm{~nm}$ is produced [230]. This system has been tested as an intracellular excitation source for PDT by Hsu et al. [231]. They took advantage of the quantum dots (QDs) emission at $655 \mathrm{~nm}$ to activate the PS (m-THPC, Foscan) because it is easier to tune the emission of a quantum dot than the BL system (Figure 8).

Other similar systems have used other PS as chlorin e6 (Ce6) [232]. Despite a delay in tumour growth (higher when using QDs than without them) and localization on the external surface of cells were demonstrated, there was significant toxicity to healthy cells. Besides, the authors have demonstrated that BRET energy generates a stronger PDT effect in the cellular membrane than a $1000 \times$ higher laser energy dose and the efficiency is considerably higher than firefly BL PDT [228,231]. However, several shortcomings must be addressed, e.g., other components different from quantum dot must be explored (due to toxicity), the two-step energy transfer efficiency has to be increased, the BL and PS have to be in the same subcellular location (selective delivery) and the used PS has to be optimized for the emission wavelengths. To overcome these problems, recent works have proposed gene transfection using luciferase-fused genes (some risk of genotoxicity) [233] and BL-induced proteinaceous PDT based on a protein biosensor, capable of generating ROS without the need of PS [234].

In conclusion, the potential of self-illuminated systems is enormous but they are still in their infancy. Several reports using CL and BL have demonstrated intracellular activation of different PS. Among them, Rluc-coelenterazine and luminol systems have been able to induce considerable PDT effect both in vivo and in vitro. Despite this, it cannot be found in the literature a plausible explanation about discrepancies of generated light fluences found in different articles. The main cause could be the required short distance between the substrate, the catalyst and the PS (and the variability of this parameter in real systems). Further research on advanced delivery systems, which can locate these components efficiently to the cancer region at the same time, is required. In this regard, if this is achieved, CL/BL systems will maintain one of the main advantages of PDT, its selectivity (reducing also the cytotoxicity to healthy cells). On the other hand, it has to be considered that this kind of systems depends on various energy transfer steps, which can decrease the overall PDT effect. Hence, unravelling these processes is key towards a better understanding of self-illuminated systems. 


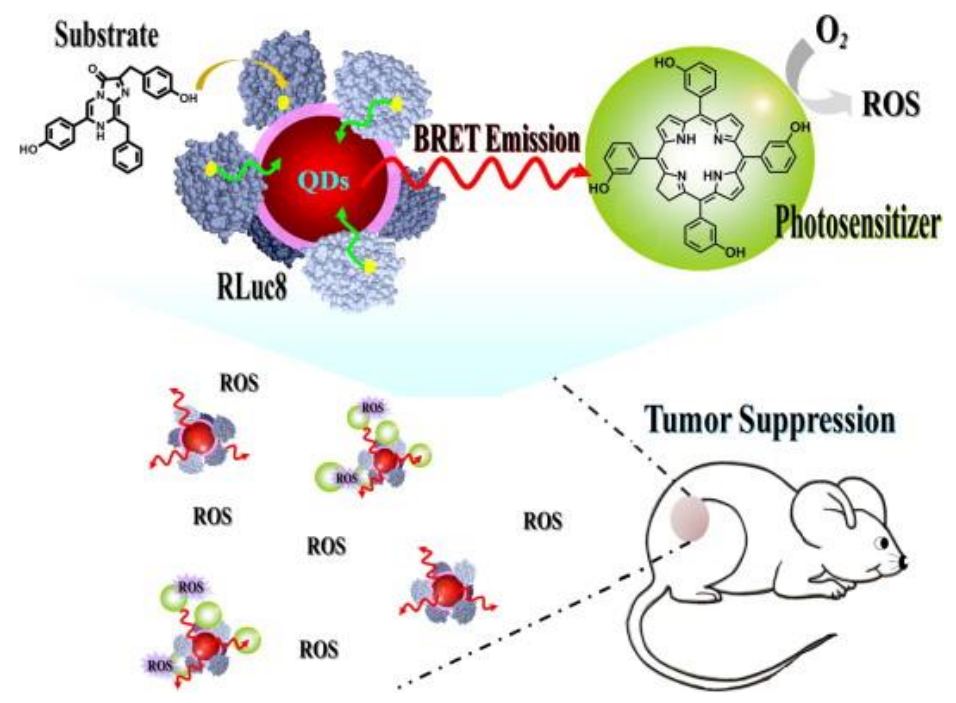

Figure 8. Schematic representation of RLuc8-immobilized QDs-655 for BRET-based PDT. Reproduced with permission from C.-Y. Hsu et al., Biomaterials; published by Elsevier, 2013 [231].

\subsubsection{Implants}

The miniaturization of electronics is opening pathways for the fabrication of implants of various sizes (mm-range or less) and shapes suitable to attach to several treatment sites. The implants consist of light sources encapsulated into a bio-compatible polymeric material [235] — with high optical transparency—that can be implanted on the tumour microenvironment, and externally activated by an electromagnetic radiation source. Several light sources have been incorporated inside the implants to activate the PS, namely: (1) persistent luminescent materials (so-called "optical batteries") such as nanoparticles (PLNPs) or green persistent luminescence materials (GPM), (2) UNCPs, and (3) microdevices including LED sources and modules. For activation of the light sources, NIR radiation [236-238], radio-frequency (RF), near-field communication (NFC) [239-241], and ultrasound [242] have demonstrated their capabilities to activate the light sources.

One of the main benefits of the use of implants is the possibility to perform metronomic PDT (mPDT) [243]. This is a modality in which low light dose (typically $<1 \mathrm{~mW} / \mathrm{cm}^{2}$ ) and slow or repeated infusion of PS is pursued over extended periods (from some hours up to tenths of hours). The use of low fluence rate over extended periods has shown clinical benefits over conventional PDT fluence rates (typically $100 \mathrm{~mW} / \mathrm{cm}^{2}$ ) $[81,210,240,244-246]$. For instance, it was found that repeated PDT yielded necrosis at deeper regions than typically expected for conventional PDT [246]. Other benefits from the use of mPDT are PS photobleaching prevention and lower oxygen consumption in the tumour due to the low light fluence rate applied, which in turn avoid any potential thermal issues. Fluence rates over $75 \mathrm{~mW} / \mathrm{cm}^{2}$ lead to fast oxygen consumption that may not be resupplied by the blood flow through the tumour vasculature [80]. In the following, we describe recent selected studies that offer a broad overview of the general status of emerging implants for PDT.

Fan et al. designed an injectable material that can produce persistent luminescence after NIR irradiation [236]. The implants consist on a dissolution of $\mathrm{ZnGa}_{1.996} \mathrm{O}_{4}: \mathrm{Cr}_{0.004}$ (ZGC) PLNPs in poly(lactic-co-glycolic acid) (PLGA)/N-methylpyrrolidone (NMP) oleosol (see Figure 9). After the oleosol injection, the material turns into a solid attaching firmly to the tumour region (despite $\mathrm{Cr}$ is a heavy toxic element, no biocompatibility issues have been observed). The ZGC shows an enhanced afterglow intensity (peak at $695 \mathrm{~nm}$ ) during hours after a short activation of a few minutes. The used PS was 2-(1-hexyloxyethyl)-2devinyl pyropheophorbide- $\alpha$ (HPPH, Photochlor). The authors demonstrate a remarkable tumour reduction in the first week, and a complete suppression in about half a month (with an additional dose of PS at day 7 and LED irradiation $24 \mathrm{~h}$ later). 


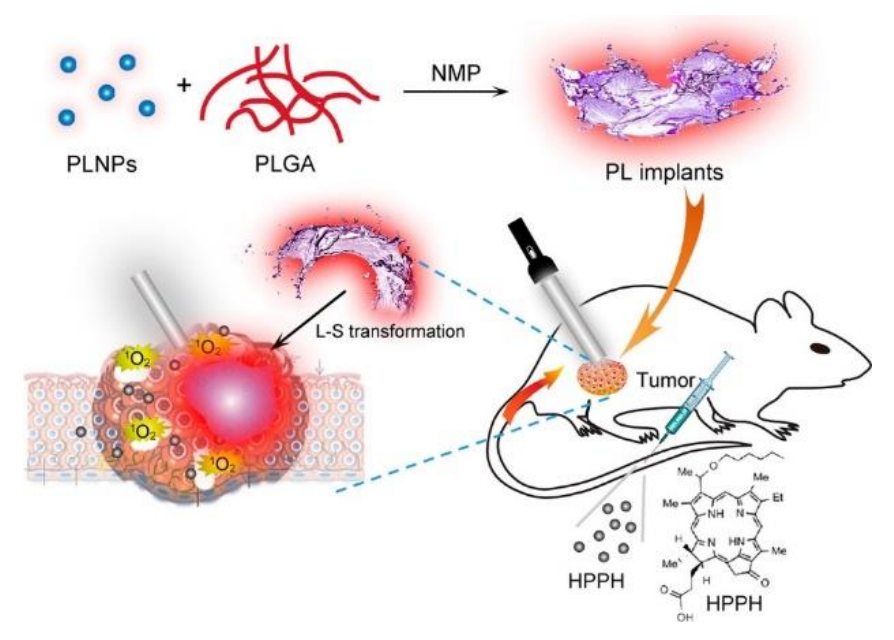

Figure 9. Schematic illustration of the construction of ZGC PL implants for in vivo LED/PersL-PDT upon LED irradiation. Reproduced with permission from W. Fan et al., ACS Nano; published by American Chemical Society, 2017 [236].

In [237], L. Hu et al. used green persistent luminescence materials (GPM), which can store energy from UV-blue light, added to PS Rose Bengal (RB) and mixed with upconversion phosphorous. For PS excitation, the NIR radiation of $980 \mathrm{~nm}$ is upconverted to $520 \mathrm{~nm}$ through a combination of upconversion materials (NaYF4:25\% Yb,0.5\%Tm) and UV rechargeable persistent phosphors $\left(\mathrm{SrAl}_{2} \mathrm{O}_{4}: 2 \% \mathrm{Eu}^{2+}, 4 \% \mathrm{Dy}^{3+}\right)$. No intravenous (IV) injection of upconversion materials is required avoiding possible toxicity problems. All components are mixed with $\mathrm{CaO}_{2}$ (to overcome hypoxia tumour) and added to polydimethylsiloxane (PDMS). The PDMS is finally solidified at $60^{\circ}$ for $1 \mathrm{~h}$. The device is implanted on a $100 \mathrm{~mm}^{3}$ tumour. Applying $2 \mathrm{~W} / \mathrm{cm}^{2}$ for $5 \mathrm{~s}$, the luminescence can persist for more than $2 \mathrm{~h}$ (it has to be noted that the authors do not take into account maximum power exposure limits to $980 \mathrm{~nm}$ excitation for human skin [247]). Despite the ${ }^{1} \mathrm{O}_{2}$ is generated inside the PDMS, the authors reported the singlet oxygen can diffuse through the PDMS reaching the tissue, and achieving cytotoxic effects. Both in vitro and in vivo results showed inhibition of tumour proliferation.

Another NIR-activated implant relays on UCNPs $\left(\mathrm{NaYF}_{4}: \mathrm{Yb}^{3+}, \mathrm{Er}^{3+}\right.$ and $\mathrm{NaYF}_{4}: \mathrm{Yb}^{3+}$, $\mathrm{Tm}^{3+}$ ) mixed with poly(ethylene glycol) diacrylate (PEGDA) and a fluorinated ethylene propylene (FEP) cladding layer to improve light transmission and minimize leakage of UCNPs [238]. The PS (5-ALA) is administrated systemically. The implant is activated with an irradiance of $725 \mathrm{~mW} / \mathrm{cm}^{2}$ of NIR at $980 \mathrm{~nm}$ (within the limits of $726 \mathrm{~mW} / \mathrm{cm}^{2}$ of maximum permissible exposure for human skin). A brain tumour is studied, the results reveal beneficial outcomes and biocompatibility of the implant in comparison to interstitial fibre optics. Optical fibre produced higher glial scarring comprising both reactive microglia and astrocytes as compared to UCNPs implant [238]. Moreover, PDT-treated mice showed shrinkage of tumour size after 16 days, these results were confirmed by immunohistochemistry staining for the gross morphology of the engrafted tumour in brain slices.

Despite the promising results of the previous systems, most of them are still limited by the penetration depth of NIR radiation $(<2 \mathrm{~cm})$ for external activation of the implant. To allow deeper penetration of external activation sources, other approaches have proposed the use of RF. We found the first proposal using RF in 2018 [239]. As can be observed in Figure 10, an implantable device ( $30 \mathrm{mg}$ weight, $15 \mathrm{~mm}^{3}$ ) is placed inside the tumour. After $4 \mathrm{~h}$ of PS (chlorin e6, Ce6) administration, an RF signal (1-1.5 GHz) is applied to activate the LED module (encapsulated in PDMS). The device consists of a printed circuit board (PCB) connected to a helical coil that receives the incident energy of the RF. The PCB integrates the two LEDs (660 and $400 \mathrm{~nm}$ to match absorption peaks of Ce6) and the RF rectifier (capacitors and Schottky diodes). For the in-vivo test, a murine model of bladder carcinoma is used. Light power of $1.3 \mathrm{~mW}$ was applied for $30 \mathrm{~min}\left(2 \mathrm{~J} / \mathrm{cm}^{2}\right)$ and the second 
round of treatment was administered after 7 days. The results reveal a tumour volume reduction over time and in some cases a complete regression.

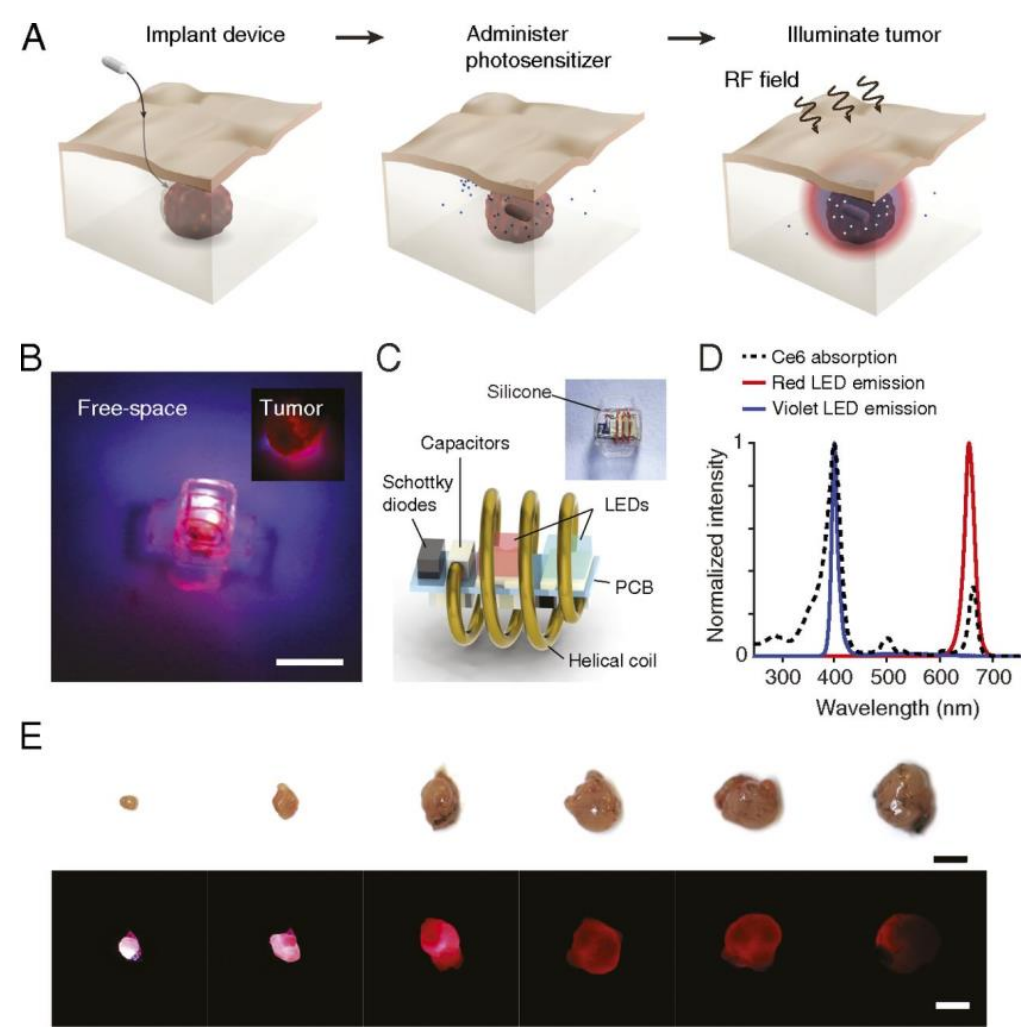

Figure 10. Wireless photonic PDT. (A) Schematic of the therapy. The therapy consists of implantation of wireless LED near the target region, administration of the PS, and wireless powering of the device. Light emitted by the device locally activates the PSs and induces tumour damage. (B) Image of the wireless photonic device emitting light. (Inset) The device illuminating an explanted tumour. (scale bar, $2 \mathrm{~mm}$.) (C) Schematic of the device and individual electronic components. (D) The optical emission spectrum of the device from two LEDs. The emission wavelengths are centred at $400 \mathrm{~nm}$ (violet) and $660 \mathrm{~nm}$ (red), overlapping with the absorption peaks in the Ce6 spectrum. (E) Image panel of the penetration of light emitted by the device (radiant power, $1.3 \mathrm{~mW}$ ) through tumours of increasing volume (scale bar, $5 \mathrm{~mm}$ ). Reproduced from A. Bansal et al. PNAS; published by National Academy of Sciences under CC BY-NC-ND or CC BY license, 2018 [239].

In 2019 Yamagishi et al. designed and manufactured a tissue-adhesive and near-field communication-based chip (a resonance frequency of $13.56 \mathrm{MHz}$ and transmission power of $3 \mathrm{~W}$ ), with red, green and blue LEDs, for mPDT [240]. The adhesive provides mechanical stability to the optical device tackling a major challenge on the use of implants in-vivo. The implants consisted of a commercial micro LED light source with an integrated coil (chips from Kyoritsu Electronic Industry) that has been encapsulated in PDMS and sandwiched in a bioadhesive material polydopamine (PDA). The PDA bounds to the biological tissue surface via a chemical reaction [240]. The approach is characterised by a low fluence rate $\mu \mathrm{W} / \mathrm{cm}^{2}$ range and long-term treatment, allowing continuous delivery of light to the target tumours for at least 10 days [240]. The device led to significant antitumour effects with 1000 -fold lower intensity than conventional PDT approaches. Because of that, the risk of thermal tissue damage is negligible. The same implant has been demonstrated recently using only green light (532 nm, power of 50-60 $\mu \mathrm{W}$ ) and PS ALA [241]. The treatments with this implant required repeated PS administration. In the former study, intravenous administration of Phorifrin was carried out. In the latter, ALA was chosen because it can be introduced orally, thus partially reducing the burden to patients. 
One of the main problems of RF activated systems is that micro-coils suffer from low power transfer efficiency and short transmission range, due to the small dimensions and the requirement of a precise alignment with the RF source [248]. To overcome these drawbacks, ultrasonic powering offers unique advantages such as higher power transfer efficiency for millimetre receivers, misalignment insensitivity, and a larger penetration depth $(>20 \mathrm{~cm})$ for implant activation [249]. As an example, in [242] an ultrasonically powered implant $\left(\sim 2 \mathrm{~mm}^{3}\right)$ based on a piezoelectric transducer with surface-mounted red and blue LEDs ( 0.048 to $6.5 \mathrm{~mW} / \mathrm{cm}^{2}$ for an ultrasound power of $185 \mathrm{~mW} / \mathrm{cm}^{2}$ at $720 \mathrm{kHz}$ ) was proposed and demonstrated.

As can be observed in Figure 11a, the microlight sources can be implanted in a deepseated tumour (e.g., pancreas). Multiple sources can be implanted at the same tumour due to misalignment insensitivity. The acoustic signal energizes the onboard LEDs, activating the PS. In Figure 11b, it is shown how the devices can be easily inserted with a biopsy needle (gauge 8). In vitro and in vivo test were made, in the latter case, the $\mu$ Light 242 was implanted in 16 mice with tumours of $200 \mathrm{~mm}^{3}$.

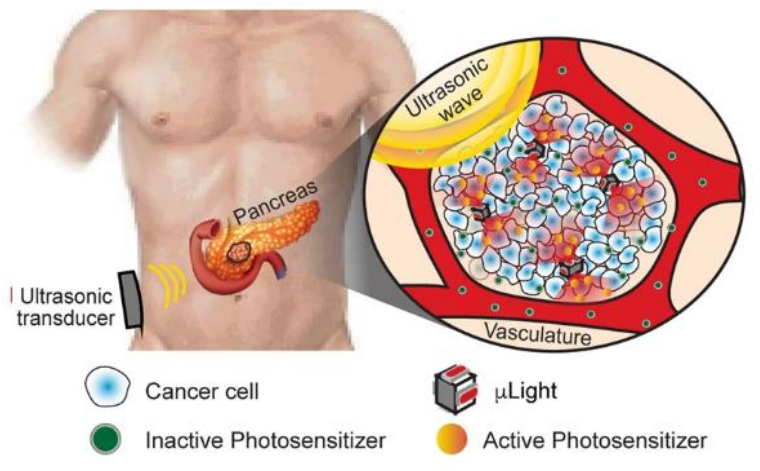

(a)

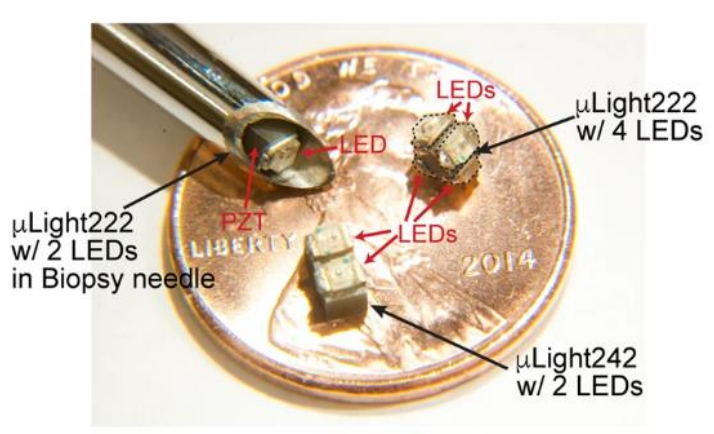

(b)

Figure 11. (a) Illustration of implantable $\mu$ Light in a deep-seated tumour: ultrasonic waves applied from an external transducer travel through the tissue to trigger light generation by the $\mu$ Light, thus activating a pre-delivered PS, which in turn generates ROS to kill cancer cells. (b) Photographs of fabricated prototypes. Reproduced with permission from A. Kim et al., Scientific Reports; published by Springer Nature, 2019 [242].

The treatment time was set to $30 \mathrm{~min}\left(2 \mathrm{~J} / \mathrm{cm}^{2}\right.$ light dose $)$. A decrease in average tumour size of $20 \%$ was observed on day 8 [242]. This study demonstrates the feasibility and advantages of ultrasonically activated implant, opening a new way to produce PDT and $\mathrm{mPDT}$.

To summarize this section, the main characteristics of implants described in this section are depicted in Table 5.

Table 5. Description of representative implants used for mPDT.

\begin{tabular}{|c|c|c|c|c|c|}
\hline Light Source & Emission & Implant Size & Encapsulation & $\begin{array}{l}\text { External Source } \\
\text { (Activa- } \\
\text { tion/Charging) }\end{array}$ & PS \\
\hline $\begin{array}{l}\text { (ZGC) PLNPs } \\
\text { [236] }\end{array}$ & $\begin{array}{l}695 \mathrm{~nm} \\
\text { Hours of emission }\end{array}$ & - & $\begin{array}{l}\text { PLGA/NMP } \\
\text { oleosol }\end{array}$ & $\begin{array}{l}\text { LED: } 400-750 \mathrm{~nm} \\
\text { for } 2 \text { or } 5 \mathrm{~min}\end{array}$ & $\begin{array}{l}\text { HPPH, Photoclor } \\
\text { Abs. peaks: } \\
385 \mathrm{~nm}, 666 \mathrm{~nm} \\
\text { Emission: } 670 \mathrm{~nm}\end{array}$ \\
\hline $\begin{array}{l}\text { GPM (+PS) } \\
\quad[237]\end{array}$ & $\begin{array}{c}520 \mathrm{~nm} \\
>2 \mathrm{~h} \text { emission }\end{array}$ & $\begin{array}{l}\text { Various shapes and sizes } \\
\text { (mm-range) }\end{array}$ & PDMS & $\begin{array}{l}\text { Laser: } 980 \mathrm{~nm} \\
2 \mathrm{~W} / \mathrm{cm}^{2} \text { for } 5 \mathrm{~s}\end{array}$ & $\begin{array}{c}\text { Rose Bengal } \\
\text { Abs. peak: } 559 \mathrm{~nm} \\
\text { Emission: } 571.5 \mathrm{~nm}\end{array}$ \\
\hline
\end{tabular}


Table 5. Cont.

\begin{tabular}{|c|c|c|c|c|c|}
\hline Light Source & Emission & Implant Size & Encapsulation & $\begin{array}{l}\text { External Source } \\
\text { (Activa- } \\
\text { tion/Charging) }\end{array}$ & PS \\
\hline $\begin{array}{c}\text { UCNPs } \\
{[238]}\end{array}$ & $635 \mathrm{~nm}$ & $3 \mathrm{~cm}$ & PEGDA+FEP & $\begin{array}{l}\text { Laser: } 980 \mathrm{~nm} \\
1109 \mathrm{~mW} / \mathrm{cm}^{2} \\
\text { for } 5-10 \mathrm{~min}\end{array}$ & $\begin{array}{c}\text { 5-ALA } \\
\text { Abs. Peaks: } \\
405 \mathrm{~nm}, 630 \mathrm{~nm}\end{array}$ \\
\hline $\begin{array}{l}\text { LEDs } \\
{[239]}\end{array}$ & 660 and $440 \mathrm{~nm}$ & $15 \mathrm{~mm}^{3}$ & $\begin{array}{l}\text { medical-grade } \\
\text { silicone }\end{array}$ & $\begin{array}{l}\mathrm{RF}(1 \text { and } 1.5 \mathrm{GHz}) \\
\quad \text { for } 30 \mathrm{~min}\end{array}$ & $\begin{array}{c}\text { Ce6 } \\
\text { Abs. Peaks: } \\
400 \mathrm{~nm}, 663 \mathrm{~nm} \\
\text { Emission at } 667 \mathrm{~nm}\end{array}$ \\
\hline $\begin{array}{l}\text { LEDs } \\
{[240]}\end{array}$ & $630,530,460 \mathrm{~nm}$ & $\begin{array}{l}\text { LED chip: } \\
7.0 \times 11 \times 0.8 \mathrm{~mm}^{3} \\
\text { +PDMS+PDA: } \\
\sim 650 \mathrm{~nm} \text {-thick }\end{array}$ & $\begin{array}{l}\text { PMDS+PDA } \\
\text { (adhesive) }\end{array}$ & $\begin{array}{l}\text { Near-field } \\
\text { communication } \\
\text { (13.56 MHz) } \\
\text { for } 10 \text { days }\end{array}$ & $\begin{array}{c}\text { Photofrin-saline \& } \\
\text { 5-ALA }\end{array}$ \\
\hline $\begin{array}{l}\text { LEDs } \\
{[242]}\end{array}$ & $640,470 \mathrm{~nm}$ & $\begin{array}{c}\quad 2 \times 2 \times 2 \mathrm{~mm}^{3} \\
2 \times 4 \times 2 \mathrm{~mm}^{3} \\
\text { +surface mounted LEDs }\end{array}$ & $\begin{array}{c}5 \mu \mathrm{m} \text { of } \\
\text { parylene-C }\end{array}$ & $\begin{array}{c}\text { Ultrasonic } \\
185 \mathrm{~mW} / \mathrm{cm}^{2} \text { at } \\
720 \mathrm{kHz} \\
\text { for } 30 \mathrm{~min}\end{array}$ & $\begin{array}{l}\text { Verteporfin } \\
\text { Abs. peak: } 415, \\
\text { 580, } 680 \mathrm{~nm} \\
\text { Emission: } 690 \mathrm{~nm}\end{array}$ \\
\hline
\end{tabular}

\section{Discussion}

A critical review of the light-based technologies and their influence on the PDT outcome has been addressed from superficial to deep techniques. The focus was set on the role of light source properties and parameters on the PDT efficacy and the light penetration into the tissue.

In particular, wavelength, coherence, incoherence, beam size, and the use of pulsed or $\mathrm{CW}$ illumination, are some of the factors covered for superficial and interstitial applications. PDT effect has been accomplished disregarding the light source nature, i.e., coherent or incoherent. There have been just a few attempts for direct comparison between light sources exhibiting similar results. Based on the existing literature, it is not possible to determine which light source type is more favourable for PDT or light penetration. However, it has been demonstrated that coherence is not lost within the tissue $(<2 \mathrm{~cm})$ by the observation of laser speckles in highly scattering media. Such speckles may exhibit significant intensity variations from the mean (up to 5 times). A possible implication of such variations on PDT is the local achievement of intensity thresholds for PS activation, thus deeper light penetration into additional regions that can experience PDT effects. Nevertheless, the relevance of such effects in clinical settings has not been determined. Specifically, to what extent is coherence influenced by the PS distribution and optical interaction has not been explored yet. Since achieving PDT of certain efficacy is also possible using incoherent sources such as LEDs, these light sources have strong potential for easier transfer to clinical settings offering more affordable solutions. One challenge is to extend beyond superficial applications and treat deep and large-seated tumours interstitially. Proper thermal control and power required (once coupled to a fibre) to surpass the minimum threshold for PS activation have to be demonstrated.

Regarding the properties of the incident light, such as pulsed or CW illumination, both regimes have shown beneficial effects. Most studies use CW light. Despite this, pulsed light has demonstrated some advantages as tissue re-oxygenation and re-accumulation of specific PS at the lesion. For light penetration, the use of pulsed light has shown a therapeutic threshold for PS activation in deeper regions of the tissue (with the same average fluence as CW but using higher fluence peaks). However, it is difficult to compare this type of illuminations based on existing literature given the diverse parameters employed-i.e., different PS, pulse duration and frequency, fluence rate and time, etc. Hence, some of the modest benefits of using pulsed or CW only apply under certain conditions. For this reason, the real advantages of pulsed illumination over $\mathrm{CW}$ are still debated. A commonly 
identified point is pulsed light typically favours apoptosis whereas CW favours necrosis. There has not been evidence contrary to tissue re-oxygenation partially avoiding hypoxia enabled by pulsed light. Systematic studies considering the implications of the pulse duration (and waveform) on the full dynamics of dependent parameters (PS activation, concentration, oxygen conditions) might shed light on the effects of using pulsed light. Other spatially-tuned light waveforms are deemed highly attractive in order to inhibit scattering and achieve deeper light penetration. Their suitability has to be envisaged.

Finding which type of light and beam parameters are better for PDT also benefits other advanced techniques (e.g., implants), in which dedicated circuits (or modes of activation) can be implemented. The main differentiators of I-PDT are the treatment of deep-seated tumours (but completely localized) and the possibility to perform full dosimetry not easy to implement by other PDT modalities.

For deep PDT, several techniques have been demonstrated. We have addressed the most relevant: chemiluminescent, bioluminescent sources, NIR, X-rays or Cherenkov radiation, and implants. Table 6 summarizes the main features and challenges of these techniques.

Table 6. Main features and challenges of deep PDT modalities and sources. Only TPA uses direct excitation of the PS whereas all the other deep PDT modalities excite the PS indirectly.

\begin{tabular}{|c|c|c|c|}
\hline $\begin{array}{l}\text { Deep PDT } \\
\text { Modality }\end{array}$ & Source & Main Potential and Benefits & Main Challenges and Limitations \\
\hline $\begin{array}{l}\text { NIR } \\
\text { radiation }\end{array}$ & $\begin{array}{c}\text { TPA } \\
\text { (ps-fs lasers) }\end{array}$ & $\begin{array}{l}\text { - } \quad \text { High selectivity } \\
\text { PSs more suitable for imaging-guided } \\
\text { PDT }\end{array}$ & $\begin{array}{ll}\text { - } & \text { Not easily accessible systems } \\
\text { - } & \text { Low ROS yield for TPA PSs } \\
\text { - } & \text { Low absorption cross-sections for } \\
\text { - } & \text { TPA PSs } \\
\text { - } & \text { Noat-Damage by fs-laser } \\
& \text { Not suitable for large tumours }\end{array}$ \\
\hline $\begin{array}{l}\text { NIR } \\
\text { radiation }\end{array}$ & $\begin{array}{l}\text { TPA, CARS, FWM, SHG. } \\
\text { (ps-fs lasers) }\end{array}$ & $\begin{array}{l}\text { - } \quad \text { High selectivity } \\
\text { Deeper penetration and enhanced } \\
\text { PDT effects than TPA alone } \\
\text { - Common PSs may be used }\end{array}$ & $\begin{array}{l}\text { - } \quad \text { Not easily accessible systems } \\
\text { - } \quad \text { Heat-damage by fs-laser } \\
\text { - Not suitable for large tumours }\end{array}$ \\
\hline $\begin{array}{l}\text { NIR } \\
\text { radiation }\end{array}$ & UCNPs & $\begin{array}{l}\text { - Conventional PSs excited in Soret } \\
\text { band } \\
\text { - } \quad \text { Lower power than TPA } \\
\text { - } \quad \text { CW can be used }\end{array}$ & $\begin{array}{l}\text { - } \\
\text { setention in the central nervous } \\
\text { - } \\
\text { - } \\
\text { - } \\
\text { Bioclearicity in normal cells } \\
\text { For FRET activated PS (most } \\
\text { efficient), it requires proximity of } \\
\text { UCNPs and PS (1-10 nm) } \\
\text { - Relatively low quantum yield }\end{array}$ \\
\hline $\begin{array}{l}\text { Ionising } \\
\text { radiation }\end{array}$ & X-rays & - Unlimited depth penetration & $\begin{array}{l}\text { - } \quad \text { Ionising radiation } \\
\text { Biocompatibility issues of some } \\
\text { SCNPs. }\end{array}$ \\
\hline $\begin{array}{l}\text { Ionising } \\
\text { radiation }\end{array}$ & Cherenkov & $\begin{array}{ll}\text { - } & \text { Unlimited penetration depth } \\
\text { - } & \text { Easier combination with radiotherapy } \\
\text { - No external radiation }\end{array}$ & 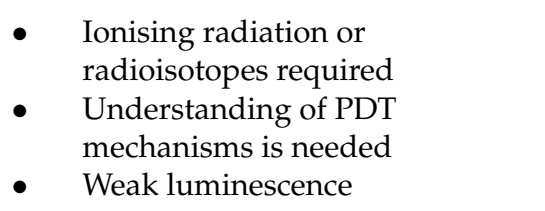 \\
\hline
\end{tabular}


Table 6. Cont.

\begin{tabular}{|c|c|c|c|}
\hline $\begin{array}{l}\text { Deep PDT } \\
\text { Modality }\end{array}$ & Source & Main Potential and Benefits & Main Challenges and Limitations \\
\hline $\begin{array}{l}\text { CRET, } \\
\text { BRET }\end{array}$ & $\begin{array}{l}\text { FireFly } \\
\text { Renilla }\end{array}$ & $\begin{array}{l}\text { - Unlimited penetration depth } \\
\text { - } \quad \text { No external radiation }\end{array}$ & $\begin{array}{ll}\text { - } & \text { Few studies, contradictory results } \\
\text { - } & \text { Not clear mechanisms of action } \\
\text { - } & \text { Low specificity } \\
\text { - } & \text { Toxicity in normal cells } \\
\text { - } & \text { efficiency } \\
\text { Weak self-luminescence }\end{array}$ \\
\hline Implants & - & $\begin{array}{ll}\text { - } & \text { Valid for mPDT } \\
\text { - } & \text { Repeated PDT with no invasion } \\
\text { - } & \text { Low fluence rates, no thermal } \\
\text { damage. } \\
\text { - }\end{array}$ & $\begin{array}{ll}\text { - } & \text { mPDT requires repeated PS } \\
\text { - } & \text { infusion } \\
\text { - } & \text { Corform dosimetry } \\
\text { - } & \text { tools } \\
\text { - } & \text { Ptability of the implant } \\
\text { - } & \text { Undesirable interaction with } \\
& \text { tumour giving rise to possible } \\
\text { seeding of cancer cells. }\end{array}$ \\
\hline $\begin{array}{l}\text { Implants } \\
\text { (NIR) }\end{array}$ & PLNPs & $\begin{array}{ll}\text { - } & \text { Injectable within tumour } \\
\text { - } & \text { Luminescence from minutes to hours } \\
\text { - } & \text { UV to NIR radiation }\end{array}$ & $\begin{array}{ll}\text { - } & \text { Poor tumour retention } \\
\text { - } & \text { Placement control or targeting } \\
\text { - } & \text { Insufficient doses } \\
\text { - } & \text { Biocompatibility and biosafety } \\
\text { - } & \text { Limitidation required } \\
\end{array}$ \\
\hline $\begin{array}{l}\text { Implants } \\
\text { (NIR) }\end{array}$ & $\begin{array}{c}\text { GPM } \\
\text { (+PS+upconversion } \\
\text { materials) }\end{array}$ & $\begin{array}{l}\text { - } \quad \text { Flexibility in shape and size design } \\
\text { - } \quad \text { Nocalized PS in the implant } \\
\text { - } \quad \text { No IV injection of upconversion } \\
\text { materials }\end{array}$ & $\begin{array}{l}\text { - Hinder cell death mechanisms } \\
\text { because intratumourally injection } \\
\text { of PS is not optimum } \\
\text { - } \quad \text { PDT relies on singlet diffusion in } \\
\text { the cells } \\
\text { - } \quad \text { PS re-infusion required for mPDT } \\
\text { difficult } \\
\text { - } \quad \text { High power for activation } \\
\text { Limited penetration depth of NIR }\end{array}$ \\
\hline
\end{tabular}

- $\quad$ No diffusion of UNCPs

- Allows to remove UCNPs

Implants

(NIR)

UCNPs

- Avoids potential UNCPs toxicity

- No electronics, no battery charging

- Bendable light guides
- $\quad$ Limited penetration depth of NIR

- Constant activation of UCNPs
Implants

(RF-NFC)
LEDs
- $\quad$ Stability demonstrated by tissue-adhesives

- Penetration depth $<10 \mathrm{~cm}$ for external activation
- Difficult alignment and low coupling efficiency of source-receiver

- $\quad$ Limited size and shapes due to coil or antenna required and electronics 
Table 6. Cont

\begin{tabular}{|c|c|c|c|}
\hline $\begin{array}{l}\text { Deep PDT } \\
\text { Modality }\end{array}$ & Source & Main Potential and Benefits & Main Challenges and Limitations \\
\hline $\begin{array}{l}\text { Implants } \\
\text { (US) }\end{array}$ & LEDs & $\begin{array}{l}\text { - Penetration depth }>10 \mathrm{~cm} \text { for external } \\
\text { activation } \\
\text { - } \quad \text { Multiple implants can be activated }\end{array}$ & $\begin{array}{l}\text { - Uniformity of treatment when } \\
\text { using multiple implants } \\
\text { Increased complexity in dose } \\
\text { determination when using } \\
\text { multiple implants }\end{array}$ \\
\hline
\end{tabular}

In the case of NIR radiation, one photon excitation is limited by the penetration depth and the available PS. TPA and FRET mechanisms are compatible with the use of longer excitation wavelengths and increase light penetration depth. For TPA, fs-laser pulses and diffraction-limited beam sizes are employed, enabling the treatment of highly localized regions (and possibly sectioning in the axial direction) and opening the possibility to avoid critical organs. It is worth mentioning that high selective treatments (disregarding sectioning) are not a particular advantage of TPA, they can also be achieved by one-photon excitation systems, but sacrificing penetration depth. To what extent the penetration depth of these focused beams is limited by the beam size (as identified in Section 2.2.2) is unknown. The low cytotoxic effects and low absorption cross-sections of the available PSs for TPA limit their use. Novel nonlinear upconversion techniques have emerged, offering better treatments as compared to TPA alone and using more conventional PSs. Their use might be limited to fine treatments due to the very small beams in which practical implementation for large tumours seems unfeasible. UCNPs (PS activation driven mainly by FRET) enable the excitation of common PSs at the visible region by converting NIR radiation to a wide range of visible light wavelengths. One of the main challenges using UCNPs is the lack of understanding of PDT mechanisms. Toxicity to normal cells has been reported, indicating that UCNPs can produce effects by themselves, and possibly, not only related to PDT mechanisms. More studies to elucidate the mechanisms of action are required to further understand the real effect of UCNPs.

Cherenkov and X-rays sources offer unlimited penetration. Despite this is a great advantage, both sources rely on ionising radiation that can damage the DNA. As it happens with UCNPs, SCNPs for ionising radiation have shown biocompatibility issues whose mechanisms are not clear. In the case of Cherenkov radiation, there is no explanation for how such small light doses can produce such a PDT effect. Further research is required to shed light on the intriguing results and to evaluate the realistic potential of these techniques.

Self-illuminated systems have demonstrated a therapeutic effect. However, their ability to translate to the clinic is in doubt. In the case of CL systems, the mechanisms of excitation are not fully understood, as only PDT effects are evaluated and usually based merely on tumour size observations. For BRET, there is also uncertainty in light fluences in tissue and the PDT effect. It is highly complex to determine the efficiency of each energy conversion step involved in the process of self-illumination. Besides, the required short distance between the substrate, the catalyst and the PS is not easily accomplished, and significant variability of the proximity may be found in real systems. Overall, CRET and BRET systems have unlimited penetration depth and no external source is required, but they are at a very early stage of development. If some issues-such as biocompatibility, uncertain dose, and specificity-are addressed, they have strong potential to become a magic bullet against cancer.

Concerning the emerging technological developments of implants, nowadays it is possible to design biocompatible implants (encapsulated with transparent polymeric materials) of different types, shapes and sizes (mm-range or below) that could be strategically allocated on the tumour surface to achieve less invasive mPDT. Tissue-adhesive implants have shown that movement difficulties and stability of the optical devices can be minimized [240]. Implants are advantageous over cases requiring bulky systems (i.e., optical 
fibre setups), in which the movement restriction turns into less practical treatments. Besides, implants could provide access to locations where interstitial delivery devices (see Section 2.2.4) have limitations. Despite all of these advantages, implants can be difficult to allocate properly for repeating the treatment in growing tumour. In addition, the risk of seeding cancer cells has to be considered for insertion and removal of the implants.

Examples of light sources externally activated are persistent luminescent materials—or so-called "optical batteries" - LED sources and even upconversion materials. Specifically, PLNPs can emit light from minutes to hours and for several wavelengths (from UV to NIR). However, most of the PLNPs utilise $\mathrm{Cr}^{3+}$ ions, and although they are mixed with an encapsulation material the heavy toxicity of $\mathrm{Cr}^{3+}$ ions would not meet requirements for environmental, biocompatible, and biosafety aspects. Whereas LEDs offer great flexibility in wavelength choice, power, and modes of activation, the implant geometry is limited by the size of the coil or receiver for activation. Another alternative is the use of UCNPs, which assist in the challenges of UCNPs (not implanted) regarding its retention in the central nervous system and toxicity avoidance by encapsulating the materials within the implant.

Considering the modes of external activation of the implants, different radiation sources (e.g., NIR radiation, RF, NFC, ultrasounds) have been demonstrated. Each radiation source has its particularities and specific benefits and weaknesses depending on the application (Table 4). For instance, ultrasonic radiation offers the highest penetration into the tissue for external activation of the implants $(>10 \mathrm{~cm})$, as compared to RF $(<10 \mathrm{~cm})$ and NIR $(<2 \mathrm{~cm})$. Whereas RF requires precise alignment between the energy radiation source and the receiver in the implant, ultrasonic radiation does not require alignment facilitating the allocation of multiple implants on the tumour surface. The uniformity on the activation and irradiation of multiple implants is still unknown, and thus their implications on PDT. NIR has limited penetration depth, but allows the use of UCNPs with the benefits explained above.

Different PSs have also been tested (e.g., 5-ALA, HPPH, Rose Bengal, Ce6, verteporfin) with treatment times extended up to tenths of hours, all implants achieving anti-tumour effects. Most studies used animal models to demonstrate the capabilities of the specific implant designs. Some others are targeting the treatment of deep-seated tumours such as the pancreas, in which $80 \%$ of the tumours are unresectable and easily recurrent [242]. mPDT through implants can mitigate such effects and find application in other tumours. Implants including the PS (RB) have been reported. This approach may offer important benefits. The PS is highly localized within the implant; thus, in principle, PS infusion is no longer required, avoiding drug-light intervals and burden to patients. However, it is well-established that direct injection of PS into the tumour (as also done for UCNPs) hinders the shutdown of microvessels which is one of the main cell death mechanisms [90]. Moreover, $m$ PDT requires several PS infusion sessions increasing the invasions if non-IV PS is uptaken. Another issue is that the singlet oxygen is generated inside the implant and the cytotoxic effect relies on the diffusion of the singlet oxygen to the tumour passing through the encapsulation (i.e., PDMS) to reach the tumour cells. It is known that the diffusion length of the singlet oxygen in cells is $<1 \mu \mathrm{m}$ (for typical lifetimes $<100 \mu \mathrm{s}$ ) and up to $3 \mathrm{~mm}$, considering a hypothetical lifetime of seconds. Hence, their effect might be superficial.

In spite that many light sources emit in the visible range with limited penetration depth within the tissue, one of the main differentiators of implants is the possibility to use mPDT, which demonstrated greater necrosis depth with beneficial effects over conventional PDT [81,210,240,244-246].

\section{Conclusions}

We have presented an overview of the status and challenges of the most relevant PDT modalities. The focus was set on the influence on PDT of light sources, devices, and systems. For conventional light sources mainly used for superficial and I-PDT (lasers, LEDs, broadband lamps), the questions about whether the nature of the light sources and parameters (coherent, incoherent, monochromatic, broadband, pulsed, $\mathrm{CW}$ ) are more 
favourable for PDT remain unclear. The influence on PDT of one or another light source and beam parameters is highly dependent on the fluence, treatment site, oxygen, and the PS. We also identified the necessity to properly report the PDT dose and beam parameters used for the treatments for a proper comparison between results. Answering these questions is of paramount importance not only for conventional PDT, but also for other PDT modalities reviewed in this work, e.g., implants.

For some deep PDT modalities such as nonlinear optical techniques or ionising radiation, we identified that the main challenges or limitations are the development of enhanced PSs, non-toxic UCNPs, and the use of ionising radiation. Self-illuminated systems are considered a potential magic bullet for cancer. They are in an initial stage and, currently, few studies report weak self-luminescence, toxicity, and low specificity without a clear understanding of the limiting factors and mechanisms of action.

There is strong potential for emerging implants given the possibility to achieve mPDT without repeated invasions. There is a wide palette of implant designs with demonstrated PDT capabilities and weaknesses. Some offer the possibility to adapt to different treatment sites. Ultrasound-activated implants appear as an attractive implementation offering deep external activation and the possibility for multiple implants allocation. On the contrary, some designs including persistent luminescence materials feature insufficient doses and stability issues. Full dosimetry might be unfeasible, and partial dosimetry has to be envisaged.

Each PDT modality offers unique capabilities. Emerging technologies overcome some of the initial challenges, but in turn, pose limitations. There is not a magic bullet for cancer based on PDT. Presently, instead of offering a broad solution, each PDT modality may find specific niches or be used in combination with other PDT modalities or therapies. Undoubtedly, PDT effects are beneficial for many treatment sites, and emerging technologies are opening new avenues towards enhanced PDT.

Author Contributions: All authors contributed equally to the manuscript. All authors have read and agreed to the published version of the manuscript.

Funding: This work was supported by Ministerio de Ciencia e Innovación and Agencia Estatal de Investigación (PID2019-107270RB-C21/AIE/10.13039/501100011033).

Conflicts of Interest: The authors declare no conflict of interest.

\section{References}

1. World Health Organization. Available online: https://www.who.int/health-topics/cancer\#tab=tab_1 (accessed on 6 April 2021).

2. Barr, H.; Tralau, C.J.; Boulos, P.B.; MacRobert, A.J.; Tilly, R.; Bown, S.G. The contrasting mechanisms of colonic collagen damage between photodynamic therapy and thermal injury. Photochem. Photobiol. 1987, 46, 795-800. [CrossRef]

3. Aniogo, E.C.; Plackal Adimuriyil George, B.; Abrahamse, H. The role of photodynamic therapy on multidrug resistant breast cancer. Cancer Cell Int. 2019, 19, 91. [CrossRef] [PubMed]

4. Kleinovink, J.W.; Van Driel, P.B.; Snoeks, T.J.; Prokopi, N.; Fransen, M.F.; Cruz, L.J.; Mezzanotte, L.; Chan, A.; Löwik, C.W.; Ossendorp, F. Combination of photodynamic therapy and specific immunotherapy efficiently eradicates established tumors. Clin. Cancer Res. 2016, 22, 1459-1468. [CrossRef] [PubMed]

5. Alzeibak, R.; Mishchenko, T.A.; Shilyagina, N.Y.; Balalaeva, I.V.; Vedunova, M.V.; Krysko, D.V. Targeting immunogenic cancer cell death by photodynamic therapy: Past, present and future. J. Immunother. Cancer 2021, 9, e001926. [CrossRef] [PubMed]

6. Celli, J.P.; Spring, B.Q.; Rizvi, I.; Evans, C.L.; Samkoe, K.S.; Verma, S.; Pogue, B.W.; Hasan, T. Imaging and photodynamic therapy: Mechanisms, monitoring, and optimization. Chem. Rev. 2010, 110, 2795-2838. [CrossRef] [PubMed]

7. Hamblin, M.R.; Huang, Y. Imaging in Photodynamic Therapy; Taylor \& Francis: London, UK, 2017.

8. Kim, M.M.; Darafsheh, A. Light Sources and Dosimetry Techniques for Photodynamic Therapy. Photochem. Photobiol. 2020, 96, 280-294. [CrossRef] [PubMed]

9. Pogue, B.W.; Elliott, J.T.; Kanick, S.C.; Davis, S.C.; Samkoe, K.S.; Maytin, E.V.; Pereira, S.P.; Hasan, T. Revisiting photodynamic therapy dosimetry: Reductionist \& surrogate approaches to facilitate clinical success. Phys. Med. Biol. 2016, 61, R57-R89. [PubMed]

10. Nowis, D.; Makowski, M.; Stokłosa, T.; Legat, M.; Issat, T.; Gołąb, J. Direct tumor damage mechanisms of photodynamic therapy. Acta Biochim. Pol. 2005, 52, 339-352. [CrossRef]

11. Castano, A.P.; Demidova, T.N.; Hamblin, M.R. Mechanisms in photodynamic therapy: Part two-Cellular signaling, cell metabolism and modes of cell death. Photodiagn. Photodyn. Ther. 2005, 2, 1-23. [CrossRef] 
12. Robertson, C.A.; Evans, D.H.; Abrahamse, H. Photodynamic therapy (PDT): A short review on cellular mechanisms and cancer research applications for PDT. J. Photochem. Photobiol. B Biol. 2009, 96, 1-8. [CrossRef] [PubMed]

13. Mroz, P.; Yaroslavsky, A.; Kharkwal, G.B.; Hamblin, M.R. Cell death pathways in photodynamic therapy of cancer. Cancers 2011, 3, 2516-2539. [CrossRef] [PubMed]

14. Yoo, J.O.; Ha, K.S. New Insights into the Mechanisms for Photodynamic Therapy-Induced Cancer Cell Death. In International Review of Cell and Molecular Biology; Elsevier Inc.: Amsterdam, The Netherlands, 2012; Volume 295, pp. 139-174.

15. Kushibiki, T.; Hirasawa, T.; Okawa, S.; Ishihara, M. Responses of cancer cells induced by photodynamic therapy. J. Healthc. Eng. 2013, 4, 87-108. [CrossRef] [PubMed]

16. Allison, R.R.; Moghissi, K. Photodynamic therapy (PDT): PDT mechanisms. Clin. Endosc. 2013, 46, 24-29. [CrossRef] [PubMed]

17. Alsaab, H.O.; Alghamdi, M.S.; Alotaibi, A.S.; Alzhrani, R.; Alwuthaynani, F.; Althobaiti, Y.S.; Almalki, A.H.; Sau, S.; Iyer, A.K. Progress in clinical trials of photodynamic therapy for solid tumors and the role of nanomedicine. Cancers 2020, $12,2793$. [CrossRef] [PubMed]

18. Brancaleon, L.; Moseley, H. Laser and non-laser light sources for photodynamic therapy. Lasers Med. Sci. 2002, 17, 173-186. [CrossRef] [PubMed]

19. Mang, T.S. Lasers and light sources for PDT: Past, present and future. Photodiagn. Photodyn. Ther. 2004, 1, 43-48. [CrossRef]

20. Finlay, J.C.; Darafsheh, A. Light sources, drugs, and dosimetry. In Biomedical Optics in Otorhinolaryngology: Head and Neck Surgery; Wong, B.J.-F., Ilgner, J., Eds.; Springer: New York, NY, USA, 2016; pp. 311-336. ISBN 9781493917587.

21. Mallidi, S.; Anbil, S.; Bulin, A.L.; Obaid, G.; Ichikawa, M.; Hasan, T. Beyond the barriers of light penetration: Strategies, perspectives and possibilities for photodynamic therapy. Theranostics 2016, 6, 2458-2487. [CrossRef] [PubMed]

22. Tuchin, V.V. Optical Properties of Tissues with Strong (Multiple) Scattering. In Tissue Optics: Light Scattering Methods and Instruments for Medical Diagnostics; SPIE: Bellingham, DC, USA; Washington, DC, USA, 2015; p. 4.

23. Jacques, S.L.; Prahl, S.A. Available online: https:/ / omlc.org/spectra/ (accessed on 6 June 2021).

24. van Veen, R.L.P.; Sterenborg, H.J.C.M.; Pifferi, A.; Torricelli, A.; Cubeddu, R. Determination of VIS-NIR absorption coefficients of mammalian fat, with time- and spatially resolved diffuse reflectance and transmission spectroscopy. In Proceedings of the Biomedical Topical Meeting (2004), Miami Beach, FL, USA, 14-17 April 2004; p. SF4.

25. Tsai, C.L.; Chen, J.C.; Wang, W.J. Near-infrared absorption property of biological soft tissue constituents. J. Med. Biol. Eng. 2001, 21,7-14.

26. Hale, G.M.; Querry, M.R. Optical Constants of Water in the 200-nm to 200- $\mu$ m Wavelength Region. Appl. Opt. 1973, 12, 555. [CrossRef]

27. Suzaki, H.; Kobayashi, N.; Nagaoka, T.; Iwasaki, K.; Umezu, M.; Takeda, S.; Togawa, T. Noninvasive measurement of total hemoglobin and hemoglobin derivatives using multiwavelength pulse spectrophotometry—In vitro study with a mock circulatory system. In Proceedings of the Annual International Conference of the IEEE Engineering in Medicine and Biology Society, New York, NY, USA, 30 August-3 September 2006; pp. 799-802.

28. Allison, R.R. Photodynamic therapy: Oncologic horizons. Future Oncol. 2014, 10, 123-142. [CrossRef]

29. Starkey, J.R.; Rebane, A.K.; Drobizhev, M.A.; Meng, F.; Gong, A.; Elliott, A.; McInnerney, K.; Spangler, C.W. New two-photon activated photodynamic therapy sensitizers induce xenograft tumor regressions after near-IR laser treatment through the body of the host mouse. Clin. Cancer Res. 2008, 14, 6564-6573. [CrossRef] [PubMed]

30. Welsher, K.; Sherlock, S.P.; Dai, H. Deep-tissue anatomical imaging of mice using carbon nanotube fluorophores in the second near-infrared window. Proc. Natl. Acad. Sci. USA 2011, 108, 8943-8948. [CrossRef] [PubMed]

31. Valeur, B.; Berberan-Santos, M.N. Molecular Fluorescence: Principles and Applications, Second ed.; Wiley-VCH: Weinheim, Germany, 2012; ISBN 9783527328376.

32. Plaetzer, K.; Krammer, B.; Berlanda, J.; Berr, F.; Kiesslich, T. Photophysics and photochemistry of photodynamic therapy: Fundamental aspects. Lasers Med. Sci. 2009, 24, 259-268. [CrossRef] [PubMed]

33. Taniguchi, M.; Du, H.; Lindsey, J.S. PhotochemCAD 3: Diverse Modules for Photophysical Calculations with Multiple Spectral Databases. Photochem. Photobiol. 2018, 94, 277-289. [CrossRef] [PubMed]

34. Taniguchi, M.; Lindsey, J.S. Database of Absorption and Fluorescence Spectra of $>300$ Common Compounds for use in PhotochemCAD. Photochem. Photobiol. 2018, 94, 290-327. [CrossRef] [PubMed]

35. Lovell, J.F.; Liu, T.W.B.; Chen, J.; Zheng, G. Activatable photosensitizers for imaging and therapy. Chem. Rev. 2010, 110, $2839-2857$. [CrossRef]

36. O'Connor, A.E.; Gallagher, W.M.; Byrne, A.T. Porphyrin and nonporphyrin photosensitizers in oncology: Preclinical and clinical advances in photodynamic therapy. Photochem. Photobiol. 2009, 85, 1053-1074. [CrossRef]

37. Mfouo-Tynga, I.S.; Dias, L.D.; Inada, N.M.; Kurachi, C. Features of Third Generation Photosensitizers Used in Anticancer Photodynamic Therapy: Review. Photodiagn. Photodyn. Ther. 2021, 34, 102091. [CrossRef]

38. Zhu, T.C.; Finlay, J.C.; Wilson, B. TH-A-T-6C-01: Photodynamic Therapy: Fundamentals and Dosimetry. Med. Phys. 2005, 32, 2150. [CrossRef]

39. Jenkins, P.A.; Carroll, J.D. How to report low-level laser therapy (LLLT)/photomedicine dose and beam parameters in clinical and laboratory studies. Photomed. Laser Surg. 2011, 29, 785-787. [CrossRef]

40. Keiser, G. Light-Tissue Interactions. In Biophotonics; Springer: Singapore, 2016; pp. 147-196. 
41. Katarina, S.; Bendsoe, N.; Axelsson, J.; Andersson-Engels, S.; Svanberg, S. Photodynamic therapy: Superficial and interstitial illumination. J. Biomed. Opt. 2010, 15, 041502.

42. Peng, Q.; Juzeniene, A.; Chen, J.; Svaasand, L.O.; Warloe, T.; Giercksky, K.E.; Moan, J. Lasers in medicine. Rep. Prog. Phys. 2008, 71, 56701. [CrossRef]

43. Szeimies, R.-M.; Radny, P.; Sebastian, M.; Borrosch, F.; Dirschka, T.; Krähn-Senftleben, G.; Reich, K.; Pabst, G.; Voss, D.; Foguet, M.; et al. Photodynamic therapy with BF-200 ALA for the treatment of actinic keratosis: Results of a prospective, randomized, double-blind, placebo-controlled phase III study. Br. J. Dermatol. 2010, 163, 386-394. [CrossRef] [PubMed]

44. Morton, C.A. Methyl Aminolevulinate: Actinic Keratoses and Bowen's Disease. Dermatol. Clin. 2007, 25, 81-87. [CrossRef] [PubMed]

45. Allison, R.R.; Sibata, C.H. Photodynamic therapy: Mechanism of action and role in the treatment of skin disease. G. Ital. Dermatol. Venereol. Organo Uff. Soc. Ital. Dermatol. Sifilogr. 2010, 145, 491-507.

46. Morton, C.; Horn, M.; Leman, J.; Tack, B.; Bedane, C.; Tjioe, M.; Ibbotson, S.; Khemis, A.; Wolf, P. Comparison of Topical Methyl Aminolevulinate Photodynamic Therapy With Cryotherapy or Fluorouracil for Treatment of Squamous Cell Carcinoma In Situ. Arch. Dermatol. 2006, 142, 729-735. [CrossRef]

47. Basset-Seguin, N.; Ibbotson, S.H.; Emtestam, L.; Tarstedt, M.; Morton, C.; Maroti, M.; Calzavara-Pinton, P.; Varma, S.; Roelandts, R.; Wolf, P. Topical methyl aminolaevulinate photodynamic therapy versus cryotherapy for superficial basal cell carcinoma: A 5 year randomized trial. Eur. J. Dermatol. 2008, 18, 547-553.

48. Fan, W.; Huang, P.; Chen, X. Overcoming the Achilles' heel of photodynamic therapy. Chem. Soc. Rev. 2016, 45, 6488-6519. [CrossRef] [PubMed]

49. Shafirstein, G.; Bellnier, D.; Oakley, E.; Hamilton, S.; Potasek, M.; Beeson, K.; Parilov, E. Interstitial photodynamic therapy-A focused review. Cancers 2017, 9, 12. [CrossRef]

50. Swartling, J.; Axelsson, J.; Ahlgren, G.; Kälkner, K.M.; Nilsson, S.; Svanberg, S.; Svanberg, K.; Andersson-Engels, S. System for interstitial photodynamic therapy with online dosimetry: First clinical experiences of prostate cancer. J. Biomed. Opt. 2010, 15, 058003. [CrossRef]

51. Shikunova, I.A.; Dolganova, I.N.; Dubyanskaya, E.N.; Mukhina, E.E.; Zaytsev, K.I.; Kurlov, V.N. Sapphire capillary interstitial irradiators for laser medicine. In Proceedings of the Saratov Fall Meeting 2017: Optical Technologies in Biophysics and Medicine XIX, Saratov, Russian, 26 April 2018; Volume 10716.

52. Schmidt, M.H.; Bajic, D.M.; Reichert, K.W.; Martin, T.S.; Meyer, G.A.; Whelan, H.T. Light-emitting Diodes as a Light Source for Intraoperative Photodynamic Therapy. Neurosurgery 1996, 38, 552-557. [PubMed]

53. Vu, H.; Kieu, N.M.; Gam, D.T.; Shin, S.; Tien, T.Q.; Vu, N.H. Design and Evaluation of Uniform LED Illumination Based on Double Linear Fresnel Lenses. Appl. Sci. 2020, 10, 3257. [CrossRef]

54. Meulemans, J.; Delaere, P.; Vander Poorten, V. Photodynamic therapy in head and neck cancer: Indications, outcomes, and future prospects. Curr. Opin. Otolaryngol. Head Neck Surg. 2019, 27, 136-141. [CrossRef] [PubMed]

55. Bown, S.G. Photodynamic therapy for cancer of the pancreas-The story so far. Photonics Lasers Med. 2016, 5, 91-100. [CrossRef]

56. Wang, L.; Yang, H.; Li, B. Photodynamic therapy for prostate cancer: A systematic review and meta-analysis. Prostate Int. 2019, 7, 83-90. [CrossRef]

57. Wang, K.; Yu, B.; Pathak, J.L. An update in clinical utilization of photodynamic therapy for lung cancer. J. Cancer 2021, 12, 1154-1160. [CrossRef] [PubMed]

58. Quirk, B.J.; Brandal, G.; Donlon, S.; Vera, J.C.; Mang, T.S.; Foy, A.B.; Lew, S.M.; Girotti, A.W.; Jogal, S.; LaViolette, P.S.; et al. Photodynamic therapy (PDT) for malignant brain tumors-Where do we stand? Photodiagn. Photodyn. Ther. 2015, 12, 530-544. [CrossRef] [PubMed]

59. Ostańska, E.; Aebisher, D.; Bartusik-Aebisher, D. The Potential of Photodynamic Therapy in Current Breast Cancer Treatment Methodologies; Elsevier: Roma, Italy, 2021; Volume 137.

60. Banerjee, S.M.; El-Sheikh, S.; Malhotra, A.; Mosse, C.A.; Parker, S.; Williams, N.R.; MacRobert, A.J.; Hamoudi, R.; Bown, S.G.; Keshtgar, M.R.S. Photodynamic Therapy in Primary Breast Cancer. J. Clin. Med. 2020, 9, 483. [CrossRef]

61. Trevisan, E.; Menegazzi, R.; Zabucchi, G.; Troian, B.; Prato, S.; Vita, F.; Rapozzi, V.; Grandolfo, M.; Borelli, V. Effect of methylene blue photodynamic therapy on human neutrophil functional responses. J. Photochem. Photobiol. B Biol. 2019, $199,111605$. [CrossRef] [PubMed]

62. Kercher, E.M.; Zhang, K.; Waguespack, M.; Lang, R.T.; Olmos, A.; Spring, B.Q. High-power light-emitting diode array design and assembly for practical photodynamic therapy research. J. Biomed. Opt. 2020, 25, 1. [CrossRef] [PubMed]

63. Hempstead, J.; Jones, D.P.; Ziouche, A.; Cramer, G.M.; Rizvi, I.; Arnason, S.; Hasan, T.; Celli, J.P. Low-cost photodynamic therapy devices for global health settings: Characterization of battery-powered LED performance and smartphone imaging in 3D tumor models. Sci. Rep. 2015, 5, 10093. [CrossRef]

64. Daly, S.R.; Zheng, F.; Krouse, M.; Guo, Z.; Mahoney, P.; McIlroy, B.W. Novel LED array used for photodynamic therapy (PDT). Light Emit. Diodes Res. Manuf. Appl. VII 2003, 4996, 229.

65. Kamanlı, A.F.; Yıldız, M.Z.; Özyol, E.; Deveci Ozkan, A.; Sozen Kucukkara, E.; Guney Eskiler, G. Investigation of LED-based photodynamic therapy efficiency on breast cancer cells. Lasers Med. Sci. 2020. [CrossRef] 
66. Duchi, S.; Ramos-Romero, S.; Dozza, B.; Guerra-Rebollo, M.; Cattini, L.; Ballestri, M.; Dambruoso, P.; Guerrini, A.; Sotgiu, G.; Varchi, G.; et al. Development of near-infrared photoactivable phthalocyanine-loaded nanoparticles to kill tumor cells: An improved tool for photodynamic therapy of solid cancers. Nanomed. Nanotechnol. Biol. Med. 2016, 12, 1885-1897. [CrossRef] [PubMed]

67. Tunér, J.; Jenkins, P. Complications in comparing lasers and LED. Comment on Esper MA, Nicolau RA, Arisawa EA (2011) the effect of two phototherapy protocols on pain control in orthodontic procedure-A preliminary clinical study. Lasers Med. Sci. 2012, 27, 1257-1258. [CrossRef] [PubMed]

68. Woodburn, K.W.; Young, S.W.; Qing, F.; Miles, D.R.; Thiemann, P.A. Light Emitting Diode versus Laser Irradiation Phototherapy with Lutetium Texaphyrin (PCI-0123). In Proceedings of the Optical Methods for Tumor Treatment and Detection: Mechanisms and Techniques in Photodynamic Therapy VI, San Jose, CA, USA, 8 May 1997; Dougherty, T.J., Ed.; SPIE: Washington, DC, USA, 1997; Volume 2972, pp. 46-53.

69. Yu, C.H.; Lin, H.P.; Chen, H.M.; Yang, H.; Wang, Y.P.; Chiang, C.P. Comparison of clinical outcomes of oral erythroleukoplakia treated with photodynamic therapy using either light-emitting diode or laser light. Lasers Surg. Med. 2009, 41, 628-633. [CrossRef] [PubMed]

70. de Jode, M.L.; McGilligan, J.A.; Dilkes, M.G.; Cameron, I.; Hart, P.B.; Grahn, M.F. A comparison of novel light sources for photodynamic therapy. In Lasers Medical Science; Springer: London, UK, 1997; Volume 12, pp. 260-268.

71. Jacques, S.L. How tissue optics affect dosimetry of photodynamic therapy. J. Biomed. Opt. 2010, 15, 051608. [CrossRef]

72. Dimofte, A.; Finlay, J.C.; Zhu, T.C. A method for determination of the absorption and scattering properties interstitially in turbid media. Phys. Med. Biol. 2005, 50, 2291-2311. [CrossRef] [PubMed]

73. Bashkatov, A.N.; Genina, E.A.; Kochubey, V.I.; Tuchin, V.V. Optical properties of human skin, subcutaneous and mucous tissues in the wavelength range from 400 to $2000 \mathrm{~nm}$. J. Phys. D Appl. Phys 2005, 38, 2543-2555. [CrossRef]

74. Bargo, P.R.; Prahl, S.A.; Goodell, T.T.; Sleven, R.A.; Koval, G.; Blair, G.; Jacques, S.L. In vivo determination of optical properties of normal and tumor tissue with white light reflectance and an empirical light transport model during endoscopy. J. Biomed. Opt. 2005, 10, 034018. [CrossRef] [PubMed]

75. Jacques, S.L. Optical properties of biological tissues: A review. Phys. Med. Biol. 2013, 58, R37. [CrossRef] [PubMed]

76. Hode, T.; Jenkins, P.; Jordison, S.; Hode, L. To what extent is coherence lost in tissue? In Proceedings of the Mechanisms for Low-Light Therapy VI, San Francisco, CA, USA, 10 February 2011; Hamblin, M.R., Waynant, R.W., Anders, J., Eds.; SPIE: Washington, DC, USA, 2011; Volume 7887, p. 788703.

77. Fixler, D.; Duadi, H.; Ankri, R.; Zalevsky, Z. Determination of coherence length in biological tissues. Lasers Surg. Med. 2011, 43, 339-343. [CrossRef] [PubMed]

78. Hode, T.; Duncan, D.; Kirkpatrick, S.; Jenkins, P.; Hode, L. The importance of coherence in phototherapy. In Proceedings of the Mechanisms for Low-Light Therapy IV, San Francisco, CA, USA, 10 February 2011; Hamblin, M.R., Waynant, R.W., Anders, J., Eds.; SPIE: Washington, DC, USA, 2009; Volume 7165, p. 716507.

79. Rubinov, A.N. Physical grounds for biological effect of laser radiation. J. Phys. D Appl. Phys. 2003, 36, 2317-2330. [CrossRef]

80. Hamblin, M.R.; Abrahamse, H. Factors Affecting Photodynamic Therapy and Anti-Tumor Immune Response. Anticancer. Agents Med. Chem. 2020, 21, 123-136. [CrossRef] [PubMed]

81. Santos, A.F.; Almeida, D.R.Q.; Terra, L.F.; Wailemann, R.A.M.; Gomes, V.M.; Arini, G.S.; Ravagnani, F.G.; Baptista, M.S.; Labriola, L. Fluence Rate Determines PDT Efficiency in Breast Cancer Cells Displaying Different GSH Levels. Photochem. Photobiol. 2020, 96, 658-667. [CrossRef] [PubMed]

82. Welch, A.J.; van Gemert, M.J.C.; Star, W.M.; Wilson, B.C. Definitions and Overview of Tissue Optics. In Optical-Thermal Response of Laser-Irradiated Tissue; Springer: Boston, MA, USA, 1995; pp. 15-46.

83. Ash, C.; Dubec, M.; Donne, K.; Bashford, T. Effect of wavelength and beam width on penetration in light-tissue interaction using computational methods. Lasers Med. Sci. 2017, 32, 1909-1918. [CrossRef] [PubMed]

84. Yassine, A.A.; Lilge, L.; Betz, V. Optimizing interstitial photodynamic therapy with custom cylindrical diffusers. J. Biophotonics 2019, 12, e201800153. [CrossRef]

85. Sun, Z.; Zhang, L.-P.; Wu, F.; Zhao, Y. Photosensitizers for Two-Photon Excited Photodynamic Therapy. Adv. Funct. Mater. 2017, 27, 1704079. [CrossRef]

86. de Bruijn, H.S.; Kruijt, B.; van der Ploeg-van den Heuvel, A.; Sterenborg, H.J.C.M.; Robinson, D.J. Increase in protoporphyrin IX after 5-aminolevulinic acid based photodynamic therapy is due to local re-synthesis. Photochem. Photobiol. Sci. 2007, 6, 857-864. [CrossRef] [PubMed]

87. Huang, Y.; Qiu, F.; Chen, R.; Yan, D.; Zhu, X. Fluorescence resonance energy transfer-based drug delivery systems for enhanced photodynamic therapy. J. Mater. Chem. B 2020, 8, 3772-3788. [CrossRef]

88. Inglut, C.T.; Gaitan, B.; Najafali, D.; Lopez, I.A.; Connolly, N.P.; Orsila, S.; Perttilä, R.; Woodworth, G.F.; Chen, Y.; Huang, H. Predictors and Limitations of the Penetration Depth of Photodynamic Effects in the Rodent Brain. Photochem. Photobiol. 2020, 96, 301-309. [CrossRef] [PubMed]

89. Cincotta, L.; Szeto, D.; Lampros, E.; Hasan, T.; Cincotta, A.H. Benzophenothiazine and Benzoporphyrin Derivative Combination Phototherapy Effectively Eradicates Large Murine Sarcomas. Photochem. Photobiol. 1996, 63, 229-237. [CrossRef] [PubMed]

90. Hamblin, M.R. Upconversion in photodynamic therapy: Plumbing the depths. Dalton Trans. 2018, 47, 8571-8580. [CrossRef] [PubMed] 
91. Bashkatov, A.N.; Berezin, K.V.; Dvoretskiy, K.N.; Chernavina, M.L.; Genina, E.A.; Genin, V.D.; Kochubey, V.I. Measurement of tissue optical properties in the context of tissue optical clearing. J. Biomed. Opt. 2018, 23, 1. [CrossRef] [PubMed]

92. Vargas, G.; Chan, E.K.; Barton, J.K.; Rylander, H.G.; Welch, A.J. Use of an agent to reduce scattering in skin. Lasers Surg. Med. 1999, 24, 133-141. [CrossRef]

93. Sterenborg, H.J.C.M.; Gemert, M.J.C. van Photodynamic therapy with pulsed light sources: A theoretical analysis. Phys. Med. Biol. 1996, 41, 835-849. [CrossRef] [PubMed]

94. Pogue, B.W.; Lilge, L.; Patterson, M.S.; Wilson, B.C.; Hasan, T. Absorbed photodynamic dose from pulsed versus continuous wave light examined with tissue-simulating dosimeters. Appl. Opt. 1997, 36, 7257. [CrossRef] [PubMed]

95. Kawauchi, S.; Morimoto, Y.; Sato, S.; Arai, T.; Seguchi, K.; Asanuma, H.; Kikuchi, M. Differences between cytotoxicity in photodynamic therapy using a pulsed laser and a continuous wave laser: Study of oxygen consumption and photobleaching. Lasers Med. Sci. 2004, 18, 179-183. [CrossRef]

96. Grecco, C.; Moriyama, L.T.; Cosci, A.; Pratavieira, S.; Bagnato, V.S.; Kurachi, C. Necrosis response to photodynamic therapy using light pulses in the femtosecond regime. Lasers Med. Sci. 2013, 28, 1177-1182. [CrossRef]

97. Grecco, C.; Pratavieira, S.; Bagnato, V.; Kurachi, C. Comparison of two photosensitizers in photodynamic therapy using light pulses in femtosecond regime: An animal study. In Proceedings of the Optical Methods for Tumor Treatment and Detection: Mechanisms and Techniques in Photodynamic Therapy XXV, San Francisco, CA, USA, 1 March 2016; Kessel, D.H., Hasan, T., Eds.; SPIE: Washington, DC, USA, 2016; Volume 9694, p. 969417.

98. Klimenko, V.V.; Knyazev, N.A.; Moiseenko, F.V.; Rusanov, A.A.; Bogdanov, A.A.; Dubina, M.V. Pulse mode of laser photodynamic treatment induced cell apoptosis. Photodiagn. Photodyn. Ther. 2016, 13, 101-107. [CrossRef] [PubMed]

99. Kuznetsova, D.S.; Shirmanova, M.V.; Dudenkova, V.V.; Subochev, P.V.; Turchin, I.V.; Zagaynova, E.V.; Lukyanov, S.A.; Shakhov, B.E.; Kamensky, V.A. Photobleaching and phototoxicity of KillerRed in tumor spheroids induced by continuous wave and pulsed laser illumination. J. Biophotonics 2015, 8, 952-960. [CrossRef]

100. Miyamoto, Y.; Umebayashi, Y.; Nishisaka, T. Comparison of phototoxicity mechanism between pulsed and continuous wave irradiation in photodynamic therapy. J. Photochem. Photobiol. B Biol. 1999, 53, 53-59. [CrossRef]

101. Strasswimmer, J.; Grande, D.J. Do pulsed lasers produce an effective photodynamic therapy response? Lasers Surg. Med. 2006, 38, 22-25. [CrossRef]

102. Alexiades-Armenakas, M.R.; Geronemus, R.G. Laser-mediated photodynamic therapy of actinic keratoses. Arch. Dermatol. 2003, 139, 1313-1320. [CrossRef] [PubMed]

103. Alexiades-Armenakas, M. Laser-mediated photodynamic therapy. Clin. Dermatol. 2006, 24, 16-25. [CrossRef] [PubMed]

104. Yu, H.; Park, J.; Lee, K.; Yoon, J.; Kim, K.; Lee, S.; Park, Y. Recent advances in wavefront shaping techniques for biomedical applications. Curr. Appl. Phys. 2015, 15, 632-641. [CrossRef]

105. Bender, N.; Yamilov, A.; Yllmaz, H.; Cao, H. Fluctuations and Correlations of Transmission Eigenchannels in Diffusive Media. Phys. Rev. Lett. 2020, 125, 165901. [CrossRef] [PubMed]

106. Vellekoop, I.M.; Mosk, A.P. Phase control algorithms for focusing light through turbid media. Opt. Commun. 2008, 281, 3071-3080. [CrossRef]

107. Maire, C.; Vignion-Dewalle, A.S.; Cartier, H.; Mordon, S. Artificial white light photodynamic therapy for actinic keratosis: A study of 38 patients in private office practice. J. Eur. Acad. Dermatol. Venereol. 2020. [CrossRef]

108. Marra, K.; LaRochelle, E.P.; Chapman, M.S.; Hoopes, P.J.; Lukovits, K.; Maytin, E.V.; Hasan, T.; Pogue, B.W. Comparison of Blue and White Lamp Light with Sunlight for Daylight-Mediated, 5-ALA Photodynamic Therapy, in vivo. Photochem. Photobiol. 2018, 94, 1049-1057. [CrossRef]

109. Lerche, C.M.; Heerfordt, I.M.; Heydenreich, J.; Wulf, H.C. Alternatives to outdoor daylight illumination for photodynamic therapy-Use of greenhouses and artificial light sources. Int. J. Mol. Sci. 2016, 17, 309. [CrossRef] [PubMed]

110. Mordon, S.; Thécua, E.; Ziane, L.; Lecomte, F.; Deleporte, P.; Baert, G.; Vignion-Dewalle, A. Light emitting fabrics for photodynamic therapy: Technology, experimental and clinical applications. Transl. Biophotonics 2020, 2, e202000005. [CrossRef]

111. O'Mahoney, P.; Haigh, N.; Wood, K.; Brown, C.T.A.; Ibbotson, S.; Eadie, E. A novel light source with tuneable uniformity of light distribution for artificial daylight photodynamic therapy. Photodiagn. Photodyn. Ther. 2018, 23, 144-150. [CrossRef] [PubMed]

112. Cochrane, C.; Mordon, S.R.; Lesage, J.C.; Koncar, V. New design of textile light diffusers for photodynamic therapy. Mater. Sci. Eng. C 2013, 33, 1170-1175. [CrossRef] [PubMed]

113. Tylcz, J.B.; Vicentini, C.; Mordon, S. Light emitting textiles for a photodynamic therapy. In Smart Textiles and Their Applications; Elsevier Inc.: Amsterdam, The Netherlands, 2016; pp. 71-87. ISBN 9780081005835.

114. Masuda, H.; Kimura, M.; Nishioka, A.; Kato, H.; Morita, A. Dual wavelength 5-aminolevulinic acid photodynamic therapy using a novel flexible light-emitting diode unit. J. Dermatol. Sci. 2019, 93, 109-115. [CrossRef] [PubMed]

115. Xie, H.; Xie, Z.; Mousavi, M.; Bendsoe, N.; Brydegaard, M.; Axelsson, J.; Andersson-Engels, S. Design and validation of a fiber optic point probe instrument for therapy guidance and monitoring. J. Biomed. Opt. 2014, 19, 071408. [CrossRef]

116. Rendon, A.; Weersink, R.; Lilge, L. Towards conformal light delivery using tailored cylindrical diffusers: Attainable light dose distributions. Phys. Med. Biol. 2006, 51, 5967-5975. [CrossRef]

117. Stock, K.; Stegmayer, T.; Graser, R.; Förster, W.; Hibst, R. Comparison of different focusing fiber tips for improved oral diode laser surgery. Lasers Surg. Med. 2012, 44, 815-823. [CrossRef] 
118. Mikolajewska, P.; Donnelly, R.F.; Garland, M.J.; Morrow, D.I.J.; Singh, T.R.R.; Iani, V.; Moan, J.; Juzeniene, A. Microneedle pre-treatment of human skin improves 5-aminolevulininc acid (ALA)- and 5-aminolevulinic acid methyl ester (MAL)-induced PpIX production for topical photodynamic therapy without increase in pain or erythema. Pharm. Res. 2010, 27, 2213-2220. [CrossRef] [PubMed]

119. Dolganova, I.N.; Shikunova, I.A.; Katyba, G.M.; Zotov, A.K.; Mukhina, E.E.; Shchedrina, M.A.; Tuchin, V.V.; Zaytsev, K.I.; Kurlov, V.N. Optimization of sapphire capillary needles for interstitial and percutaneous laser medicine. J. Biomed. Opt. 2019, $24,1$. [CrossRef]

120. Dolganova, I.N.; Shikunova, I.A.; Zotov, A.K.; Shchedrina, M.A.; Reshetov, I.V.; Zaytsev, K.I.; Tuchin, V.V.; Kurlov, V.N. Microfocusing sapphire capillary needle for laser surgery and therapy: Fabrication and characterization. J. Biophotonics 2020, 13, e202000164. [CrossRef] [PubMed]

121. Jäger, H.R.; Taylor, M.N.; Theodossy, T.; Hopper, C. MR Imaging-Guided Interstitial Photodynamic Laser Therapy for Advanced Head and Neck Tumors. Am. J. Neuroradiol. 2005, 26, 1193-1200. [PubMed]

122. Johansson, A.; Faber, F.; Kniebühler, G.; Stepp, H.; Sroka, R.; Egensperger, R.; Beyer, W.; Kreth, F.-W. Protoporphyrin IX Fluorescence and Photobleaching During Interstitial Photodynamic Therapy of Malignant Gliomas for Early Treatment Prognosis. Lasers Surg. Med. 2013, 45, 225-234. [CrossRef] [PubMed]

123. Osuchowski, M.; Bartusik-Aebisher, D.; Osuchowski, F.; Aebisher, D. Photodynamic therapy for prostate cancer-A narrative review. Photodiagn. Photodyn. Ther. 2021, 33, 102158. [CrossRef] [PubMed]

124. Hu, Y.; Wang, K.; Zhu, T.C. A light blanket for intraoperative photodynamic therapy. In Photodynamic Therapy: Back to the Future; SPIE: Washington, DC, USA, 2009; Volume 7380, p. 73801W.

125. Chamberlain, S.; Bellnier, D.; Yendamuri, S.; Lindenmann, J.; Demmy, T.; Nwogu, C.; Ramer, M.; Tworek, L.; Oakley, E.; Mallory, M.; et al. An Optical Surface Applicator for Intraoperative Photodynamic Therapy. Lasers Surg. Med. 2020, 52, 523-529. [CrossRef] [PubMed]

126. Protti, S.; Albini, A.; Viswanathan, R.; Greer, A. Targeting Photochemical Scalpels or Lancets in the Photodynamic Therapy Field-The Photochemist's Role. Photochem. Photobiol. 2017, 93, 1139-1153. [CrossRef] [PubMed]

127. Mordon, S. New optical sources for interstitial and metronomic photodynamic therapy. Photodiagn. Photodyn. Ther. 2018, 23, 209-211. [CrossRef] [PubMed]

128. Swartling, J.; Höglund, O.V.; Hansson, K.; Södersten, F.; Axelsson, J.; Lagerstedt, A.-S. Online dosimetry for temoporfin-mediated interstitial photodynamic therapy using the canine prostate as model. J. Biomed. Opt. 2016, 21, 028002. [CrossRef]

129. Cassidy, J.; Betz, V.; Lilge, L. Treatment plan evaluation for interstitial photodynamic therapy in a mouse model by Monte Carlo simulation with FullMonte. Front. Phys. 2015, 3, 6. [CrossRef]

130. Wang, K.K.-H.; Zhu, T.C. Reconstruction of in-vivo optical properties for human prostate using interstitial diffuse optical tomography. Opt. Express 2009, 17, 11665. [CrossRef]

131. Chinna Ayya Swamy, P.; Sivaraman, G.; Priyanka, R.N.; Raja, S.O.; Ponnuvel, K.; Shanmugpriya, J.; Gulyani, A. Near Infrared (NIR) absorbing dyes as promising photosensitizer for photodynamic therapy. Coord. Chem. Rev. 2020, 411, 213233. [CrossRef]

132. Bolze, F.; Jenni, S.; Sour, A.; Heitz, V. Molecular photosensitisers for two-photon photodynamic therapy. Chem. Commun. 2017, 53, 12857-12877. [CrossRef] [PubMed]

133. Gu, B.; Zhao, C.; Baev, A.; Yong, K.-T.; Wen, S.; Prasad, P.N. Molecular nonlinear optics: Recent advances and applications. Adv. Opt. Photonics 2016, 8, 328. [CrossRef]

134. Lenz, P. In vivo excitation of photosensitizers by infrared light. Photochem. Photobiol. 1995, 62, 333-338. [CrossRef]

135. Collins, H.A.; Khurana, M.; Moriyama, E.H.; Mariampillai, A.; Dahlstedt, E.; Balaz, M.; Kuimova, M.K.; Drobizhev, M.; Yang, V.X.D.; Phillips, D.; et al. Blood-vessel closure using photosensitizers engineered for two-photon excitation. Nat. Photonics 2008, 2, 420-424. [CrossRef]

136. Kachynski, A.V.; Pliss, A.; Kuzmin, A.N.; Ohulchanskyy, T.Y.; Baev, A.; Qu, J.; Prasad, P.N. Photodynamic therapy by in situ nonlinear photon conversion. Nat. Photonics 2014, 8, 455-461. [CrossRef]

137. Qiu, H.; Tan, M.; Ohulchanskyy, T.Y.; Lovell, J.F.; Chen, G. Recent progress in upconversion photodynamic therapy. Nanomaterials 2018, 8, 344. [CrossRef]

138. Huang, C.X.; Chen, H.J.; Li, F.; Wang, W.N.; Li, D.D.; Yang, X.Z.; Miao, Z.H.; Zha, Z.B.; Lu, Y.; Qian, H.S. Controlled synthesis of upconverting nanoparticles / CuS yolk-shell nanoparticles for: In vitro synergistic photothermal and photodynamic therapy of cancer cells. J. Mater. Chem. B 2017, 5, 9487-9496. [CrossRef] [PubMed]

139. Wu, J.; Du, S.; Wang, Y. Photosensitizer coated upconversion nanoparticles for triggering reactive oxygen species under $980 \mathrm{~nm}$ near-infrared excitation. J. Mater. Chem. B 2019, 7, 7306-7313. [CrossRef] [PubMed]

140. Xiang, H.; Chen, Y. Energy-Converting Nanomedicine. Small 2019, 15, 1805339. [CrossRef] [PubMed]

141. Zheng, B.; Wang, H.; Pan, H.; Liang, C.; Ji, W.; Zhao, L.; Chen, H.; Gong, X.; Wu, X.; Chang, J. Near-Infrared Light Triggered Upconversion Optogenetic Nanosystem for Cancer Therapy. ACS Nano 2017, 11, 11898-11907. [CrossRef] [PubMed]

142. Guo, D.; Xu, S.; Wang, N.; Jiang, H.; Huang, Y.; Jin, X.; Xue, B.; Zhang, C.; Zhu, X. Prodrug-embedded angiogenic vessel-targeting nanoparticle: A positive feedback amplifier in hypoxia-induced chemo-photo therapy. Biomaterials 2017, 144, 188-198. [CrossRef]

143. Le, X.T.; Youn, Y.S. Emerging NIR light-responsive delivery systems based on lanthanide-doped upconverting nanoparticles Arch. Pharm. Res. 2020, 43, 134-152. [CrossRef] [PubMed] 
144. Zhao, T.; Li, L.; Li, S.; Jiang, X.F.; Jiang, C.; Zhou, N.; Gao, N.; Xu, Q.H. Gold nanorod-enhanced two-photon excitation fluorescence of conjugated oligomers for two-photon imaging guided photodynamic therapy. J. Mater. Chem. C 2019, 7, 14693-14700. [CrossRef]

145. Yaghini, E.; Seifalian, A.M.; MacRobert, A.J. Quantum dots and their potential biomedical applications in photosensitization for photodynamic therapy. Nanomedicine 2009, 4, 353-363. [CrossRef]

146. Fowley, C.; Nomikou, N.; McHale, A.P.; McCaughan, B.; Callan, J.F. Extending the tissue penetration capability of conventional photosensitisers: A carbon quantum dot-protoporphyrin IX conjugate for use in two-photon excited photodynamic therapy. Chem. Commun. 2013, 49, 8934-8936. [CrossRef] [PubMed]

147. Liu, C.P.; Cheng, S.H.; Chen, N.T.; Lo, L.W. Intra/inter-particle energy transfer of luminescence nanocrystals for biomedical applications. J. Nanomater. 2012, 2012, 16. [CrossRef]

148. Edelhoch, H.; Brand, L.; Wilchek, M. Fluorescence Studies with Tryptophyl Peptides. Biochemistry 1967, 6, 547-559. [CrossRef]

149. Vekshin, N. Energy Transfer in Macromolecules; SPIE: Washington, DC, USA, 1996; ISBN 9780819420817.

150. Lakowicz, J.R. Principles of Fluorescence Spectroscopy; Springer: Berlin/Heidelberg, Germany, 2006 ; ISBN 0387312781.

151. Lucky, S.S.; Soo, K.C.; Zhang, Y. Nanoparticles in photodynamic therapy. Chem. Rev. 2015, 115, 1990-2042. [CrossRef] [PubMed]

152. Liu, Y.; Meng, X.; Bu, W. Upconversion-based photodynamic cancer therapy. Coord. Chem. Rev. 2019, 379, 82-98. [CrossRef]

153. Shen, J.; Chen, G.; Vu, A.M.; Fan, W.; Bilsel, O.S.; Chang, C.C.; Han, G. Engineering the upconversion nanoparticle excitation wavelength: Cascade sensitization of tri-doped upconversion colloidal nanoparticles at $800 \mathrm{~nm}$. Adv. Opt. Mater. 2013, 1, 644-650. [CrossRef]

154. Hou, Z.; Zhang, Y.; Deng, K.; Chen, Y.; Li, X.; Deng, X.; Cheng, Z.; Lian, H.; Li, C.; Lin, J. UV-emitting upconversion-based $\mathrm{TiO}_{2}$ photosensitizing nanoplatform: Near-infrared light mediated in vivo photodynamic therapy via mitochondria-involved apoptosis pathway. ACS Nano 2015, 9, 2584-2599. [CrossRef] [PubMed]

155. Zeng, L.; Pan, Y.; Tian, Y.; Wang, X.; Ren, W.; Wang, S.; Lu, G.; Wu, A. Doxorubicin-loaded NaYF 4 : Yb/Tm-TiO 2 inorganic photosensitizers for NIR-triggered photodynamic therapy and enhanced chemotherapy in drug-resistant breast cancers. Biomaterials 2015, 57, 93-106. [CrossRef] [PubMed]

156. Lucky, S.S.; Muhammad Idris, N.; Li, Z.; Huang, K.; Soo, K.C.; Zhang, Y. Titania coated upconversion nanoparticles for near-infrared light triggered photodynamic therapy. ACS Nano 2015, 9, 191-205. [CrossRef] [PubMed]

157. Zhang, L.; Zeng, L.; Pan, Y.; Luo, S.; Ren, W.; Gong, A.; Ma, X.; Liang, H.; Lu, G.; Wu, A. Inorganic photosensitizer coupled Gd-based upconversion luminescent nanocomposites for invivo magnetic resonance imaging and near-infrared-responsive photodynamic therapy in cancers. Biomaterials 2015, 44, 82-90. [CrossRef] [PubMed]

158. Dou, Q.Q.; Rengaramchandran, A.; Selvan, S.T.; Paulmurugan, R.; Zhang, Y. Core-Shell upconversion nanoparticleSemiconductor heterostructures for photodynamic therapy. Sci. Rep. 2015, 5, 8252. [CrossRef] [PubMed]

159. Zhang, P.; Steelant, W.; Kumar, M.; Scholfield, M. Versatile photosensitizers for photodynamic therapy at infrared excitation. J. Am. Chem. Soc. 2007, 129, 4526-4527. [CrossRef] [PubMed]

160. Liu, K.; Liu, X.; Zeng, Q.; Zhang, Y.; Tu, L.; Liu, T.; Kong, X.; Wang, Y.; Cao, F.; Lambrechts, S.A.G.; et al. Covalently assembled NIR nanoplatform for simultaneous fluorescence imaging and photodynamic therapy of cancer cells. ACS Nano 2012, 6, 4054-4062. [CrossRef]

161. Borodziuk, A.; Kowalik, P.; Duda, M.; Wojciechowski, T.; Minikayev, R.; Kalinowska, D.; Klepka, M.; Sobczak, K.; Kłopotowski, Ł.; Sikora, B. Unmodified Rose Bengal photosensitizer conjugated with $\mathrm{NaYF}_{4}: \mathrm{Yb}$,Er upconverting nanoparticles for efficient photodynamic therapy. Nanotechnology 2020, 31, 465101. [CrossRef] [PubMed]

162. Guo, H.; Qian, H.; Idris, N.M.; Zhang, Y. Singlet oxygen-induced apoptosis of cancer cells using upconversion fluorescent nanoparticles as a carrier of photosensitizer. Nanomed. Nanotechnol. Biol. Med. 2010, 6, 486-495. [CrossRef]

163. Li, S.; Cui, S.; Yin, D.; Zhu, Q.; Ma, Y.; Qian, Z.; Gu, Y. Dual antibacterial activities of a chitosan-modified upconversion photodynamic therapy system against drug-resistant bacteria in deep tissue. Nanoscale 2017, 9, 3912-3924. [CrossRef] [PubMed]

164. Wang, C.; Tao, H.; Cheng, L.; Liu, Z. Near-infrared light induced in vivo photodynamic therapy of cancer based on upconversion nanoparticles. Biomaterials 2011, 32, 6145-6154. [CrossRef]

165. Zhou, A.; Wei, Y.; Wu, B.; Chen, Q.; Xing, D. Pyropheophorbide A and c(RGDyK) comodified chitosan-wrapped upconversion nanoparticle for targeted near-infrared photodynamic therapy. Mol. Pharm. 2012, 9, 1580-1589. [CrossRef] [PubMed]

166. Park, Y.I.; Kim, H.M.; Kim, J.H.; Moon, K.C.; Yoo, B.; Lee, K.T.; Lee, N.; Choi, Y.; Park, W.; Ling, D.; et al. Theranostic Probe Based on Lanthanide-Doped Nanoparticles for Simultaneous In Vivo Dual-Modal Imaging and Photodynamic Therapy. Adv. Mater. 2012, 24, 5755-5761. [CrossRef] [PubMed]

167. Cui, S.; Chen, H.; Zhu, H.; Tian, J.; Chi, X.; Qian, Z.; Achilefu, S.; Gu, Y. Amphiphilic chitosan modified upconversion nanoparticles for in vivo photodynamic therapy induced by near-infrared light. J. Mater. Chem. 2012, 22, 4861-4873. [CrossRef]

168. Lim, M.E.; Lee, Y.L.; Zhang, Y.; Chu, J.J.H. Photodynamic inactivation of viruses using upconversion nanoparticles. Biomaterials 2012, 33, 1912-1920. [CrossRef] [PubMed]

169. Qiao, X.F.; Zhou, J.C.; Xiao, J.W.; Wang, Y.F.; Sun, L.D.; Yan, C.H. Triple-functional core-shell structured upconversion luminescent nanoparticles covalently grafted with photosensitizer for luminescent, magnetic resonance imaging and photodynamic therapy in vitro. Nanoscale 2012, 4, 4611-4623. [CrossRef] [PubMed]

170. Idris, N.M.; Gnanasammandhan, M.K.; Zhang, J.; Ho, P.C.; Mahendran, R.; Zhang, Y. In vivo photodynamic therapy using upconversion nanoparticles as remote-controlled nanotransducers. Nat. Med. 2012, 18, 1580-1585. [CrossRef] 
171. Shan, J.; Budijono, S.J.; Hu, G.; Yao, N.; Kang, Y.; Ju, Y.; Prud'homme, R.K. Pegylated Composite Nanoparticles Containing Upconverting Phosphors and meso-Tetraphenyl porphine (TPP) for Photodynamic Therapy. Adv. Funct. Mater. 2011, 21, 2488-2495. [CrossRef]

172. Liang, L.; Lu, Y.; Zhang, R.; Care, A.; Ortega, T.A.; Deyev, S.M.; Qian, Y.; Zvyagin, A.V. Deep-penetrating photodynamic therapy with KillerRed mediated by upconversion nanoparticles. Acta Biomater. 2017, 51, 461-470. [CrossRef]

173. Mironova, K.E.; Khochenkov, D.A.; Generalova, A.N.; Rocheva, V.V.; Sholina, N.V.; Nechaev, A.V.; Semchishen, V.A.; Deyev, S.M.; Zvyagin, A.V.; Khaydukov, E.V. Ultraviolet phototoxicity of upconversion nanoparticles illuminated with near-infrared light. Nanoscale 2017, 9, 14921-14928. [CrossRef] [PubMed]

174. Khaydukov, E.V.; Mironova, K.E.; Semchishen, V.A.; Generalova, A.N.; Nechaev, A.V.; Khochenkov, D.A.; Stepanova, E.V.; Lebedev, O.I.; Zvyagin, A.V.; Deyev, S.M.; et al. Riboflavin photoactivation by upconversion nanoparticles for cancer treatment. Sci. Rep. 2016, 6, 35103. [CrossRef] [PubMed]

175. Yang, G.; Yang, D.; Yang, P.; Lv, R.; Li, C.; Zhong, C.; He, F.; Gai, S.; Lin, J. A Single 808 nm Near-Infrared Light-Mediated Multiple Imaging and Photodynamic Therapy Based on Titania Coupled Upconversion Nanoparticles. Chem. Mater. 2015, 27, 7957-7968. [CrossRef]

176. Wang, D.; Xue, B.; Kong, X.; Tu, L.; Liu, X.; Zhang, Y.; Chang, Y.; Luo, Y.; Zhao, H.; Zhang, H. 808 nm driven Nd ${ }^{3+}$-sensitized upconversion nanostructures for photodynamic therapy and simultaneous fluorescence imaging. Nanoscale 2015, 7, 190-197. [CrossRef]

177. Lv, R.; Yang, D.; Yang, P.; Xu, J.; He, F.; Gai, S.; Li, C.; Dai, Y.; Yang, G.; Lin, J. Integration of Upconversion Nanoparticles and Ultrathin Black Phosphorus for Efficient Photodynamic Theranostics under $808 \mathrm{~nm}$ Near-Infrared Light Irradiation. Chem. Mater. 2016, 28, 4724-4734. [CrossRef]

178. Ai, F.; Ju, Q.; Zhang, X.; Chen, X.; Wang, F.; Zhu, G. A core-shell-shell nanoplatform upconverting near-infrared light at $808 \mathrm{~nm}$ for luminescence imaging and photodynamic therapy of cancer. Sci. Rep. 2015, 5, 10785. [CrossRef] [PubMed]

179. Cline, B.; Delahunty, I.; Xie, J. Nanoparticles to mediate X-ray-induced photodynamic therapy and Cherenkov radiation photodynamic therapy. Wiley Interdiscip. Rev. Nanomed. Nanobiotechnol. 2019, 11, e1541. [CrossRef] [PubMed]

180. Chen, W.; Zhang, J. Using nanoparticles to enable simultaneous radiation and photodynamic therapies for cancer treatment. J. Nanosci. Nanotechnol. 2006, 6, 1159-1166. [CrossRef]

181. Chen, X.; Song, J.; Chen, X.; Yang, H. X-ray-activated nanosystems for theranostic applications. Chem. Soc. Rev. 2019, 48, 3073-3101. [CrossRef] [PubMed]

182. Sun, W.; Zhou, Z.; Pratx, G.; Chen, X.; Chen, H. Nanoscintillator-mediated X-ray induced photodynamic therapy for deep-seated tumors: From concept to biomedical applications. Theranostics 2020, 10, 1296-1318. [CrossRef]

183. Ren, X.D.; Hao, X.Y.; Li, H.C.; Ke, M.R.; Zheng, B.Y.; Huang, J.D. Progress in the development of nanosensitizers for X-ray-induced photodynamic therapy. Drug Discov. Today 2018, 23, 1791-1800. [CrossRef]

184. Larue, L.; Ben Mihoub, A.; Youssef, Z.; Colombeau, L.; Acherar, S.; André, J.C.; Arnoux, P.; Baros, F.; Vermandel, M.; Frochot, C. Using X-rays in photodynamic therapy: An overview. Photochem. Photobiol. Sci. 2018, 17, 1612-1650. [CrossRef]

185. Ma, L.; Zou, X.; Bui, B.; Chen, W.; Song, K.H.; Solberg, T. X-ray excited ZnS:Cu,Co afterglow nanoparticles for photodynamic activation. Appl. Phys. Lett. 2014, 105, 013702. [CrossRef]

186. Daouk, J.; Dhaini, B.; Petit, J.; Frochot, C.; Barberi-Heyob, M.; Schohn, H. Can Cerenkov Light Really Induce an Effective Photodynamic Therapy? Radiation 2020, 1, 2. [CrossRef]

187. Sudheendra, L.; Das, G.K.; Li, C.; Stark, D.; Cena, J.; Cherry, S.; Kennedy, I.M. NaGdF4:Eu ${ }^{3+}$ nanoparticles for enhanced X-ray excited optical imaging. Chem. Mater. 2014, 26, 1881-1888. [CrossRef] [PubMed]

188. Clement, S.; Deng, W.; Camilleri, E.; Wilson, B.C.; Goldys, E.M. X-ray induced singlet oxygen generation by nanoparticlephotosensitizer conjugates for photodynamic therapy: Determination of singlet oxygen quantum yield. Sci. Rep. 2016, 6, 19954. [CrossRef] [PubMed]

189. Chen, H.; Wang, G.D.; Chuang, Y.J.; Zhen, Z.; Chen, X.; Biddinger, P.; Hao, Z.; Liu, F.; Shen, B.; Pan, Z.; et al. NanoscintillatorMediated X-ray Inducible Photodynamic Therapy for in Vivo Cancer Treatment. Nano Lett. 2015, 15, 2249-2256. [CrossRef] [PubMed]

190. Zou, X.; Yao, M.; Ma, L.; Hossu, M.; Han, X.; Juzenas, P.; Chen, W. X-ray-induced nanoparticle-based photodynamic therapy of cancer. Nanomedicine 2014, 9, 2339-2351. [CrossRef] [PubMed]

191. Tang, Y.; Hu, J.; Elmenoufy, A.H.; Yang, X. Highly Efficient FRET System Capable of Deep Photodynamic Therapy Established on X-ray Excited Mesoporous $\mathrm{LaF}_{3}$ :Tb Scintillating Nanoparticles. ACS Appl. Mater. Interfaces 2015, 7, 12261-12269. [CrossRef]

192. Elmenoufy, A.H.; Tang, Y.; Hu, J.; Xu, H.; Yang, X. A novel deep photodynamic therapy modality combined with CT imaging established via X-ray stimulated silica-modified lanthanide scintillating nanoparticles. Chem. Commun. 2015, 51, 12247-12250. [CrossRef] [PubMed]

193. Fabbri, F.; Rossi, F.; Attolini, G.; Salviati, G.; Dierre, B.; Sekiguchi, T.; Fukata, N. Luminescence properties of $\mathrm{SiC} / \mathrm{SiO}_{2}$ core-shell nanowires with different radial structure. Mater. Lett. 2012, 71, 137-140. [CrossRef]

194. Chen, H.; Wang, F.; Moore, T.L.; Qi, B.; Sulejmanovic, D.; Hwu, S.J.; Mefford, O.T.; Alexis, F.; Anker, J.N. Bright X-ray and up-conversion nanophosphors annealed using encapsulated sintering agents for bioimaging applications. J. Mater. Chem. B 2017, 5, 5412-5424. [CrossRef] [PubMed] 
195. Bulin, A.L.; Truillet, C.; Chouikrat, R.; Lux, F.; Frochot, C.; Amans, D.; Ledoux, G.; Tillement, O.; Perriat, P.; Barberi-Heyob, M.; et al. X-ray-induced singlet oxygen activation with nanoscintillator-coupled porphyrins. J. Phys. Chem. C 2013, 117, 21583-21589. [CrossRef]

196. Kaščáková, S.; Giuliani, A.; Lacerda, S.; Pallier, A.; Mercère, P.; Tóth, É.; Réfrégiers, M. X-ray-induced radiophotodynamic therapy (RPDT) using lanthanide micelles: Beyond depth limitations. Nano Res. 2015, 8, 2373-2379. [CrossRef]

197. Lan, G.; Ni, K.; Xu, R.; Lu, K.; Lin, Z.; Chan, C.; Lin, W. Nanoscale Metal-Organic Layers for Deeply Penetrating X-ray-Induced Photodynamic Therapy. Angew. Chem. 2017, 56, 12102-12106. [CrossRef] [PubMed]

198. Ma, L.; Zou, X.; Chen, W. A new x-ray activated nanoparticle photosensitizer for cancer treatment. J. Biomed. Nanotechnol. 2014, 10, 1501-1508. [CrossRef] [PubMed]

199. Zhang, C.; Zhao, K.; Bu, W.; Ni, D.; Liu, Y.; Feng, J.; Shi, J. Marriage of scintillator and semiconductor for synchronous radiotherapy and deep photodynamic therapy with diminished oxygen dependence. Angew. Chem. Int. Ed. 2015, 54, 1770-1774. [CrossRef] [PubMed]

200. Chen, H.; Sun, X.; Wang, G.D.; Nagata, K.; Hao, Z.; Wang, A.; Li, Z.; Xie, J.; Shen, B. LiGa $\mathrm{O}_{8}$ :Cr-based theranostic nanoparticles for imaging-guided X-ray induced photodynamic therapy of deep-seated tumors. Mater. Horiz. 2017, 4, 1092-1101. [CrossRef] [PubMed]

201. Hsu, C.C.; Lin, S.L.; Chang, C.A. Lanthanide-Doped Core-Shell-Shell Nanocomposite for Dual Photodynamic Therapy and Luminescence Imaging by a Single X-ray Excitation Source. ACS Appl. Mater. Interfaces 2018, 10, 7859-7870. [CrossRef]

202. Sengar, P.; Juárez, P.; Verdugo-Meza, A.; Arellano, D.L.; Jain, A.; Chauhan, K.; Hirata, G.A.; Fournier, P.G.J. Development of a functionalized UV-emitting nanocomposite for the treatment of cancer using indirect photodynamic therapy. J. Nanobiotechnol. 2018, 16, 1-19. [CrossRef]

203. Ran, C.; Zhang, Z.; Hooker, J.; Moore, A. In vivo photoactivation without "light": Use of cherenkov radiation to overcome the penetration limit of light. Mol. Imaging Biol. 2012, 14, 156-162. [CrossRef]

204. Robertson, R.; Germanos, M.S.; Li, C.; Mitchell, G.S.; Cherry, S.R.; Silva, M.D. Optical imaging of Cerenkov light generation from positron-emitting radiotracers. Phys. Med. Biol. 2009, 54, 355-365. [CrossRef]

205. Kotagiri, N.; Sudlow, G.P.; Akers, W.J.; Achilefu, S. Breaking the depth dependency of phototherapy with Cerenkov radiation and low-radiance-responsive nanophotosensitizers. Nat. Nanotechnol. 2015, 10, 370-379. [CrossRef] [PubMed]

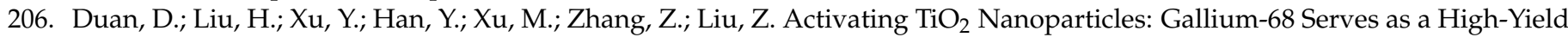
Photon Emitter for Cerenkov-Induced Photodynamic Therapy. ACS Appl. Mater. Interfaces 2018, 10, 5278-5286. [CrossRef] [PubMed]

207. Hartl, B.A.; Hirschberg, H.; Marcu, L.; Cherry, S.R. Activating photodynamic therapy in vitro with Cerenkov radiation generated from yttrium-90. J. Environ. Pathol. Toxicol. Oncol. 2016, 35, 185-192. [CrossRef] [PubMed]

208. Pratx, G.; Kapp, D.S. Is Cherenkov luminescence bright enough for photodynamic therapy? Nat. Nanotechnol. 2018, $13,354$. [CrossRef]

209. Glaser, A.K.; Zhang, R.; Andreozzi, J.M.; Gladstone, D.J.; Pogue, B.W. Cherenkov radiation fluence estimates in tissue for molecular imaging and therapy applications. Phys. Med. Biol. 2015, 60, 6701-6718. [CrossRef] [PubMed]

210. Henderson, B.W.; Busch, T.M.; Snyder, J.W. Fluence rate as a modulator of PDT mechanisms. Lasers Surg. Med. 2006, 38, 489-493. [CrossRef] [PubMed]

211. Administration of Radioactive Substances Advisory Committee, Notes for Guidance: Good Clinical Practice in Nuclear Medicine. Available online: https://www.gov.uk/government/publications/arsac-notes-for-guidance (accessed on 6 June 2021).

212. Lahham, A.; Issa, A.; Masri, H.A.L. Patient radiation dose from chest X-ray examinations in the West Bank-Palestine. Radiat. Prot. Dosim. 2018, 178, 298-303. [CrossRef] [PubMed]

213. Smith-Bindman, R.; Lipson, J.; Marcus, R.; Kim, K.P.; Mahesh, M.; Gould, R.; Berrington de González, A.; Miglioretti, D.L. Radiation dose associated with common computed tomography examinations and the associated lifetime attributable risk of cancer. Arch. Intern. Med. 2009, 169, 2078-2086. [CrossRef] [PubMed]

214. American College of Radiology, Radiation Dose to Adults from Common Imaging Examinations. Available online: https: / / www.acr.org/-/media/ACR/Files/Radiology-Safety / Radiation-Safety/Dose-Reference-Card.pdf (accessed on 6 June 2021).

215. Packer, S. Tumor detection with radiopharmaceuticals. Semin. Nucl. Med. 1984, 14, 21-30. [CrossRef]

216. Magalhães, C.M.; Esteves da Silva, J.C.G.; Pinto da Silva, L. Chemiluminescence and Bioluminescence as an Excitation Source in the Photodynamic Therapy of Cancer: A Critical Review. ChemPhysChem 2016, 17, 2286-2294. [CrossRef] [PubMed]

217. Laptev, R.; Nisnevitch, M.; Siboni, G.; Malik, Z.; Firer, M.A. Intracellular chemiluminescence activates targeted photodynamic destruction of leukaemic cells. Br. J. Cancer 2006, 95, 189-196. [CrossRef]

218. Yuan, H.; Chong, H.; Wang, B.; Zhu, C.; Liu, L.; Yang, Q.; Lv, F.; Wang, S. Chemical molecule-induced light-activated system for anticancer and antifungal activities. J. Am. Chem. Soc. 2012, 134, 13184-13187. [CrossRef]

219. Davis, R.W.; Snyder, E.; Miller, J.; Carter, S.; Houser, C.; Klampatsa, A.; Albelda, S.M.; Cengel, K.A.; Busch, T.M. Luminol Chemiluminescence Reports Photodynamic Therapy-Generated Neutrophil Activity in vivo and Serves as a Biomarker of Therapeutic Efficacy. Photochem. Photobiol. 2019, 95, 430-438. [CrossRef] [PubMed]

220. Lu, X.; Song, X.; Wang, Q.; Hu, W.; Shi, W.; Tang, Y.; Wu, Z.; Fan, Q.; Huang, W. Chemiluminescent organic nanophotosensitizer for a penetration depth independent photodynamic therapy. RSC Adv. 2020, 10, 11861-11864. [CrossRef] 
221. Zhang, Y.; Pang, L.; Ma, C.; Tu, Q.; Zhang, R.; Saeed, E.; Mahmoud, A.E.; Wang, J. Small Molecule-Initiated Light-Activated Semiconducting Polymer Dots: An Integrated Nanoplatform for Targeted Photodynamic Therapy and Imaging of Cancer Cells. Anal. Chem. 2014, 86, 3092-3099. [CrossRef]

222. Jiang, L.; Bai, H.; Liu, L.; Lv, F.; Ren, X.; Wang, S. Luminescent, Oxygen-Supplying, Hemoglobin-Linked Conjugated Polymer Nanoparticles for Photodynamic Therapy. Angew. Chem. Int. Ed. 2019, 58, 10660-10665. [CrossRef] [PubMed]

223. Yang, K.; Wang, C.; Wei, X.; Ding, S.; Liu, C.; Tian, F.; Li, F. Self-Illuminating Photodynamic Therapy with Enhanced Therapeutic Effect by Optimization of the Chemiluminescence Resonance Energy Transfer Step to the Photosensitizer. Bioconjug. Chem. 2019, 31, 595-604. [CrossRef] [PubMed]

224. Vieira, J.; Da Silva, L.P.; Da Silva, J.C.G.E. Advances in the knowledge of light emission by firefly luciferin and oxyluciferin. J. Photochem. Photobiol. B Biol. 2012, 117, 33-39. [CrossRef] [PubMed]

225. Pinto da Silva, L.; Esteves da Silva, J.C.G. Firefly Chemiluminescence and Bioluminescence: Efficient Generation of Excited States. ChemPhysChem 2012, 13, 2257-2262. [CrossRef] [PubMed]

226. da Silva, L.P.; Esteves da Silva, J.C.G. Computational studies of the luciferase light-emitting product: Oxyluciferin. J. Chem. Theory Comput. 2011, 7, 809-817. [CrossRef]

227. Theodossiou, T.; Hothersall, J.S.; Woods, E.A.; Okkenhaug, K.; Jacobson, J.; MacRobert, A.J. Firefly luciferin-activated rose bengal: In vitro photodynamic therapy by intracellular chemiluminescence in transgenic NIH 3T3 cells. Cancer Res. 2003, 63, 1818-1821. [PubMed]

228. Schipper, M.L.; Patel, M.R.; Gambhir, S.S. Evaluation of Firefly Luciferase Bioluminescence Mediated Photodynamic Toxicity in Cancer Cells. Mol. Imaging Biol. 2006, 8, 218-225. [CrossRef] [PubMed]

229. Yang, K.; Wang, C.; Liu, C.; Ding, S.; Tian, F.; Li, F. Bioluminescence-initiated photodynamic therapy bridged on high-luminescent carbon dots-conjugated protoporphyrin IX. J. Mater. Sci. 2019, 54, 3383-3391. [CrossRef]

230. Stepanyuk, G.A.; Liu, Z.J.; Markova, S.S.; Frank, L.A.; Lee, J.; Vysotski, E.S.; Wang, B.C. Crystal structure of coelenterazine-binding protein from Renilla muelleri at $1.7 \AA$ A Why it is not a calcium-regulated photoprotein. Photochem. Photobiol. Sci. 2008, 7, $442-447$. [CrossRef] [PubMed]

231. Hsu, C.Y.; Chen, C.W.; Yu, H.P.; Lin, Y.F.; Lai, P.S. Bioluminescence resonance energy transfer using luciferase-immobilized quantum dots for self-illuminated photodynamic therapy. Biomaterials 2013, 34, 1204-1212. [CrossRef] [PubMed]

232. Kim, Y.R.; Kim, S.; Choi, J.W.; Choi, S.Y.; Lee, S.H.; Kim, H.; Hahn, S.K.; Koh, G.Y.; Yun, S.H. Bioluminescence-activated deep-tissue photodynamic therapy of cancer. Theranostics 2015, 5, 805-817. [CrossRef] [PubMed]

233. Proshkina, G.M.; Shramova, E.I.; Shilova, O.N.; Ryabova, A.V.; Deyev, S.M. Phototoxicity of flavoprotein miniSOG induced by bioluminescence resonance energy transfer in genetically encoded system NanoLuc-miniSOG is comparable with its LED-excited phototoxicity. J. Photochem. Photobiol. B Biol. 2018, 188, 107-115. [CrossRef] [PubMed]

234. Kim, E.H.; Park, S.; Kim, Y.K.Y.P.; Moon, M.; Park, J.; Lee, K.J.; Lee, S.; Kim, Y.K.Y.P. Self-luminescent photodynamic therapy using breast cancer targeted proteins. Sci. Adv. 2020, 6, 3009-3020. [CrossRef] [PubMed]

235. Teo, A.J.T.; Mishra, A.; Park, I.; Kim, Y.J.; Park, W.T.; Yoon, Y.J. Polymeric Biomaterials for Medical Implants and Devices. ACS Biomater. Sci. Eng. 2016, 2, 454-472. [CrossRef] [PubMed]

236. Fan, W.; Lu, N.; Xu, C.; Liu, Y.; Lin, J.; Wang, S.; Shen, Z.; Yang, Z.; Qu, J.; Wang, T.; et al. Enhanced Afterglow Performance of Persistent Luminescence Implants for Efficient Repeatable Photodynamic Therapy. ACS Nano 2017, 11, 5864-5872. [CrossRef] [PubMed]

237. Hu, L.; Wang, P.; Zhao, M.; Liu, L.; Zhou, L.; Li, B.; Albaqami, F.H.; El-Toni, A.M.; Li, X.; Xie, Y.; et al. Near-infrared rechargeable "optical battery" implant for irradiation-free photodynamic therapy. Biomaterials 2018, 163, 154-162. [CrossRef] [PubMed]

238. Teh, D.B.L.; Bansal, A.; Chai, C.; Toh, T.B.; Tucker, R.A.J.; Gammad, G.G.L.; Yeo, Y.; Lei, Z.; Zheng, X.; Yang, F.; et al. A Flexi-PEGDA Upconversion Implant for Wireless Brain Photodynamic Therapy. Adv. Mater. 2020, 32, 2001459. [CrossRef] [PubMed]

239. Bansal, A.; Yang, F.; Xi, T.; Zhang, Y.; Ho, J.S. In vivo wireless photonic photodynamic therapy. Proc. Natl. Acad. Sci. USA 2018, 115, 1469-1474. [CrossRef] [PubMed]

240. Yamagishi, K.; Kirino, I.; Takahashi, I.; Amano, H.; Takeoka, S.; Morimoto, Y.; Fujie, T. Tissue-adhesive wirelessly powered optoelectronic device for metronomic photodynamic cancer therapy. Nat. Biomed. Eng. 2019, 3, 27-36. [CrossRef] [PubMed]

241. Kirino, I.; Fujita, K.; Sakanoue, K.; Sugita, R.; Yamagishi, K.; Takeoka, S.; Fujie, T.; Uemoto, S.; Morimoto, Y. Metronomic photodynamic therapy using an implantable LED device and orally administered 5-aminolevulinic acid. Sci. Rep. 2020, 10, 22017. [CrossRef]

242. Kim, A.; Zhou, J.; Samaddar, S.; Song, S.H.; Elzey, B.D.; Thompson, D.H.; Ziaie, B. An Implantable Ultrasonically-Powered Micro-Light-Source ( $\mu$ Light) for Photodynamic Therapy. Sci. Rep. 2019, 9, 1395. [CrossRef] [PubMed]

243. Bisland, S.K.; Lilge, L.; Lin, A.; Rusnov, R.; Wilson, B.C. Metronomic Photodynamic Therapy as a New Paradigm for Photodynamic Therapy: Rationale and Preclinical Evaluation of Technical Feasibility for Treating Malignant Brain Tumors. Photochem. Photobiol. 2004, 80, 22-30. [CrossRef]

244. Morrison, S.A.; Hill, S.L.; Rogers, G.S.; Graham, R.A. Efficacy and safety of continuous low-irradiance photodynamic therapy in the treatment of chest wall progression of breast cancer. J. Surg. Res. 2014, 192, 235-241. [CrossRef] [PubMed] 
245. Guo, H.W.; Lin, L.T.; Chen, P.H.; Ho, M.H.; Huang, W.T.; Lee, Y.J.; Chiou, S.H.; Hsieh, Y.S.; Dong, C.Y.; Wang, H.W. Low-fluence rate, long duration photodynamic therapy in glioma mouse model using organic light emitting diode (OLED). Photodiagn. Photodyn. Ther. 2015, 12, 504-510. [CrossRef] [PubMed]

246. de Vijlder, H.C.; Sterenborg, H.J.C.M.; Martino Neumann, H.A.; Robinson, D.J.; de Haas, E.R.M. Light fractionation significantly improves the response of superficial basal cell carcinoma to aminolaevulinic acid photodynamic therapy: Five-year follow-up of a randomized, prospective trial. Acta Derm. Venereol. 2012, 92, 641-647. [CrossRef] [PubMed]

247. Laser Institute of America. American National Standard for Safe Use of Lasers; Laser Institute of America: Orlando, FL, USA, 2000.

248. Ho, J.S.; Yeh, A.J.; Kim, S.; Poon, A.S.Y. Wireless Powering for Miniature Implantable Systems; Springer: New York, NY, USA, 2014; ISBN 9781461481515.

249. Ozeri, S.; Shmilovitz, D. Ultrasonic transcutaneous energy transfer for powering implanted devices. Ultrasonics 2010, 50, 556-566. [CrossRef] [PubMed] 